\title{
Ultra Low Sulfur Home Heating Oil Demonstration Project
}

\section{Summary Report}

\author{
Project Funded by: \\ The New York State Energy Research and Development Authority
}

Agreement Number: 10007

Project Conducted by:

John E. Batey, PE,

Energy Research Center, Inc

Roger McDonald

Brookhaven National Laboratory

With the assistance of

Oil Services, Inc 


\section{NOTICE}

This report was prepared by the Energy Research Center, Inc. and Brookhaven National Laboratory in the course of performing work contracted for and sponsored by the New York State Energy Research and Development Authority (hereafter referred to as "NYSERDA"). The opinions expressed in this report do not necessarily reflect the those of the NYSERDA or the State of New York, and reference to any specific product, service, process, or method does not constitute an imply or expressed recommendation or endorsement of it. Further, NYSERDA, the State of New York, and the contractor make no warranties of representations, expressed or implied, as to the fitness for particular purpose or merchantability of any product, apparatus, or service, or the usefulness, completeness, or accuracy of any processes, methods, or other information contained, described, disclosed, or referred to in this report. NYSERDA, the State of New York, and the contractor make no representation that the use of any product, apparatus, process, method, or other information will not infringe privately owned rights and will assume no liability for any loss, injury, or damage resulting from, or occurring in connection with, the use of information contained, described, disclosed, or referred to in this report. 


\section{Dedications}

This work is dedicated to two valued colleagues who were the bedrock of the Oil Heat Research Program at Brookhaven National Laboratory for more than 35 years - Roger McDonald and Dr. Abe Berlad who are no longer with us, but who are not forgotten.

Roger was one of the first application engineers to join BNL's Oil Heat Program in the 1970 's and the most conscientious and valued member of the team who worked on advancing oil burner and heating equipment technology at the lab until his death on December 3, 2010. Roger led the laboratory testing of and contributed enormously to advancing the state of the art of residential heating equipment including flame retention oil burners and high efficiency heaters that are now the standard for the oil heat industry. He was a tireless engineer who was very skilled at applying engineering principles to practical applications, and he thoroughly enjoyed his work. His latest work involved air emission testing of heating equipment in collaboration with the USEPA which represents a major milestone in our understanding of the subject. He was Principal Investigator for laboratory testing at BNL for the ULS heating oil project funded by NYSERDA, and contributed mightily to the field demonstration project that is reported here. He was a good engineer, loyal colleague and friend, and he is missed but will never be forgotten. We were all blessed to have had Roger in our lives.

Dr. Abraham Leon Berlad, Abe, was one of the brightest stars internationally in the field of combustion and the mentor of Roger and myself as graduates of the Engineering Program at SUNY Stony Brook. Abe was a Senior NASA Scientist who led the development of hydrogen fueled rockets in the 1950s that are still used today. He was the most intelligent man I have ever met and always helped and guided his graduate students - long after they left the university. He was a true mentor in every way and a role model for all of us throughout his life. Abe started the Oil Heat Research Program at BNL with Frank Salzano in 1974 which operated successfully for more than 30 years. He was a man of true vision and great intellect who was extremely generous with his time and talents. We were all blessed to have him in our lives, and he will always be remembered by all of those who he touched. 


\section{Acknowledgements}

The authors express their sincere appreciation to the New York State Energy Research and Development Authority (NYSERDA) for funding this multi-year field study of UltraLow Sulfur (ULS) heating oil in homes. The study has identified many important benefits of using low sulfur heating oil, and has also found several potential roadblocks to its widespread use in homes. This NYSERDA-funded Ultra Low Sulfur (15 parts per million sulfur) demonstration project is a follow-up to the prior study of Low Sulfur (500 ppm sulfur) heating oil in homes under real-world conditions. This is a critically important step toward enabling widespread use Ultra-Low Sulfur heating oil in residences.

The authors thank the NYSERDA staff for their support in completing this project, and especially Nathan Russell who was the project manager for this work and supplied valuable support and guidance.

We especially thank Oil Services Inc. of Oceanside, New York for their valuable and patient assistance and cooperation in conducting this NYSERDA field study. This work would not be possible without their assistance.

The authors thank the Program Advisory Group that included Victor Turk of RW Beckett Corporation, and Dale Hunsberger with Suntec Industries for their valuable input in project planning and review of laboratory and field test results.

We thank Dr. C. R. Krishna formerly with BNL and Dr. Clifford Martin for their assistance with final editing of the report.

The authors acknowledge the valuable contribution of the National Oilheat Research Alliance for support of this project in helping to accomplish the work. 


\section{DRAFT FINAL REPORT NYSERDA Ultra-Low Sulfur Heating Oil Demonstration Project}

\section{Contents}

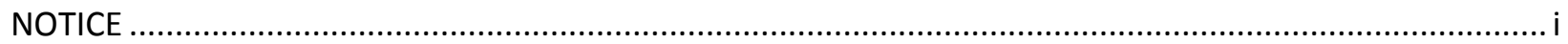

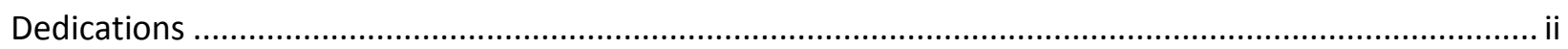

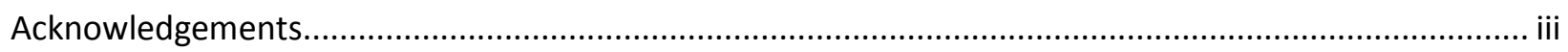

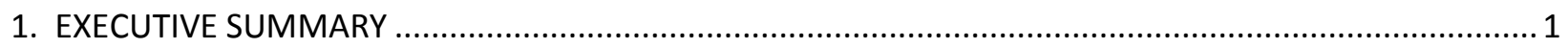

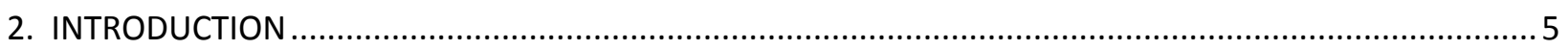

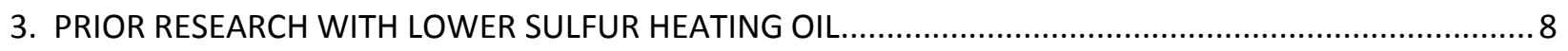

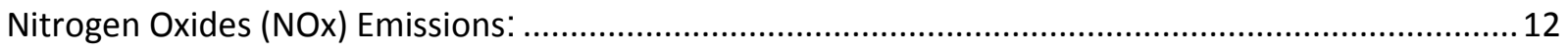

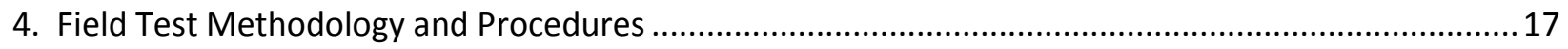

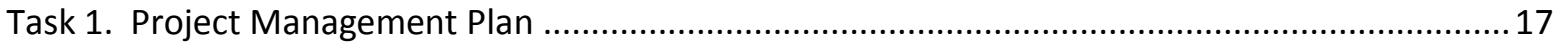

Task 2. Define Test Program and Data Collection Procedures........................................................ 18

Task 3. Training Sessions for the Oil Company and Service Technicians ......................................... 31

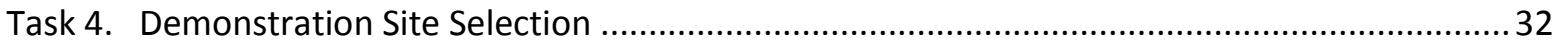

Task 5. Field Testing - Data Collection and Analysis.................................................................... 33

Task 6. Final Report, Technology Transfer, and Metrics ........................................................ 34

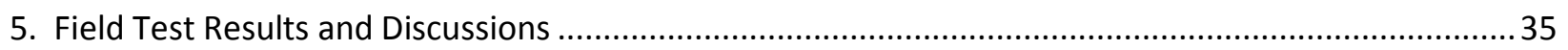

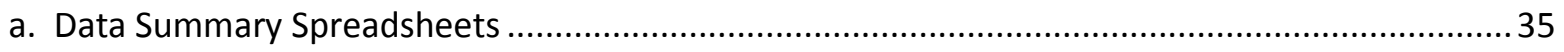




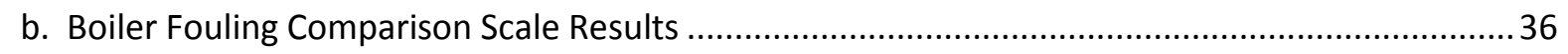

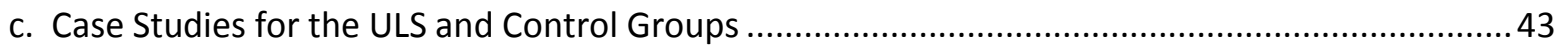

d. Service Record Review and Analysis for ULS Heating Oil and Control Group............................63

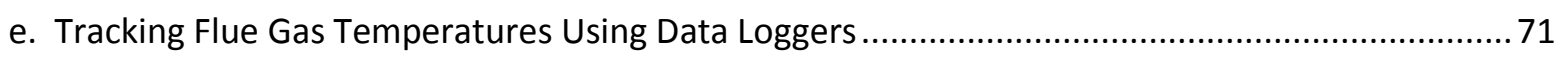

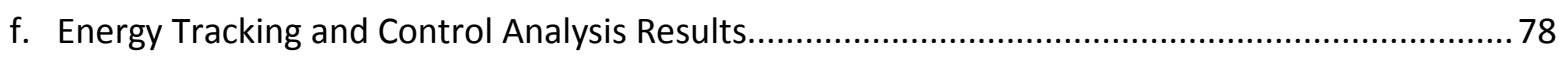

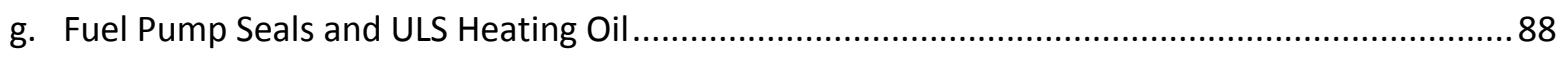

6. Benefits of ULS Heating Oil and Potential Barriers to Widespread Use .........................................97

a. Environmental Benefits of ULS Heating Oil - Reduced Sulfur Oxides and PM ............................97

b. Reduced Costs for Oil Heating Equipment Cleaning ........................................................... 100

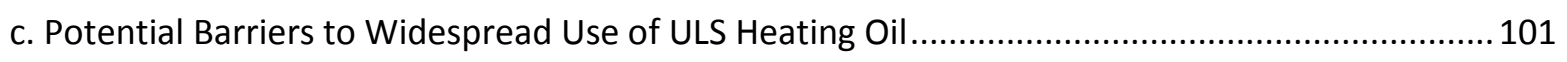

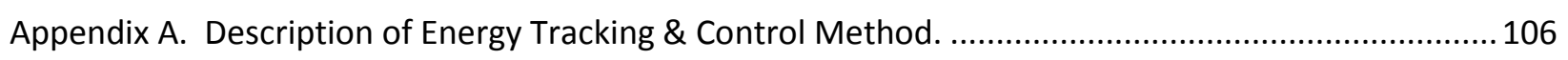

Appendix B. Laboratory Test Results for Normal S Heating Oil ...................................................... 111

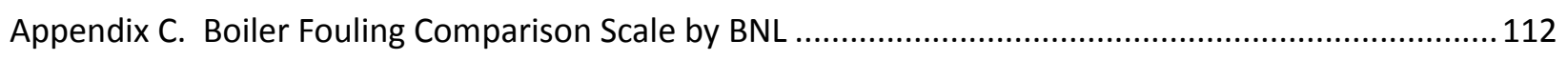

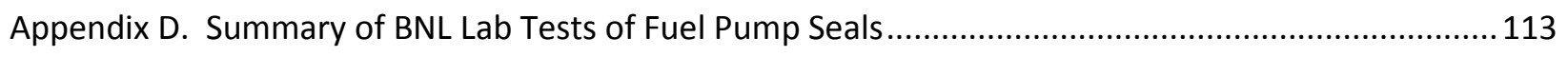




\section{EXECUTIVE SUMMARY}

This Ultra Low Sulfur (ULS) Home Heating Oil Demonstration Project was funded by the New York State Energy Research and Development Authority (NYSERDA) and has successfully quantified the environmental and economic benefits of switching to ULS (15 PPM sulfur) heating oil. It advances a prior field study of Low Sulfur (500 ppm sulfur) heating oil funded by NYSERDA and laboratory research conducted by Brookhaven National Laboratory (BNL) and Canadian researchers. The sulfur oxide and particulate matter (PM) emissions are greatly reduced as are boiler cleaning costs through extending cleaning intervals. Both the sulfur oxide and PM emission rates are directly related to the fuel oil sulfur content. The sulfur oxide and PM emission rates approach near-zero levels by switching heating equipment to ULS fuel oil, and these emissions become comparable to heating equipment fired by natural gas.

The ULS Home Heating Oil Demonstration Project was conducted by the Energy Research Center, Inc and Brookhaven National Laboratory and it monitored and quantified changes in performance of home heating equipment using ULS heating oil, compared to a higher sulfur control group. The metrics that were applied to the study included: service record review and analysis, combustion testing, flue gas temperature measurements using data loggers, use of a "Boiler Fouling Scale" developed by BNL, and the Energy Tracking and Control system to measure changes in fuel use. The Boiler Fouling Scale was a primary measure for this project based on prior BNL research and the prior Low Sulfur Study funded by NYSERDA (Figure 4-2). Each of these measures were applied to the ULS test group and to a control group of houses using conventional heating oil with 2000 ppm sulfur.

A detailed House Characterization Form was completed for ULS test and control group houses at the start of the project that fully described the house and heating equipment. An Initial Cleaning Checklist was completed at the start of the project of the ULS and control group houses that included combustion test results and initial Boiler Fouling Scale readings. Annual Boiler Inspection and Burner Tune-up Checklist forms were completed for ULS and control group houses each year (with some cleanings extended two or three years) which supplied Boiler Fouling Scale readings and photographs, and combustion test results before and after cleaning. This allowed changes in fouling rates and combustion performance to be evaluated on an on-going basis throughout the test project. Differences in boiler fouling rates between the ULS test and control groups were then compared to evaluate the impact of ULS heating oil.

The test results were tracked through a detailed spreadsheet that was constructed for both the ULS and control houses that was updated by BNL on a regular basis as field 
data forms were received from the participation oil company. The average fouling rate for the control group with heating oil containing $2000 \mathrm{ppm}$ sulfur was a factor of 4.6 times higher than the fouling rate for the houses using Ultra Low Sulfur heating oil. This can substantially reduce service costs by extending the cleaning interval from 1 to or 1.5 years to 5 or 7 years. These results for ULS heating oil were consistent with the prior findings of the Low Sulfur (500 ppm) Study, with even greater reductions for the ULS fuel as expected.

A number of case studies are presented in this report that compare ULS and Conventional (2000 ppm sulfur heating oil) that include photographs of boiler heat exchanges before and after cleaning for one year and two or three year cleaning intervals. The ULS Case Studies \#1 through \#5 show minimal increases in the Boiler Fouling Scale number and in some cases near-zero fouling after one or two years between cleanings. In contrast Case Studies \#6 to \#10 show for higher sulfur control group houses show much higher rates of boiler fouling than with ULS heating oil. This is especially noticeable after the second year of operation without boiler cleaning. Fouling rates near the top of the Boiler Fouling Scale were observed in some of these cases which exhibited heavy boiler corrosion on heat transfer surfaces. These example cases supply clear visual evidence of the difference corrosion and fouling rates for conventional higher sulfur heating oil compared to ULS home heating oil.

This demonstration project included an in-depth review and analysis of service records for both the ULS and control groups to determine any difference in the service needs for the two groups. The detailed service records for both groups were collected and analyzed and the results were entered into two spreadsheets that enabled a quantitative side-by-side comparison of equipment service for the entire duration of the ULS test project. The service frequency for the ULS and control group were very similar and did indicate increased service frequency for the ULS group. In fact, the service frequency with the ULS group was slightly less $(7.5$ percent) than the control group. The only exception was that three burner fuel pump required replacement for the ULS group and none were required for the control group.

The project included the installation of 10 dataloggers were to track changes in flue gas temperature for 5 ULS and 5 control group houses for part of the heating season. The results of six of these are included in this report, but no significant changes in flue gas temperature were observed over time for the ULS or control groups. The time interval for collecting data was only several months and no meaningful temperature trends were observed. 
Energy Tracking and Control (ETC) is a new method for accurately tracking fuel use that was developed by ERC, and it was an additional measure used for the ULS test project. It was used to more accurately predict tank levels at the start of the project so that larger fuel drops were made and the volume of ULS heating fuel drops were increased compared to convectional heating degree day methods. ETC was also used to precisely measure changes in fuel use rate for selected test cases to determine changes in boiler efficiency enabling to be determined by using ULS heating oil in place of conventional higher sulfur oil. Two cases that were examined showed potential fuel savings of 11 percent and 12 percent by using ULS. It also precisely measured the increased fuel use produced by heavy soot production and boiler soot fouling during the heating season.

One unexpected results from the ULS demonstration study and related laboratory investigation at Brookhaven National laboratory was the potential shortening of some oil burner pump seals when using ULS heating when compared to higher sulfur oil. Both pumps with Viton (brown) lip seals and one of the three pumps using the more common Nitrile (black) pump seals experienced early failure and leakage. The single pump that was tested with a carbon face seal passed the lab tests. This finding was substantiated by the field testing that found three failures of fuel pumps with the viton seal during the test project. Further pump seal testing using ULS heating oil is highly recommended, and service technicians should include inspection of pump seals for any sign of leakage during annual tune-ups for houses using ULS heating oil. This potential materials compatibility issue can be corrected by upgrading pump seal materials and designs, and replacing fuel units when switching to ULS heating oil. Work is on-going to find and implement solutions. The substantial air emissions and cleaning costs reductions likely outweigh any potential pump seal issue that can be rectified.

ULS heating oil offers important advantages over conventional higher sulfur oil including: reduction in sulfur oxide air emissions (by 99 percent), and reduction in particulate matter (PM) air emissions (by 98 percent), which are emissions approaching near-zero levels and comparable to natural gas fired heating equipment. The reduction in sulfur oxide and PM emissions also reduce the fouling rates of boiler heat transfer surfaces and flue gas passages. This increases boiler efficiency over the heating season and substantially reduces the need for boiler vacuum cleaning that can extended in some cases to 5 to 7 years based on the results of this study. This can produce potential annual savings of $\$ 50$ million to $\$ 100$ million in New York State, and five times that amount in the US.

Potential barriers for the use of ULS heating oil include added fuel cost, fuel pump seal compatibility, and education and training needs for oil companies and oil heat service 
technicians. The added cost of ULS heating oil versus higher sulfur oil is one potential obstacle, but is much smaller than the savings produced by extending the cleaning interval for oil boilers and furnaces (ref 14). This no longer a concern in New York State as ULS heating oil is now mandated. Oil burner pump seal compatibility was an unexpected potential barrier to widespread use of ULS heating oil in residences, and more testing is needed to fully evaluate this issue and to identify and implement solutions. Work is now on-going by pump manufacturers. Education and training efforts are needed to homeowners, fuel oil marketers, oil heat service technicians after these issues are resolved and solutions are identified and tested. The many environmental and cost benefits of using ULS heating oil appear to out-weigh potential barriers to its use that were identified during this field demonstration. 


\section{INTRODUCTION: Project Overview and Background}

\section{a. Project Overview}

Home heating oil used in the US has historically contained fuel sulfur of between 0.20 percent (2000 parts per million) to 0.25 percent (2500 parts per million), with some regions in the past as high as 1.0 percent (10,000 parts per million). The more recent trend over the past 10 to 15 years is toward lower sulfur heating oil consistent with reductions in the sulfur content of on-highway diesel fuel that has been lowered to 500 ppm and then to $15 \mathrm{ppm}$ in the recent years. Residential heating oil is a similar distillate product and has also seen a substantial reductions in fuel sulfur content that has produced important environmental benefits in the form of reduced Sulfur Oxide emissions and reduced Particulate Matter (PM) emissions. In addition, heating equipment performance benefits are produced by using lower sulfur heating oil including: reduced fouling deposits on internal heating surfaces, reduced equipment cleaning intervals and lowered cleaning costs, and improved long-term heating system efficiency and lowered annual heating costs.

The New York State Energy Research and Development Authority (NYSERDA) funded a project in 2000 conducted by the Energy Research Center, Inc. and Brookhaven National Laboratory to investigate the benefits and potential obstacles to the use of Low Sulfur heating oil containing $500 \mathrm{ppm}$ of sulfur. This study was conducted with the cooperation of a fuel oil marketer and service company in New York State and it demonstrated and documented the environmental benefits and cost savings to homeowners by using this lower sulfur product (ref 13).

This report summarizes the results of the follow-up project that was funded by NYSERDA and conducted by the same investigators to evaluate, demonstrate and document the advantages and potential obstacles to the use of Ultra Low Sulfur (15 ppm) heating oil in residences in New York State and in all oil heat regions of the US. This project demonstrated important environmental benefits of ULS heating oil and documented potential savings to homeowners that are produced by increased heating system efficiency and extending the time interval for vacuum cleaning of internal heat transfer surfaces. This results directly from much lower rate of fouling of heat transfer surfaces in boilers and furnaces with the Ultra Low Sulfur heating oil compared to higher sulfur fuel oil. Some potential barrier to the use of ULS heating oil were also discovered, but are expected to be resolved by revised equipment inspection and service procedures, including more frequent replacement of fuel oil pumps that are a component of residential oil burners. 


\section{b. Project Background}

The sulfur contained in home heating oil is the fuel is converted to sulfur oxides, primarily $\mathrm{SO}_{2}$ and $\mathrm{SO}_{3}$, by the oil burner during the combustion process, and directly contributes to the formation of particulate matter (PM) in the post flame gases. The sulfur oxides and PM that is produced forms deposits on the heat transfer surfaces within the hot water boiler or warm air furnace. These deposits lower heat transfer rates and reduce heater efficiency over time. In addition, as these fouling deposits build up over a heating season, they can begin to block or plug the flue passages in the boiler. This can cause a gradual reduction in flow rate and an increase in soot production by the heating equipment. It has been recommended and standard oil heat industry practice that the flue passages of boilers and furnaces be vacuum-cleaned every year or year and a half to prevent excessive build-up of these combustion deposits.

Research by BNL found that the rate of these fouling deposits on heat transfer surfaces and flue gas passages in the boiler or furnace is directly and linearly related to the sulfur content of the heating oil. That is, if the sulfur content is reduced by a factor of two, the fouling rate is also reduced by a factor of two. The mechanisms of boiler fouling rates as a function of fuel sulfur content was established in the test laboratory at Brookhaven National Laboratory as part of the USDOE-funded Combustion Equipment Technology Program. This work included the development and evaluation of fouling rates of castiron and steel test section that were exposed to flue gases from oil flames firing fuel oil with varying sulfur contents. This work was corroborated by the CANMET Energy Technology Center in Ottawa, Canada. The Canadian work found that found very similar results for fouling rates as a function of heating oil sulfur content. This work quantified the relationship between fuel sulfur percent, PM production, and boiler fouling rates in the laboratory.

The combustion of fuel oil converts the sulfur contained in the fuel to sulfur dioxide $\left(\mathrm{SO}_{2}\right)$ and sulfur trioxide $\left(\mathrm{SO}_{3}\right)$ in the product gases that pass from the combustion chamber through the boiler or furnace flue passages. These gases transfer most of their heat and then exit the boiler as exhaust gases. The BNL tests found that 98 to 99 percent of the fuel sulfur is converted to $\mathrm{SO}_{2}$, and the rest to $\mathrm{SO}_{3}$. The $\mathrm{SO}_{2}$ that is emitted from the exhaust is a primary criteria pollutant that contributes to acid rain and it is controlled by the USEPA. The $\mathrm{SO}_{3}$ from the flame reacts to form sulfuric acid that reacts with iron in the boiler or furnace to produce sulfate scale on heat transfer surfaces. The sulfur content of the fuel is directly related to this sulfate fouling and the need for frequent vacuum cleaning of heating surfaces in boilers and furnaces. BNL lab studies showed that lowering the sulfur content of the fuel lowers this fouling rate. 
The prior Low Sulfur Heating Oil and current Ultra Low Sulfur Heating Oil demonstration projects were funded by NYSERDA to extend these findings to actual field results. These field studies in oil heated houses were conducted to evaluate and qualify the benefits of LS and ULS heating oil, and to investigate and document operational concerns related to the lower sulfur fuel oil. Some initial concerns included potentially negative impacts on equipment performance related to reduced fuel lubricity and fuel pump failure, reduced fuel stability from oxidation during storage, and increased service requirements from plugged fuel lines, filters, and strainers. The results of the ULS demonstration project that follow directly address these concerns.

New York State consumes approximately one-fifth of all the oil used in residences in the US and is by far the largest consumer of home heating oil. The goal of the ULS heating oil demonstration project was to quantify the benefits, both environmentally and economically, produced by switching to ULS heating oil in residences. These benefits include a 99 percent reduction in sulfur oxide emissions by switching from heating oil with 2,000 ppm sulfur to heating oil containing $15 \mathrm{ppm}$ sulfur. The sulfur oxide emissions with ULS oil approach the near-zero levels of natural gas powered equipment. Similarly, particulate matter emissions are reduced to near-zero levels by using ULS heating oil based on research at Brookhaven National Laboratory (ref 14). Finally, oil heating equipment cleaning intervals can be extended, reducing annual cleaning costs in New York State by 50 to 100 million dollars a year, and by several million dollars a year in the US. 


\section{PRIOR RESEARCH WITH LOWER SULFUR HEATING OIL}

\section{Low Sulfur (500 parts per million) Heating Oil Demonstration (NYSERDA)}

A prior field demonstration project for evaluating the performance of Low Sulfur (LS) heating oil containing 500 parts per million of sulfur was also funded by the New York State Energy Research and Development Authority (NYSERDA) and was completed in 2005. The sulfur content of this Low Sulfur heating oil was substantially lower than conventional home heating oil which typically contains between 2,000 and 2,500 ppm. This prior study identified a number of benefits from using Low Sulfur heating oil including substantially reduced sulfur oxide emissions and reduced boiler cleaning costs through the lower deposition rates that are produced by the lower sulfur heating oil. A brief summary of these results follows.

The Low Sulfur (LS) study clearly demonstrated many advantages of using lower sulfur content heating oil to provide thermal comfort in homes and substantiated prior laboratory research showing the potential benefits of using reduced sulfur heating oil. The Low Sulfur research project was conducted to provide clear evidence of the many real-world advantages of marketing and using low sulfur content (500 ppm) No. 2 fuel oil. The positive results helped to establish this fuel as a desirable option for fuel marketers and homeowners.

These findings and earlier research offered the technical basis for oil heat associations including the National Oilheat Research Alliance (NORA) to fully support voluntary use of lower sulfur home heating oil nationwide. Similarly, the Oilheat Manufacturers Association (OMA) also supports using lower sulfur home heating oil in the equipment that they manufacture.

Using lower sulfur heating oil, both Low Sulfur (500 ppm) and Ultra Low Sulfur (15 ppm) oils, lowers boiler and furnace fouling rates and thereby reduces the cost of boiler and furnace cleaning. The prior Low Sulfur NYSERDA project included 1,000 occupied residential homes over the course of three heating seasons. The reductions in fouling rates that were demonstrated by this project closely matched predictions based on prior laboratory studies. Boiler fouling rates were reduced by a factor of two to three by using Low Sulfur heating oil with a comparable reduction expected in service costs by extending boiler cleaning intervals, yielding potential service costs savings by as much as up to $\$ 200$ million a year nationwide.

The expected cost savings by extended boiler cleaning intervals are higher than the added cost of the lower sulfur fuel, producing attractive paybacks. The LS study found 
that the expected benefit is a factor of two to four times higher than the added fuel cost for the lower sulfur product. Reference 13 provides more details in cost-benefit comparisons.

Sulfur oxide and nitrogen oxide air emissions are reduced substantially by using lower sulfur fuel oil in homes. Sulfur oxides emissions are lowered by 75 percent by switching from 0.20 percent $(2000 \mathrm{ppm})$ to $0.05(500 \mathrm{ppm})$ percent sulfur oil. This is a reduction of approximately 63,000 tons a year nationwide. In New York State, sulfur oxide emissions are reduced by 13,000 tons a year. It represents an important and easily implemented reduction in air pollutants that contribute directly to acid rain and other adverse impacts in the United States. Sulfur oxide emission reduction by using ULS heating oil with only $15 \mathrm{ppm}$ of sulfur is even higher. In fact, when all air emissions are included, Ultra Low Sulfur (ULS) home heating oil and utility supplied natural gas are virtually equal in their environmental impacts.

Reference 13 is the summary report for the Low Sulfur (500 ppm) heating oil project and contains additional details on these results, and additional information on prior research related to the performance and advantages of lower sulfur heating oil. A comparison of the field test results of the LS and ULS field studies is included later in this report.

\section{Earlier Research on Lower Sulfur Heating Oil}

Brookhaven National Laboratory in New York and Canadian researchers conducted laboratory studies of deposition rates and emissions from home heating oil with lower sulfur contents. This work and NYSERDA's Low Sulfur (LS) Field demonstration provided the basis for the ULS demonstration project that is reported here. This section of the report briefly summarizes some of the past work.

The sulfur content of home heating oil in the past has been in the range of 2000 parts per million $(0.20 \%)$ to $2500 \mathrm{ppm}(0.25 \%)$, and in some regions had been as high as 10,000 ppm or 1.0 percent. When Low Sulfur ( 500 ppm sulfur) highway diesel began to reach the market, the average sulfur content of home heating oil dropped and has varied from 1987 to 2002 as shown in (Figure 3-1 ) based on annual Petroleum Product Surveys (Ref 1 ). 


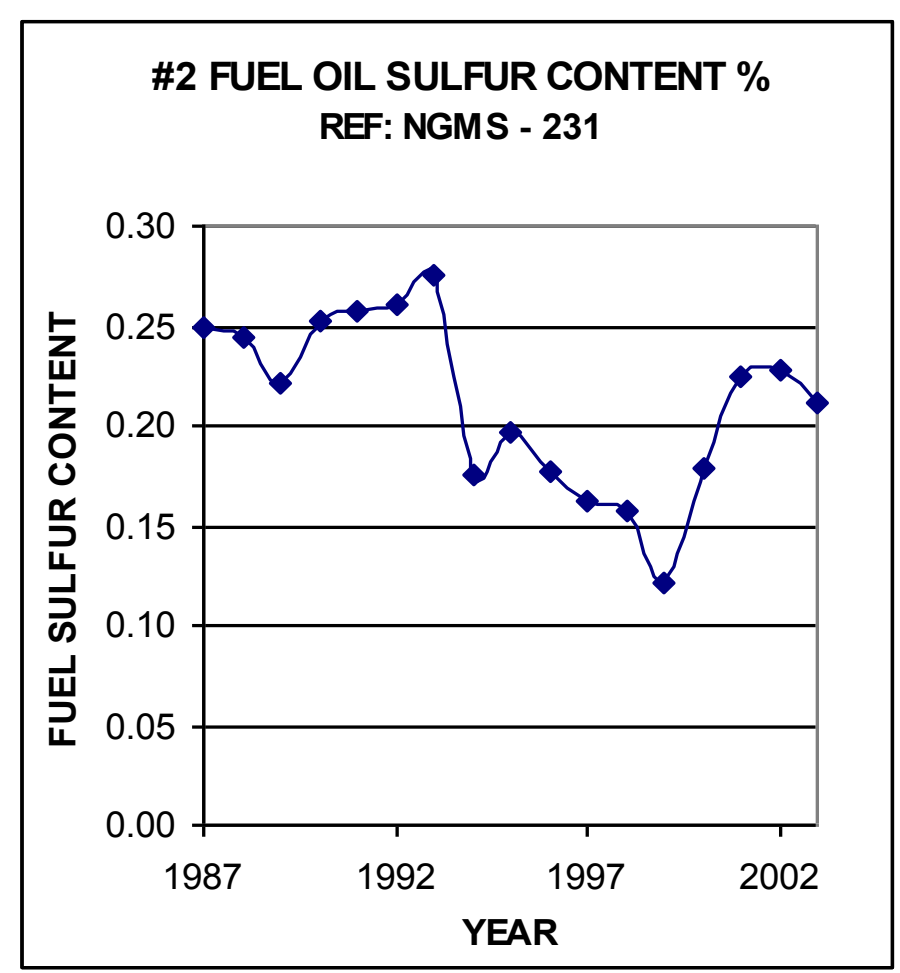

Figure 3-1.

At the start of that time interval, the average sulfur content of home heating oil remained at approximately 0.25 percent, but then dropped to below 2000 ppm, and then rose again. These results are based on relatively small sample sizes, and the actual average sulfur content of oil used in homes has not been accurately determined, but suggests a typical range of home heating oil sulfur content of between 2000 ppm and 2500 ppm over that time period.

\section{Air Emissions Reductions with low Sulfur Fuel}

\section{Sulfur Oxide $\left(\mathrm{SO}_{2}\right)$ Emissions}

The sulfur contained in heating oil and all fuels produces sulfur oxides that are emitted into the atmosphere when it is burned. Virtually all of the sulfur in the fuel is converted to sulfur dioxide which is emitted in the exhaust. Changing to low sulfur (LS) fuel with 500 ppm sulfur eliminates about 75 to 80 percent of the sulfur dioxide emissions from residential oil heating systems. This was documented in research that was reported by S. Win Lee, Ph.D., of the CANMET Energy Technology Center-Ottawa, Natural Resources Canada (Ref 2). When Ultra Low Sulfur heating oil that contains 15 ppm of sulfur is burned, 99 percent of the sulfur oxide emissions are eliminated when compared to home heating oil with 2000 ppm sulfur. Research at BNL shows that these levels are 
comparable to those from natural gas burners. Both ULS heating oil and natural gas have near-zero sulfur oxide emissions.

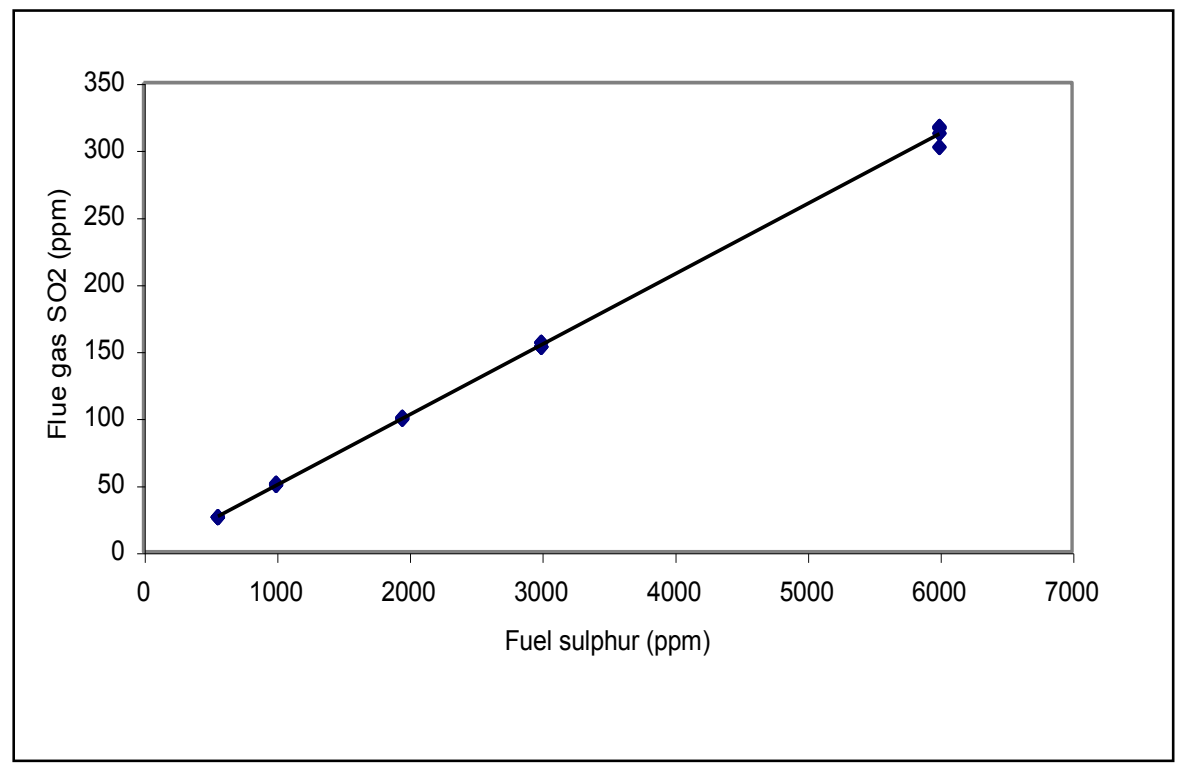

Figure 3-2 Effect of fuel sulfur on flue gas $\mathrm{SO}_{2}$ emissions

Figure 3-2 shows $\mathrm{SO}_{2}$ emission rates for fuel oils of various sulfur contents from 0.05 percent $(500 \mathrm{ppm})$ up to 0.6 percent $(6000 \mathrm{ppm})$, and the linear relationship between sulfur content in the fuel and $\mathrm{SO}_{2}$ emission rate resulting from combustion of the fuel is evident.

\section{Particulate Matter Emission}

Particulate Matter (PM) in the ambient air is becoming an increasingly important aair pollutant as its impacts on human health which include lung disease, cancer, heart attacks, and premature death are better understood. Particulates from oil-fired heating systems include both solid particulates (smoke and soot) and condensable components that form PM in the air. These condensable particulates are combustion products that leave the heating system as vapors but that later condense into particles after mixing with cooler ambient air. Condensable particulates have important health affects and are being studied in more detail in recent years.

BNL research found that oil burners emit PM that is approximately one-fourth filterable and three-fourths condensable (Ref 3 ), and the condensable particulate matter is mostly sulfates. Because condensable are mostly sulfates, oil burner PM emissions are 
significantly reduced by using lower sulfur content heating oil. Figure 3-3 shows this relationship.

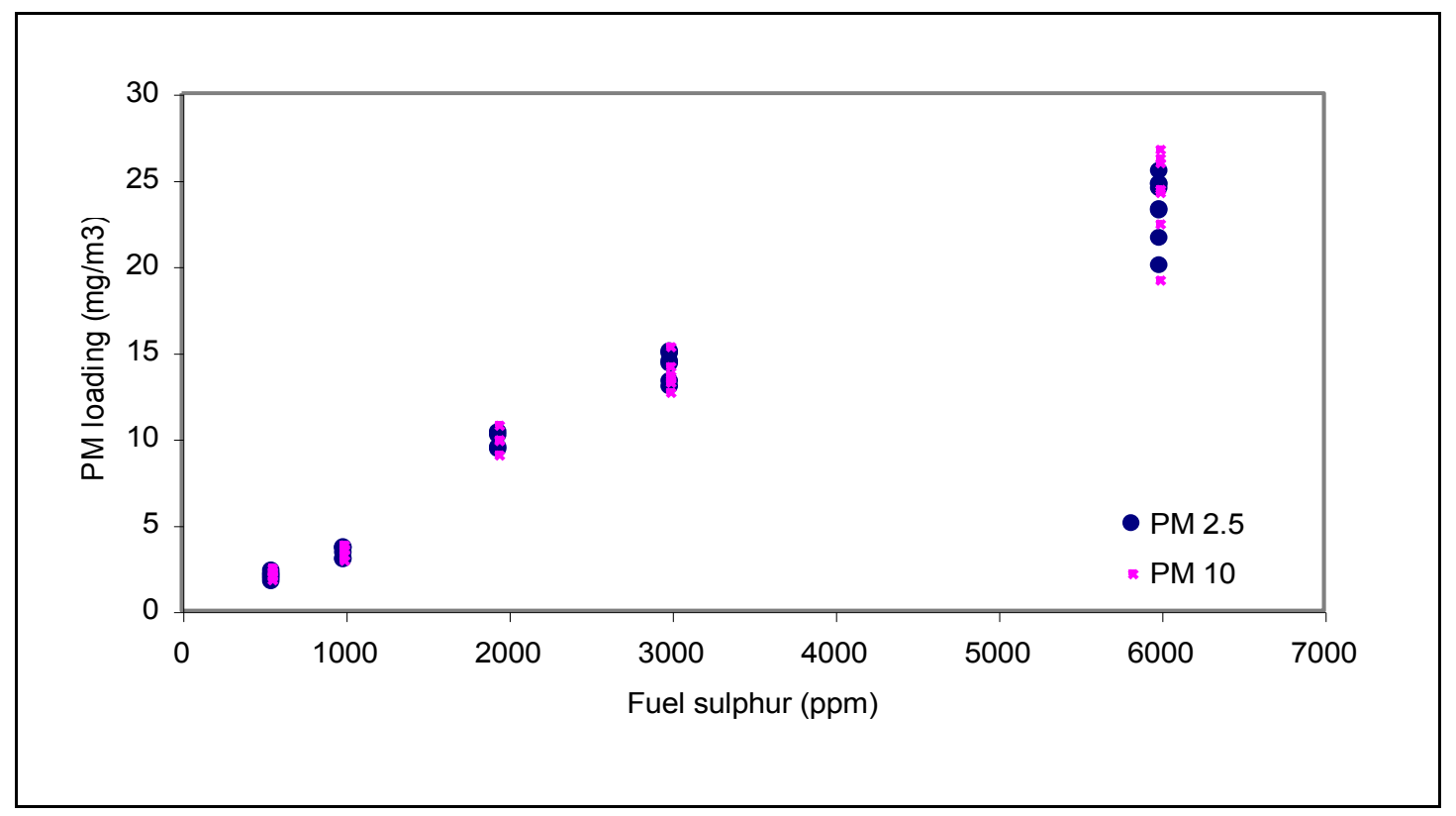

Figure 3-3 Effect of fuel sulfur on $\mathrm{PM}_{2.5}$ and $\mathrm{PM}_{10}$ emissions

\section{Nitrogen Oxides (NOx) Emissions:}

Most petroleum heating oil contains nitrogen and sulfur compounds in small amounts that contribute to nitrogen oxide and sulfur oxide emissions, respectively during combustion. The chemical processing that lowers the sulfur content of fuels also removes some of its nitrogen compounds. Removing some of these fuel-bound nitrogen compounds also lowers nitrogen oxide emissions.

Testing reported by the R.W. Beckett Corporation (Ref 4) measured the change in NOx emissions produced by reduced sulfur (and nitrogen) fuel contents in three different burner designs. Three fuels were tested for NOx emissions from residential oil burners. These were standard heating oil, low sulfur (500 ppm) oil, and ultra low sulfur (15 ppm) heating oil. The tests revealed that the low sulfur fuel reduced $\mathrm{NO}_{x}$ by $5-10 \%$ compared to the standard fuel, and the ultra low sulfur fuel reducing $\mathrm{NO}_{x}$ by $20-30 \%$ compared to the standard fuel. Clearly, lower sulfur heating oil also produces lower nitrogen oxide emissions as some of the fuel bound nitrogen is removed from the fuel with the sulfur. 


\section{Past and Recent Environmental Regulations}

Past studies have demonstrated a relationship between fine PM emissions and adverse health effects that include cardiopulmonary and cardiovascular illnesses, and premature deaths in susceptible people. In 1997 The U.S. Environmental Protection Agency (USEPA) revised National Ambient Air Quality Standards (NAAQS) for ozone and particulate matter. The PM standard was revised to include both $10 \mu \mathrm{m}$ particles (PM10) and finer sized PM with a diameter less than $2.5 \mu \mathrm{m}$, commonly known as $\mathrm{PM}_{2.5}$,

Shifting to low sulfur fuel substantially lowers fine particulate matter emissions and its adverse health and environmental impacts. The oilheat industry has endorsed and fully supported the use of lower sulfur heating oil and has become a leader in air emissions reduction. This includes voluntary endorsements of lower sulfur oil by National Ollheat Research Alliance (NORA) and the Oilheat Manufacturers Association (OMA). In addition, New York State mandated the use of Ultra low Sulfur heating oil in homes as of 2012.

\section{Reduced Equipment Cleaning and Cost Savings Potential}

Research in the laboratory and field has clearly shown the direct relationship between the sulfur content of home heating oil and fouling deposits on heat transfer surfaces. Lower sulfur content heating oil produces lower heater fouling rates. This allows extended time intervals between oil boiler vacuum cleanings, substantially lowering service costs, improving customer satisfaction with oil, and improving oilheat's image as a "clean fuel". This report offers more detailed analysis, evaluations, and documentation in support of this conclusion.

\section{Laboratory Tests at Brookhaven National Laboratory}

Brookhaven National laboratory (BNL) has operated an oil heat research program for more than 35 years that was primarily funded by the US Department of Energy and NYSERDA. This research included evaluating boiler heat exchanger deposition rates as a function of sulfur content of the fuel. The BNL tests found that the rate of heat exchanger fouling is directly proportional to the fuel's sulfur content. The majority of deposits in oil-powered equipment are now from sulfates that are directly proportional to the sulfur content of the fuel.

Figure 3-4 shows photographs illustrating the differences in boiler deposition rates based on BNL testing and clearly demonstrates how boiler deposits decrease as the fuel sulfur content is reduced from 10,800 parts per million (1.08\%) to $400 \mathrm{ppm}(0.04 \%)$. 
The deposition rates drops as the fuel sulfur content decreases. The 400 percent sulfur is close to low sulfur (LS) fuel oil, while ULS is even lower at only $15 \mathrm{ppm}(0.0015 \%)$ which would show lower deposition rates than that shown in the upper left photograph.

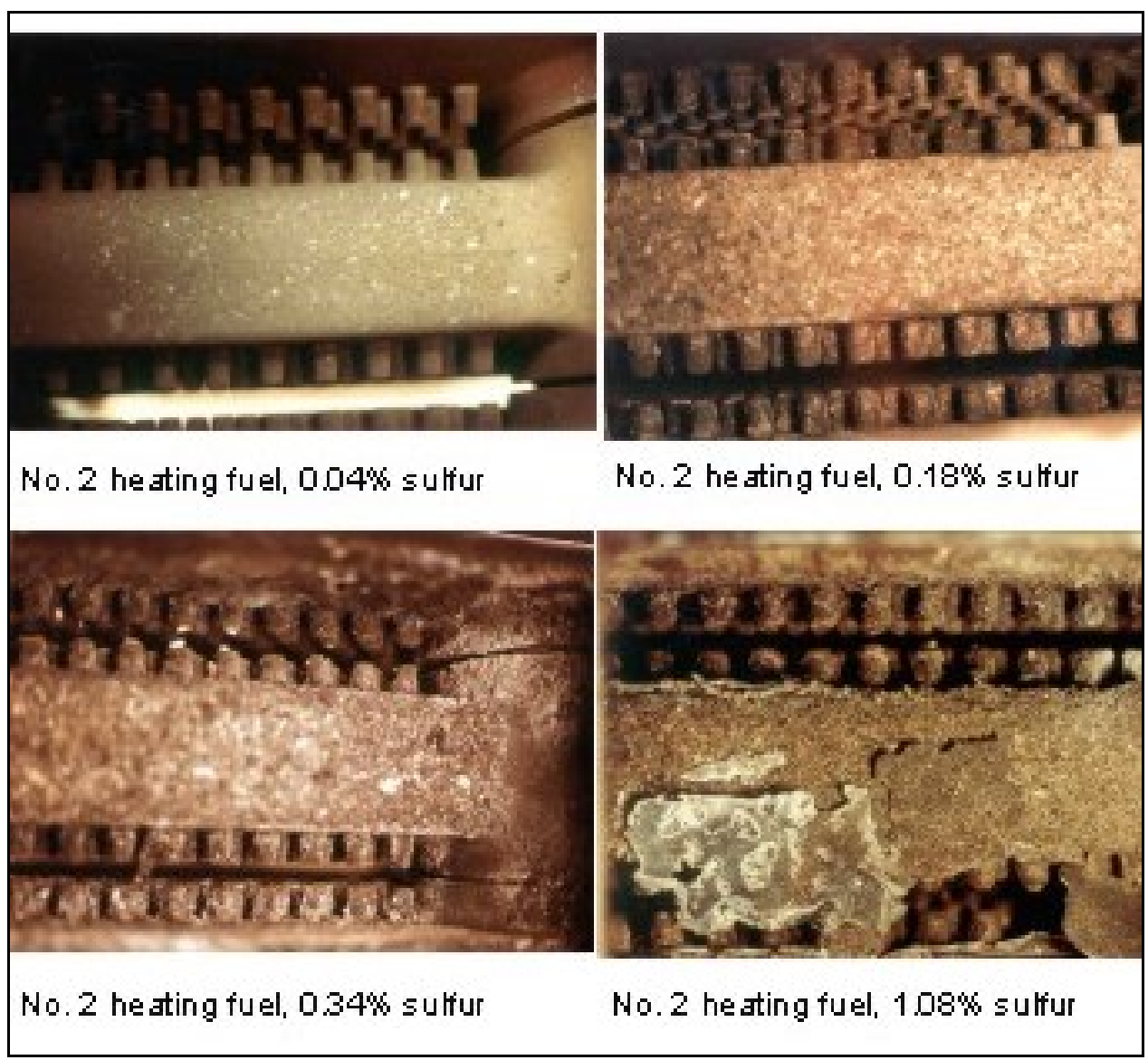

Figure 3-4. Boiler Deposition for Varying Fuel Sulfur Contents

These research findings by BNL graphically demonstrate the advances offered by LS and ULS heating oil and was the basis for the boiler Visual Fouling Scale that was developed by Roger McDonald of BNL and this scale became a primary metric used in this ULS demonstration project and the prior Low Sulfur field test project.

Early research by Brookhaven in 1997 (Ref 5) developed a laboratory test method for measuring boiler deposition rates on a cast iron test section constructed from a conventional boiler. Exhaust gases from fuels with varying sulfur content were passed over the section and the deposition rate was measured. These tests first established 
the direct relationship between sulfur content and boiler fouling rates as summarized below in Figure 3-5.

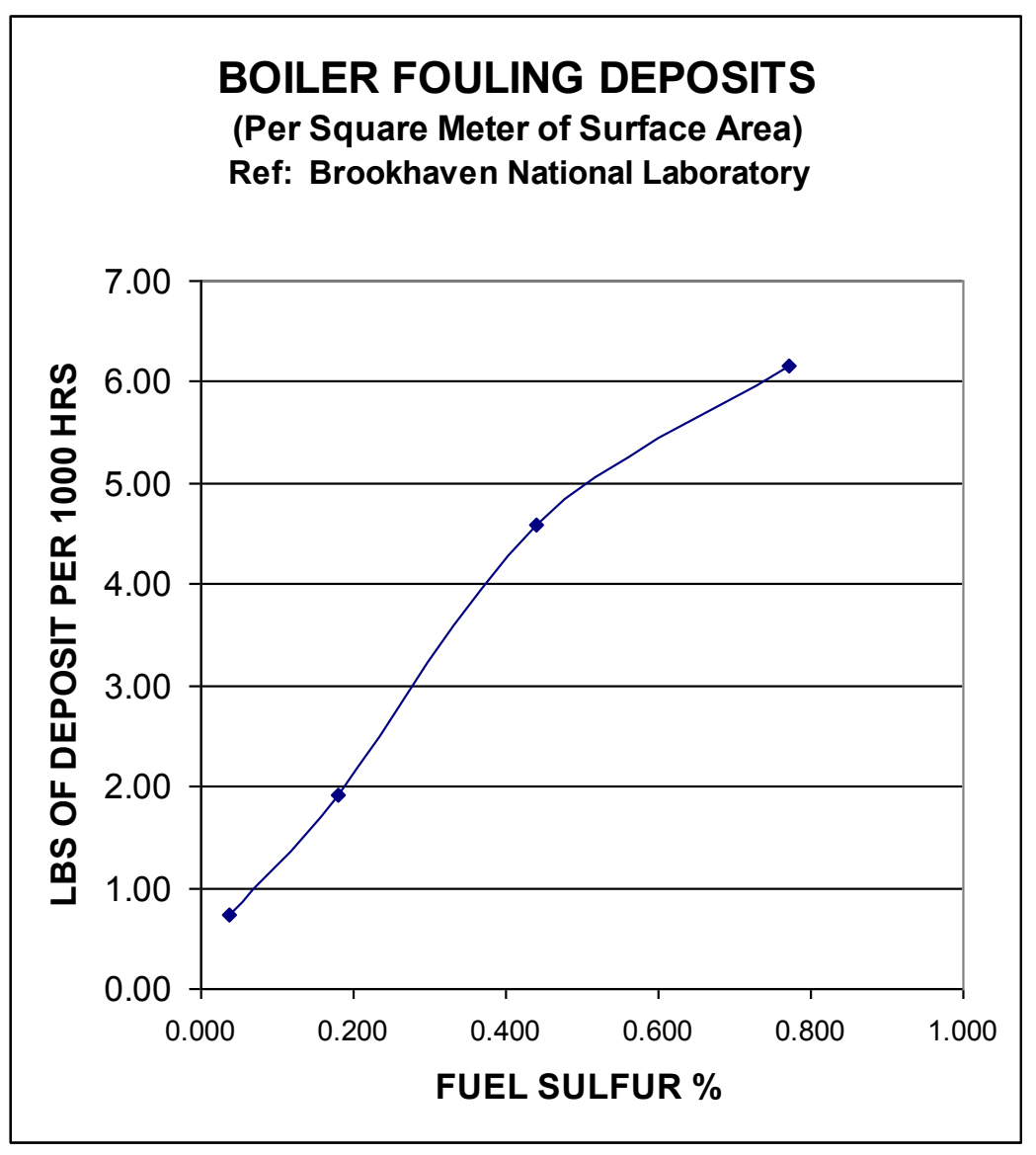

Figure 3-5

These results show deposits per square meter for 1000 hours of operation measured for varying fuel sulfur contents ranging from $400 \mathrm{ppm}(0.04 \%)$ to $8,000 \mathrm{ppm}(0,80 \%)$. The deposition rate or fouling rate drops to only $\mathbf{0 . 7 3}$ pounds when the fuel sulfur content is $\mathbf{0 . 0 4 \%}$. These tests revealed that using lower sulfur fuel oil lowers boiler fouling rates and can lower the frequency of costly vacuum cleaning. 


\section{Laboratory Tests at Canadian Energy Technology Center}

The early BNL fouling test for various fuel sulfur contents were duplicated in Canada using a test method that is similar to the one used at BNL. The test results corroborate the BNL results, as seen in Figure 3-6. While the actual deposits in the Canadian tests were slightly higher, the overall trend is the same.

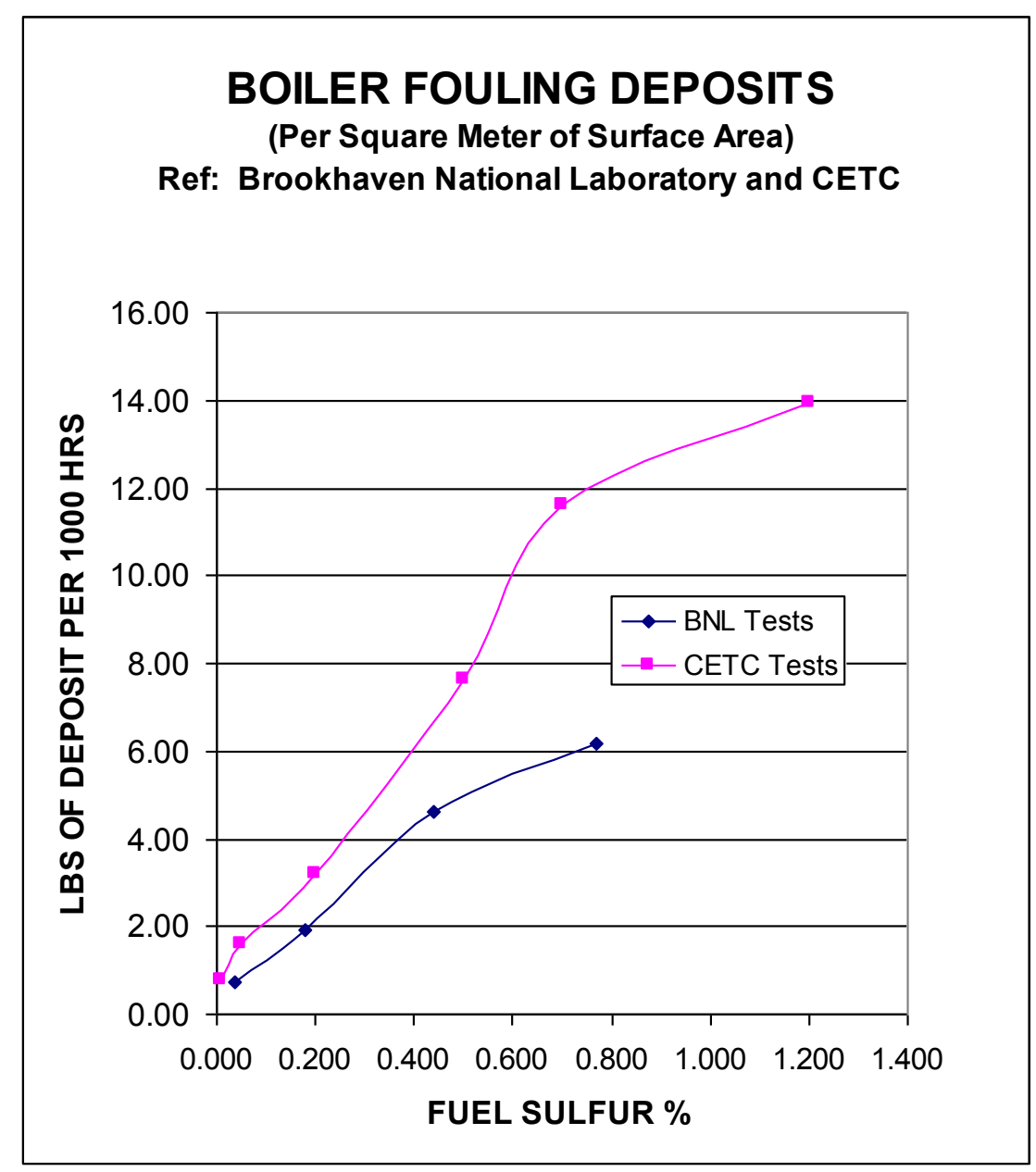

Figure 3-6

The Canadian test results show a change in deposition rate that is very close to the BNL tests and helped to validate the important relationship between fuel sulfur content and boiler fouling rates. 


\section{Field Test Methodology and Procedures}

This field demonstration project of Ultra-Low Sulfur Heating oil in residences in New York State included six initial tasks in its scope of work as follows.

Task 1. Project Management

Task 2. Define Test Program and Data Collection Procedures

Task 3. Training Sessions for Participating Oil Companies and Service Technicians Task 4. Demonstration Site Selection

Task 5. Field Testing - Data Collection and Analysis

Task 6. Final Report, Technology Transfer, and Metrics

The initial work scope was extended to include a second full year of field testing to more fully evaluate the impacts of Ultra-Low Sulfur heating oil in residential heating equipment. A brief description of each task follows.

\section{Task 1. Project Management Plan}

ERC performed the project management functions for the project that included: initial briefings with the NYSERDA Project Manager, and periodic telephone communications to review progress. In addition, monthly progress reports were prepared and submitted to the NYSERDA project manager.

A Project Management Plan was developed that defined test procedures, technical approach and timing of key events. In addition, a technical training document was prepared and presented to the participating oil technicians and service manager who managed the oil technicians on this project. The responsibilities of the Energy Research Center, Brookhaven National Laboratory, and the participating fuel oil dealer were clearly described and discussed.

In addition, a Project Advisory Group (PAG) was established to review technical plans and progress and address any key technical issues that arose during the project execution. The PAG consisted of John Batey of ERC, Roger McDonald of BNL, Victor Turk of RW Beckett Corporation, and Dale Hansberger of Suntec Corporation. Conference calls were held to discuss technical issues during the project. 


\section{Task 2. Define Test Program and Data Collection Procedures}

\section{Test Program}

This field demonstration of Ultra Low Sulfur home heating oil monitored changes in the performance of oil home heating systems when heating oil containing $15 \mathrm{ppm}$ was used in place of conventional home heating oil with 2000 ppm sulfur content.

The test program included a detailed study of 100 test houses using ULS heating oil. In addition, the test program included a control group of 100 customers of the participating fuel oil dealer that used conventional (higher sulfur) home heating oil. Ten sites were selected for enhanced data collection and analysis, and fuel use delivery and service records were collected for all 200 houses by the participating oil dealer. Key operating parameters were studied for an entire heating season and the field study was extended for an additional year. Specific measures used for the field study include the following:

Service records from the participating oil dealers for 100 ULS houses for the study period of two years, and for 100 control group houses using normal sulfur heating oil.

Combustion testing at the start of the project and each year during annual boiler check-ups and burner tune-ups. This included measurement of sulfur dioxide levels in the flue gas in several houses to assure that ULS was being used.

Flue Gas Temperature measurements each year during burner tune-ups and more frequently in some houses to track the rate of boiler fouling through increases in flue gas temperature. Fouling of the boiler's internal heat transfer surfaces occurs partly through sulfur oxide deposition and the lower sulfur in the fuel lowers the rate of deposition. The lowered deposition rates are reflected in lower boiler flue gas temperatures over time.

Boiler Fouling Scale charts that were developed by Roger McDonald at Brookhaven during the earlier Low Sulfur (500 ppm) Demonstration project that was funded by NYSERDA were used again to assess the fouling rate of the ULS test boilers and for the control houses using normal sulfur heating oil. This Visual Fouling Scale that was used successfully by ERC and BNL during the prior NYSERDA-funded low sulfur field study, and again proved to be an important measure for this ULS study. It provides a quantitative comparison of the fouling level of heat transfer surfaces inside boilers. 
Energy Tracking \& Control (ETC) is a software-based fuel tracking system that was developed by ERC and accurately detects changes in heating system efficiency by precisely tracking fuel use. It was used in conjunction with the other measures to compare the performance of the ULS houses and the control group using normal sulfur heating oil.

\section{Service Records}

Service records are maintained by the participating fuel oil distribution company and are important as they indicate any changes in service frequency and types of service required for ULS fuel compared to conventional higher sulfur heating oil. Increases in service frequency could indicate potential issues with compatibility of the ULS using conventional oil heating equipment. This was examined as part of the field demonstration. Similarly, reductions in cleaning frequency for ULS-fueled houses compared to the control group is possible due to lower fouling rates produced by the ULS fuel. All service calls for the ULS group and the control group were documented and analyzed to evaluate the frequency of service and the type of services that were performed. These service records were supplied by the participating fuel oil dealer and were accessed and analyzed.

All service records for the 100 test sites and the control group were sent to ERC and BNL on a periodic basis. Some of these data are in text message format, and these were converted to a spreadsheet format for comparison and analysis of equipment service required. A database was established to track and compare the ULS and control groups on a continuing basis as new data were received. The results are summarized in this report.

\section{Combustion Testing}

Testing of flue gas using conventional combustion test equipment following accepted industry practices was part of the study for both the ULS and control groups. All burners were adjusted for maximum efficiency at the start of the project and at the end of each heating season. Boilers were carefully cleaned by the participating oil dealer at the start of the project using procedures prescribed by ERC and BNL that represent the best accepted industry practices. Oil burners were then adjusted for peak efficiency. Lower deposition rates were observed for the burners using the ULS fuel oil. This produces less efficiency loss over time, which was evaluated each year by combustion testing that was part of annual heating equipment inspections. The relative ULS 
deposition rates and changes in flue gas temperature were compared to those for the normal sulfur heating oil control group.

In several cases, the participating oil supplier was able to extend vacuum cleaning intervals to two or three years with the ULS and conventional heating fuel. Combustion testing was an important measure in the field demonstration project.

Combustion test procedures that were used for both the ULS and control group included measurement of:

- Flue gas oxygen or carbon dioxide levels

- Flue gas temperature

- Smoke number

- Draft in the flue and over the fire

- Combustion efficiency

Sulfur dioxide readings were recorded near the start of the project for several installations during the initial cleaning and burner tune-up for boilers in the ULS group. These tests were conducted by Roger McDonald. This testing of randomly selected houses demonstrated that the ULS heating oil was being supplied.

\section{Flue Gas Temperature}

Flue gas temperature measurement which is part of combustion testing could be an indicator of internal fouling of heat transfer surfaces in boilers and furnaces. As fouling deposits (including sulfates) build up on these surfaces, heat transfer rates decrease and the flue gas temperature rises. Periodic testing of flue gas temperature is one way to track fouling rates. The participating oil dealer measured and recorded flue gas temperature for the ULS houses whenever annual service was performed. This assured flue gas temperature measurement at least once a year (before and after each burner or boiler servicing). Combustion testing was also performed for the houses in the control group with normal sulfur heating oil. This produced a substantial volume of flue gas temperature data.

In addition, ten houses were selected for detailed monitoring of flue gas temperatures over time. Battery powered data loggers that included a temperature sensor were installed in the flue pipes of these test houses. This permitted more detailed tracking of flue gas temperature in these ULS and control group test houses. The resulting flue gas temperature data were analyzed and the results are presented in this report. 
The figure that follows shows the model of data logger that was used for this demonstration project.

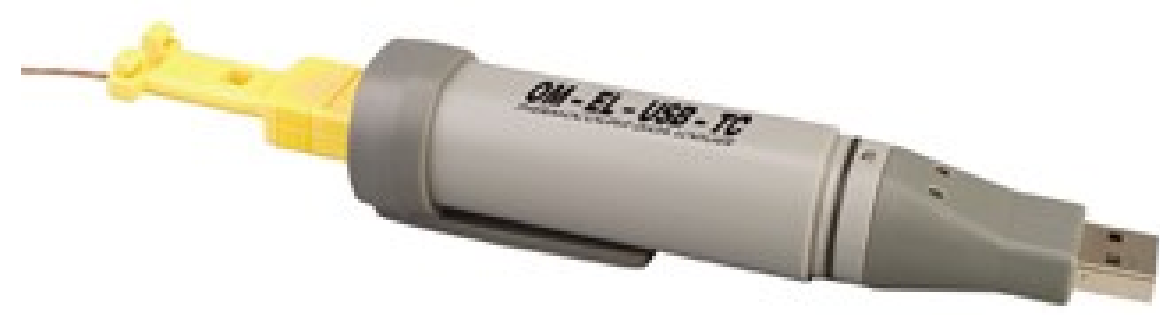

Figure 4-1. Thermocouple Data Logger used to Monitor Flue Gas Temperature in 10 houses

The thermocouple data logger was manufactured by Omega Engineering, and is a Model OM-EL-USB-TC. It is a powered by lithium batteries and measures and stores up to 32,000 temperature readings from the K-Type thermocouples that were used. After being programmed for the optimum logging rate, the thermocouple data loggers were installed in 5 ULS and 5 Control group houses to track flue gas temperatures over time. They were installed in late 2009 and remained in place until February or March 2010 so that flue gas temperatures for an entire heating season could be measured and recorded. The data logger was retrieved from the field and was then plugged into a computer at BNL and the information was transferred to an Excel spreadsheet for analysis. These data were then plotted and reviewed to determine trends in flue gas temperature for ULS and Control group test houses. Plots from these data logger are included in this report.

\section{Boiler Fouling Comparison Scale (Boiler Fouling Scale)}

A primary measure of ULS performance is the Boiler Fouling Comparison Scale (BFCS) also referred to as the Boiler Fouling Scale (BFS). The Boiler Fouling Scale was developed by Brookhaven and ERC during the earlier NYSERDA Low Sulfur (500 ppm) study as a way to assess the fouling rate of boilers in the field. The service technician uses this simple visual scale to quantify the fouling rate of a boiler before the unit is cleaned. The results of the fouling inspections using the BFS during the earlier low sulfur field study produced excellent correlation with the detailed study group in which the mass of boiler deposits were carefully collected and analyzed. 
The BFS was again used for the ULS field demonstration as a means for evaluating the condition of each of the heating systems in the ULS study and for the Control group during annual check-ups before any boiler cleaning was performed. This was an important metric of the field demonstration, and could be adapted for use by oil service technicians in the future. It was found that this scale could be used to extend the vacuum cleaning intervals beyond one year for houses in the ULS test group.

The BSF data sheets were produced by BNL and ERC and distributed to the participating oil dealer, and they were given to the service technicians prior to annual checkups for both the ULS and normal sulfur Control groups. The BFS results that were observed before each boiler cleaning were recorded on specially designed data sheets and were sent to BNL and ERC for analysis. A sample Visual Fouling Scale that was developed for this project is referred to as the Boiler Fouling Comparison Scale (BFCS).

A sample of the Boiler Fouling Scale used in this project follows in Figure 4-2. This was the primary measure used to compare deposition rates in ULS and Control group houses.

Level 1 fouling indicates negligible fouling of the boiler heat transfer surfaces. In contrast, Level 4 shows substantial fouling and boiler sulfate deposition and corrosion. Levels 2 and 3 are moderate degrees of boiler fouling. The BFS (Boiler Fouling Comparison Scale) that was used for this ULS study includes intermediate readings of $1.5,2.5$, and 3.5 in addition to the fouling levels on the origin scale developed for NYSERDA in the prior field study. This permitted more precise field evaluation of the fouling levels for both the Ultra Low Sulfur and normal sulfur control groups.

Level 1 on the Fouling Scale shows very low deposition and is typically observed with ULS heating oil or natural gas after approximately one year of operation. Level 4 shows heavy fouling, sulfate deposits and boiler corrosion that is consistent with operation with very high sulfur heating oil of 1 percent $(10,000 \mathrm{ppm})$ sulfur in the heating oil for approximately one year of operation. Clearly, using ULS heating oil with 15 parts per million sulfur content eliminates the heavy fouling that is observed for the high sulfur heating oil that was used in the past. 


\section{BOILER FOULING COMPARISON SCALE}

Visual Determination from \#1 through \#5

Customer ID \#:

Date:

$\mathrm{C}$

h

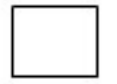

\#1 Level

e

$\mathrm{c}$

$\mathrm{k}$

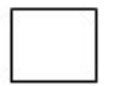

\#1.5 Level

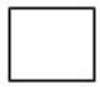

\#2 Level

nl

e

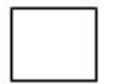

\#2.5 Level

B

o

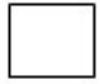

\#3 Level

$\mathrm{X}$

$\mathrm{O}$

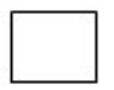

\#3.5 Level
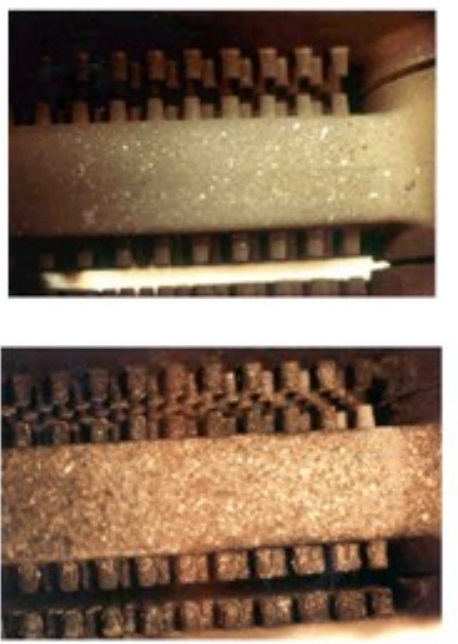

n

1

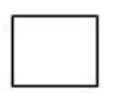

\#4 Level

y

\#5 Level [ More than \#4]
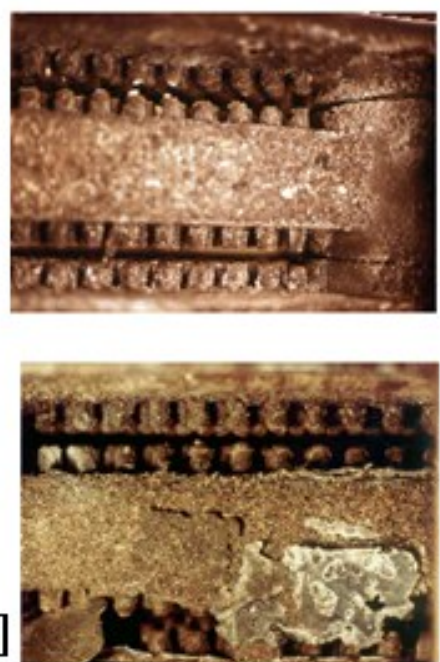

FIGURE 4-2. Boiler Fouling Comparison Scale (Boiler Fouling Scale) 


\section{Energy Tracking \& Control}

One additional measure that was applied for this field study is the proprietary Energy Tracking and Control System that was developed by the Energy Research Center, Inc. The ETC system uses fuel oil delivery records and modified heating degree day factors to accurately track fuel use in houses. It can detect changes in heating equipment efficiency on the order of one percent. It has successfully measured fuel savings in the field with an accuracy of 99 percent to 99.5 percent. Energy Tracking and Control was applied as one of the measures for the ULS project to determine changes in fuel use efficiency (boiler fouling) over time for both the ULS houses and the control groups.

ETC and other tracking systems may offer a way to change from scheduled cleaning of heating equipment to "as needed" cleaning by tracking changes in equipment efficiency using only fuel delivery data and modified heating degree data. This can be especially useful in houses where the vacuum cleaning intervals are extended to two, three, four, or more heating seasons. This can substantially lower the cost of annual equipment service to heating service companies and homeowners.

Fuel delivery data for some houses receiving ULS heating oil and for houses in the Control group were analyzed using ETC. ETC is not expected to detect efficiency changes in the ULS test houses over a single heating season, but it was able to detect changes in the normal sulfur control group houses in some cases. It also provided a diagnostic tool during the project to measure changes in fuel use and efficiency. If substantial boiler fouling occurs, then the change in fuel use efficiency can be accurately calculated. A summary and description of the ETC methodology and sample plots are contained in Appendix A.

\section{Precise House Characterization}

A detailed one-page Site Characterization Form was filled out by the participating fuel oil technicians for houses that were part of the ULS and control group. The characterization form was prepared by BNL and ERC and included a summary of the key design feature of the house that includes, boiler and burner description and manufacturer, and model number; boiler size and firing rate; vent system type, size and description including chimney type, diameter and height, boiler control temperature settings, domestic hot water source, and other key design and operating data. Digital photographs of each installation were attached. These forms were designed to be easy to complete with check boxes used wherever possible. A sample Site Characterization Data Form follows in Figure 4-3. 


\section{NYSERDA ULS STUDY - SITE CHARACTERIZATION FORM}

HOMEOWNER NAME:

ADDRESS:

CITY/STATE/ZIPCODE:

DATE:

HOUSE HEIGHT: $\quad$ Stories: $1 \quad \begin{array}{lllll} & 2 & 3 & 4 & \text { (Above ground level) }\end{array}$

BASEMENT: YES NO

CHIMNEY TYPE: BRICK MASONRY METAL OTHER

CHIMNEY LINER: CLAYTILE METAL MASONRY NONE

$\begin{array}{lllllll}\text { CHIMNEY HEIGHT: } & \text { Stories: } & 1 & 2 & 3 & 4 & \text { (Above ground level) }\end{array}$

CHIMNEY GENRAL CONDITION: EXCELLENT GOOD FAIR POOR

HEATING EQUIPMENT: BOILER FURNACE

HEATING UNIT MANUFACTURER

HEATING UNIT MODEL:

APPROXIMATE AGE (Years):

BURNER MANUFACTURER:

BURNER MODEL:

BURNER NOZZLE:

GHP

DEGREES ( _ SOLID

HOLLOW _. SS)

DOMESTIC HOT WATER: __ TANKLESS _ OIL WTR HTR _ ELEC _ GAS

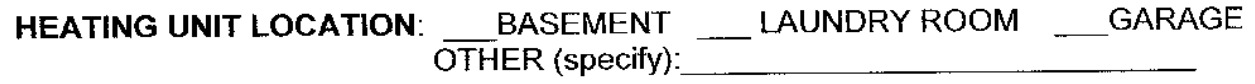

SOURCE OF COMBUSTION AIR:

FUEL TANK LOCATION:

FUEL OIL TANK SIZE (GAL):

OBSERSATIONS

PHOTOGRAPHS: HOUSE EXTERIOR\& CHIMNEY HEATING UNIT

Figure 4-3. Site Characterization Form 
These forms were completed in the field by service technicians, and were then collected and sent to ERC and BNL engineers for analysis. The data from these sheets were entered into a detailed data spreadsheet at BNL. This assisted tracking changes in fouling rates, combustion efficiency, flue gas temperature and other key parameters for each test group and control group house. It also supplied a valuable data base and indepth description of each oil heated house in the ULS and Control groups. This includes estimated boiler and burner ages, and detailed combustion efficiency test results over time for each house. The comprehensive spreadsheet allowed accurate tracking of changes in VFS over time for each house in the ULS and Control groups.

\section{Data Collection Procedures}

The Ultra Low Sulfur field demonstration included a number of work tasks that were finalized at the start of the project with the assistance of the participating fuel oil dealer. These included identification of 100 ULS test houses, identification of 100 control group houses, and training services technicians who participated in the field test program. The oil service technicians completed initial boiler cleanings, the site characterization forms, and initial cleaning checklist forms that contained boiler fouling levels and combustion test results. At the end of each study year, the service technicians inspected the boilers for fouling condition, took photographs of the heat exchanger, and performed boiler cleaning and burner tune-ups. The technicians completed an Annual Boiler Inspection and Burner Tune-up Checklist during the boiler inspections and cleanings. These forms were then delivered to BNL where the data were reviewed and entered into a master spreadsheet.

The Annual Boiler Inspection and Burner Tune-up Checklist was developed by ERC and BNL in collaboration with the participating oil dealer and service manager. The intention was to capture and record as much information on boiler condition before and after the annual service but not add to much work for the service technicians. A sample of the Initial Cleaning Checklist Form that was used for this field demonstration follows in Figure 4-4. 


\section{Initial Cleaning Checklist}

Homeowner Account \#

Address:

City/State/Zip code:

Date Of Service And Cleaning:

Serviced By:

General Condition At Start Of Cleaning:

1. Thoroughly Brush And Vacuum Heat Exchanger.

2. Vacuum Clean Combustion Chamber:

3. Vacuum Clean Inside Of Flue Connector:

4. Note Any Special Cleaning Steps Followed:

5. Notes On How Heat Exchanger Was Cleaned:

6. Complete All Other Normal Service Procedures - Following Standard Company Procedures.

7. Measure and Record Combustion Efficiency Data:

$\mathrm{CO} 2 \%$

Flue Temp:

BLR Water Temp

Smoke No:

Draft: Flue:

Inches wc. Over-Fire

or $\mathrm{O} 2 \%$ $\mathrm{F}$ gross $\mathrm{F}$ $F$ net (minus room Temp)

Combustion Test Equipment used :

8. Boiler Fouling Scale Number (after cleaning):

9. Photographs of Heat Exchanger

If you have questions about this form, call 203-459-0353 or 631-344-4197

Figure 4-4. Initial Cleaning Checklist 
The Initial Cleaning Checklist supplied a standardized method for cleaning the ULS and control group boilers at the start of the project and recorded combustion test results after boiler cleaning and burner tune-up that established a benchmark for subsequent cleanings. This procedure also established the Boiler Fouling Scale number at the start of the project and supplied baseline photographs of the inside of the boiler heat exchanger that were used to evaluate fouling rates over time for both ULS and control group boilers.

Data Collection procedures were accomplished by the participating oil company technicians using these forms that were developed by ERC and BNL engineers. Specific data that were collected during this field demonstration project included the following.

\section{Service Records}

The participating Oil Dealer tracked all service calls to both the ULS group and control group using their in-house computer-based system. Copies of service records for the ULS and Control groups were assembled and sent to ERC periodically for analysis. This included all annual check-ups, routine service, and emergency service calls that occur normally during the field demonstration project. A summary of all parts and services that were supplied were included in these detailed service records. These data were reviewed and analyzed by ERC. Master spreadsheets for both the ULS and Control Group were tabulated and the results were summarized that compared the service requirements of these two groups.

\section{Fuel Delivery Records}

The participating oil delivery and service company sent fuel delivery records for the ULS test houses and the Control Group houses to ERC for analysis using the Energy Tracking and Control program. Fuel delivery records were sent electronically for both the ULS and control groups to ERC for analysis. These data included: account number (without account name or address), delivery date, volume delivered, and Heating Degree Day interval for each delivery for each house. Analysis of ULS account delivery history using the proprietary Energy Tracking and Control system was completed at the start of the project to precisely predict fuel tank levels in each ULS test house so that the deliveries could be scheduled so that the volume of fuel delivered to each ULS tank was as large as possible. This allowed maximum volumes of ULS fuel to be delivered to each tank in the demonstration project so that the high sulfur content of the oil in the tank could be lowered more quickly. 


\section{Combustion Testing}

Service technicians with the participating fuel oil dealer performed combustion tests at the start of the demonstration project after the initial cleaning, after the first year of the test program, and after the second year of the test program for both the ULS and Control groups. The results were recorded on the Initial Cleaning Checklist Form, and then on the Annual Boiler Inspection and Burner Tune-up Checklist Forms at the end of each year of operation. The combustion test data from these forms were entered into the Master spreadsheet for the ULS and Control group houses. This spreadsheet was then used to compare changes in boiler performance over the entire field test period.

One important measure of performance that is part of combustion testing is the boiler flue gas temperature, because it indicates how much heat is being lost in the exhaust gases. It is an indication of the degree of fouling of the boiler heat transfer surfaces. Lower sulfur heating oil reduces the rate of boiler fouling and helps to keep flue gas temperatures lower during the heating season. Therefore, measurement of flue gas temperature each year is a measure included in this demonstration project. Two digital thermocouple thermometers manufactured by Omega Engineering were purchased for the service technicians working on this ULS demonstration project to improve the accuracy of flue gas temperature readings during combustion efficiency testing. These offer higher precision and accuracy than many of the thermometers that are commonly used for combustion testing.

A sample of the Annual Boiler Inspection and Burner Tune-up Checklist that was used for this field demonstration follows in Figure 4-5.

Key information recorded on these forms included Boiler Fouling Scale both before and after cleaning as determined by the service technicians, and combustion test results before and after cleaning to determine any changes in burner/boiler efficiency that occurred between cleanings/tune-ups. This supplied information on the efficiency and fouling rate for each boiler. The form also included a check on fuel pump seal condition and inspection for fuel leaks after pump leaks were observed by the BNL lab testing of ULS heating oil. This detailed information was included to the detailed data base for boilers in the ULS test and control groups. The "as found" fouling number based on the BNL fouling scale and photographs of the heat exchangers before cleaning served as primary metrics for this field demonstration project. 
Annual Boiler Inspection and Burner Tune-Up Checklist

Homeowner Account \#:

Address:

City/State/Zip code:

Date of Service:

Serviced By:

General Condition at Start of Cleaning:

1. Boiler Fouling Scale Number Before __ After Cleaning

2. Photographs of Heat Exchanger Before After Cleaning

3. "As Found" Combustion Efficiency Tests: $\mathrm{CO} 2 \%$

Flue Temp:

BLR Water Temp $F$ gross $\mathrm{F}$ or $\mathrm{O} 2 \%$ Smoke No: Draft: Flue: Inches wc. Over-Fire

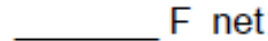

(minus room Temp)

Combustion Test Equipment used:

4. Complete Boiler Cleaning (ONLY IF NEEDED): Yes _ No

5. Conduct Burner Service and Tune-up Following Standard Company Procedures.

6. After Burner Tune-up Combustion Efficiency Tests: $\mathrm{CO} 2 \%$

Flue Temp: BLR Water Temp or $\quad \mathrm{O} 2 \%$

Smoke No:

Draft: Flue:
F (Example: $453 \mathrm{~F}$ $F$ Inches w.c. Over-Fire : Inches wc.

7. Check fuel pump seal. Any Leaks?: Yes No Notes:

If you have questions about this form, call John at 203-459-0353 or Roger at 631-344-4197

Figure 4-5. Annual Boiler Inspection and Burner Tune-up Checklist 


\section{Task 3. Training Sessions for the Oil Company and Service Technicians}

ERC and BNL engineers assembled written procedures to prescribe initial cleaning of boiler deposits, combustion test procedures, flue gas temperature measurement methods, recording combustion test data, and other data collection procedures. These were presented in written form and reviewed with the service manager of the participating oil company. The boiler cleaning and combustion test procedures were based on the PMAA Advanced Oil Heat manual that was produced by Brookhaven National Laboratory and ERC, which represents good industry practice, and is the basis for a national certification program. Data collection procedures used by service technicians and oil company participants also were reviewed. A training session with the oil company was conducted jointly by Brookhaven and ERC at the oil company office on Long Island. These program procedures were reviewed periodically with the service manager.

ERC and BNL also offered assistance with any questions related to field data collection, program procedures, and completing the data collection forms. This included oversight of some cleanings and service calls early in the demonstration project. BNL delivered the digital thermometers for flue gas temperature measurement and instruction on their use. Roger McDonald also observed some of the boiler cleaning, combustion testing, and data recording procedures at the start of the program.

The training included the need for careful and consistent boiler cleanings for each boiler in the ULS test and Control groups at the start of the low sulfur test program using accepted industry practices that are part of annual inspection and tune-up services. The same boiler inspection and cleaning procedures were used at the end of each test year. The purpose of these cleanings for this project was to start the project with clean boilers so that changes in boiler deposition rates for the ultra low sulfur and normal sulfur oil can be accurately compared.

The technicians followed standard company service practices that include heating system inspection, cleaning, burner tune-up, and safety inspections. Some additional information was recorded during the initial and final cleanings, and effort was directed toward careful and consistent cleaning procedures. It was important that the initial vacuum cleanings were as thorough as possible so that changes in boiler deposits can be visually determined. The Initial Cleaning Checklist was used by service technicians to help assure that the same cleaning technique was used for the initial, end of year, and final cleanings. 
Some additional steps were added to normal equipment service procedures to help collect the additional data that is needed for this project. These added steps included the following.

- The Boiler Fouling Scale inspection charts supplied by ERC/BNL were used to evaluate the fouling condition of each boiler at the start of the project (after boiler cleaning) and every year during boiler inspection and servicing for the Ultra Low Sulfur and Control group boilers

- A House Characterization Form was completed for both the ULS and Control group houses at the start of the project during the initial boiler cleaning. These forms were returned to BNL after they were completed.

- An Annual Boiler Inspection and Burner Tune-up Checklist form was completed for each ULS and Control group house during annual boiler inspections and burner tune-ups.

- Photographs were taken of the boiler installation and the interior of the boiler after the initial cleaning. Also additional photographs were taken prior to cleaning during annual inspections for the ULS and Control group houses. These photographs were transmitted to ERC and BNL in printed and in electronic format along with the completed Initial and Annual Inspection Forms.

\section{Task 4. Demonstration Site Selection}

A group of more than 100 homes were identified by the fuel oil dealer with the assistance ERC and BNL to receive ULS heating oil. From that group, 100 houses were selected for participation in the ULS test group. ERC applied its Energy Tracking and Control (ETC) program to identify houses with good historic data that show a consistent relationship between heat load and fuel use. This enabled more reliable fuel use tracking during the project. This information in conjunction with the ETC program also assisted the oil dealer to delay the first delivery of ULS to a point where the tank levels were low so that the ULS fuel would not be diluted too much with the higher sulfur heating oil. 
The ULS test and control groups included 10 sites where the flue gas data loggers were installed to supply more detailed information on changes in flue gas temperature over time.

For the ULS test houses, consideration was given to the location of these houses for easy delivery from a single fuel delivery truck that delivered only ULS heating oil. Houses from a single delivery town were selected to help assure that the houses receive only the ULS fuel. Houses with similar boilers were selected for the ULS and Control groups to the extent practical to eliminate boiler design differences in the study.

A group of approximately 100 customers using fuel oil with higher Sulfur ( 2000 ppm) were identified as a control group. ERC again applied its Energy Tracking and Control (ETC) program to identify houses with good historic fuel use data that showed a consistent relationship between heat load and fuel use. Selection criteria similar to the ULS test group were used and in order to find a control group that was similar to the ULS test group in as many ways as possible.

\section{Task 5. Field Testing - Data Collection and Analysis}

Delivery of the Ultra Low Sulfur fuel oil began in April 2008 after some administrative issues including exemption from the highway fuel tax were resolved. ULS fuel delivery and data collection were initially scheduled to continue for a period 12 months for each test site. This was extended to two years so that the impact of the ULS fuel oil could be more fully evaluated.

Computer reports of service records for each customer and other data were collected from the participating oil company on a periodic basis. Combustion efficiency test results, changes in flue gas temperatures, Boiler Fouling Scale data that were recorded by service technicians, fuel use data needed to produce the Energy Tracking and Control fuel use factors, and all the other measures identified in this statement of work were evaluated. In addition, changes in service call frequency and service call details were collected and analyzed by ERC using specifically designed spreadsheets. These spreadsheets allowed direct comparison of the ULS group and Control group with regard to service frequency and the specific types of service that were supplied.

Fuel use data were analyzed using the ETC program. An equation was generated for each test house that related fuel use to heat load using historic fuel delivery data collected from the fuel oil dealer at the start of the project. New fuel use data points 
were added to account equations and checked with historic data as the new delivery data was received from the oil company.

For example, in one house, the boiler was replaced and the change in fuel use profile was detected and investigated. The ETC program enabled heating equipment efficiency changes to be monitored. Changes in efficiency due to fouling of boiler heat transfer surfaces over a heating season or longer can be detected for the higher sulfur control group as boiler deposition rates increase. In one Control Group house with a data logger installed, an annual cleaning occurred while the data logger was installed and a drop in flue gas temperature was observed. The ETC program measured changes in fuel use and boiler efficiency resulting from boiler fouling in some example cases.

A plan for implementing the additional measure of procuring, testing, and installing 10 flue gas temperature data loggers was completed with the assistance of the participating fuel oil marketer. ERC and BNL supported the installation of the added instrumentation. Data produced by the added instrumentation were collected and analyzed by Roger McDonald at BNL, and was then sent to ERC.

The data collected and analyzed as part of this study were used to identify and quantify differences in heating system performance for the ULS test group and the Control group using higher sulfur heating oil including energy consumption, maintenance frequency, and other factors.

\section{Task 6. Final Report, Technology Transfer, and Metrics}

ERC prepared this final report describing the work performed and results obtained including analysis of all project data. This included preparation of a draft final to the NYSERDA Project Manager for review. A debriefing meeting with the participating oil dealer was conducted to gather any additional information related to the benefits of using Ultra Low Sulfur heating oil including the impressions of the service manager and service technicians. 


\section{Field Test Results and Discussions}

\section{a. Data Summary Spreadsheets}

A detailed Excel Spreadsheet was constructed from data for each boiler in the ULS test group and control group that contained information from the Site Characterization form, Initial Cleaning Checklist form, and Annual Boiler Inspection and Burner Tune-up Checklist forms. The spreadsheet was updated after boiler cleaning and burner tuneups. Key information in the database included the following.

- Boiler manufacturer and model number

- Boiler construction

- Boiler location in house

- Domestic hot water source

- Boiler age

- Boiler temperature settings

- Oil Burner manufacturer and model number

- Source for combustion air

- Fuel tank size and location

- House type and number of floors

- Chimney type and height

- Chimney condition

- Fuel firing rate (nozzle size)

- Fuel pump manufacturer and model

- Combustion test results for initial cleaning and for each service

- Boiler Fouling Scale number after initial cleaning

- Boiler Fouling Scale number before each cleaning and burner adjustment

- Boiler Fouling Scale number after each cleaning and burner adjustment

- Presence of any fuel leaks

- Notes from service technicians and BNL/ERC engineers

The information contained in this database served as the basis for comparing changes in fouling rates for the ULS test boiler and control group boilers that used conventional heating oil containing $2000 \mathrm{ppm}$ sulfur. The results of the comparisons follow. 


\section{b. Boiler Fouling Comparison Scale Results}

A primary metric used in this field demonstration project of ULS home heating oil was the Boiler Fouling Comparison Scale also referred to as the Boiler Fouling Scale (BFS) which was used to quantitatively compare the amount of fouling on boiler heat transfer surfaces after each year of operation. As discussed, the BFS was developed by Roger McDonald at BNL during the prior NYSERDA study of Low Sulfur (500 parts per million Sulfur) heating oil. The original fouling scale was found to accurately track the actual mass of fouling deposits on heat transfer surfaces. The BFCS is a modified version of the original Boiler Fouling Scale as shown in Figure 4-2. For the ULS field study that is the subject of this report, average fouling levels each year for the ULS test group were compared to the average fouling levels produced by convention higher sulfur heating oil that was consumed by the Control Group. The results of these comparisons follow.

\section{b.1 BNL Fouling Scale Results and Discussions}

\section{b.1.1 Average Fouling Rates for ULS and Control Groups}

At the start of the test project, descriptive data for boiler plants were collected and recorded, each of the boilers in the ULS test group and in the conventional \#2 heating oil were thoroughly cleaned using the same cleaning methods. ULS heating oil was then delivered to the test houses and the Energy Tracking \& Control calculations were used to help predict when the tank levels at each ULS test houses were getting low. Fuel deliveries were delayed so that the maximum volume of ULS heating oil could be delivered to each tank. This helped to lower the sulfur content in the ULS storage tanks more rapidly. It took multiple deliveries before the sulfur levels in each tank in the test group reached very low sulfur levels.

Combustion tests and thorough boiler cleanings occurred for the ULS and control group houses approximately one year after the initial cleanings. Boiler fouling readings using the BFS were recorded before and after each annual cleaning. However, the sulfur levels in the ULS tanks were at very low levels for only part of the heating season. The demonstration project was extended by NYSERDA for a second heating season. The boiler fouling rates for both the ULS and control group using normal sulfurs heating oil were compared at the end of the second heating season after the sulfur level in each of the ULS test houses had reached very low levels. 
The results of the Boiler Fouling Scale for both the ULS and control group houses follows. The average BFS level after the second heating season for the ULS test group was 1.47, while the average fouling level for the control group using the higher sulfur heating oil was 3.15. The lower fouling rate for the ULS test was expected and these results help to quantify the reduction in boiler fouling rates over an entire heating season by switching to ULS heating oil in houses.

The chart that follows summarizes the average fouling readings after the second heating season for both the ULS and Control groups.

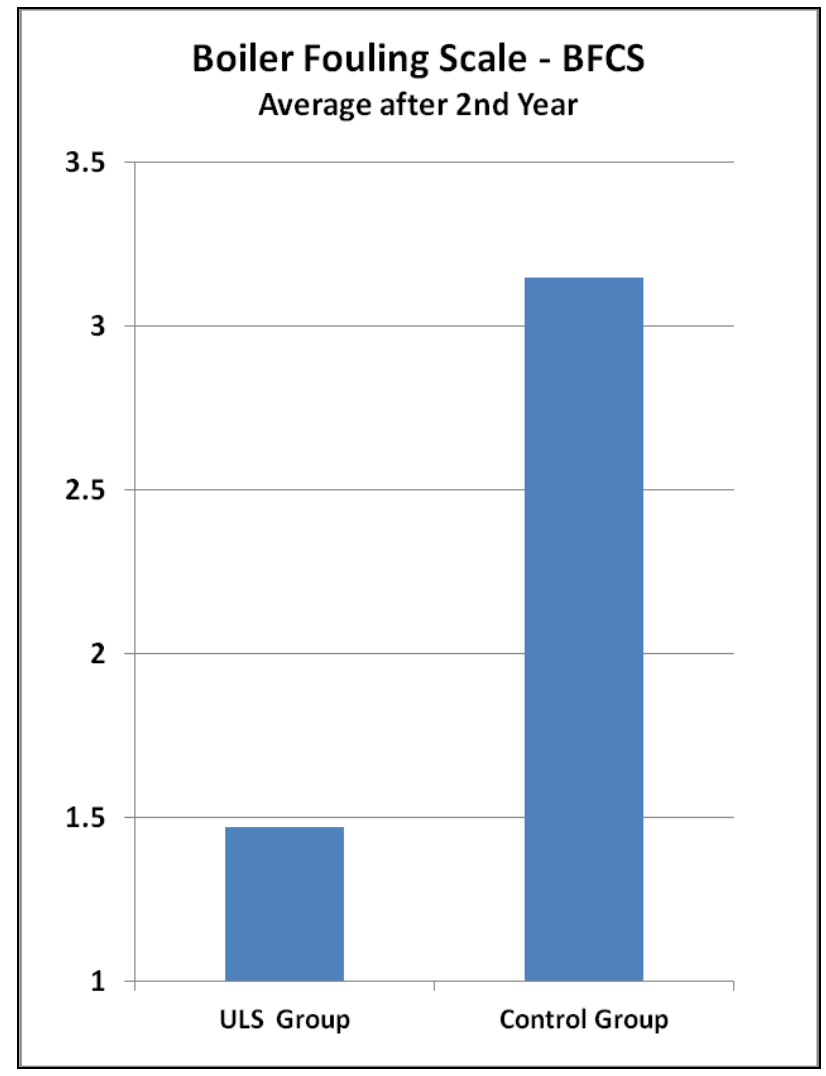

Figure 5-1. Boiler Fouling Scale Average Values

The baseline of the scale in the chart is 1.0 which represents a clean boiler on the Boiler Fouling Comparison Scale that is used for his study. The difference in the average fouling rates of the ULS houses and the normal sulfur heating oil Control Group is very significant. The ULS group average fouling rose from 1.0 to 1.47 which is an increase of only 0.47 on the scale. In contrast, the higher sulfur control group average fouling 
rate increased from 1.0 to 3.15 which is an increase of 2.15. Therefore, the ratio of fouling rates over approximately one year of operation for the Control Group over the ULS Group follows:

\section{Control Group Fouling Rate / ULS Group Fouling Rate $=2.15 / 0.47=4.6$}

This means that the average fouling rate for the Control group with the conventional sulfur content in this study is 4.6 times higher than the fouling rate for Ultra-Low Sulfur test group. This is a substantial reduction with very important benefits.

The benefits include extended cleaning interval with lower annual service costs and higher boiler efficiency over the heating season. Boiler vacuum cleaning is timeconsuming and requires partial disassembly of the boiler or furnace. Oil service companies typically service and clean boilers and furnaces every 1 to 1/1/2 years and this service usually includes vacuum cleaning of internal heat transfer surfaces. If this cleaning interval can be increase by a factor of 4.6 , then the cleaning intervals can be extended by 4.6 years to 6.9 years. This lowers annual service times for oil heat technicians and lowers service costs for homeowners.

In addition, boiler efficiencies decreases somewhat over the heating season as the heat transfer surfaces are fouled during the heating season. Switching to ULS heating oil reduces the fouling rates and can lower fuel use by an expected 1 to 2 percent. The reduced cleaning costs and lower fuel costs will be discussed in more detail in a later section of this report.

\section{Range of Fouling Rates for ULS and Control Groups}

This section supplies more detail on the range of fouling rates for both the ULS and Control Groups for after the second year of field testing. The frequency distribution for the test and controls groups is presented. The charts that follow show the number of houses at each of the fouling rates after the second year of field tests.

The chart that follows for the ULS test group shows the number of houses at each of the boiler fouling rates (BFS) after the second year of field tests. 


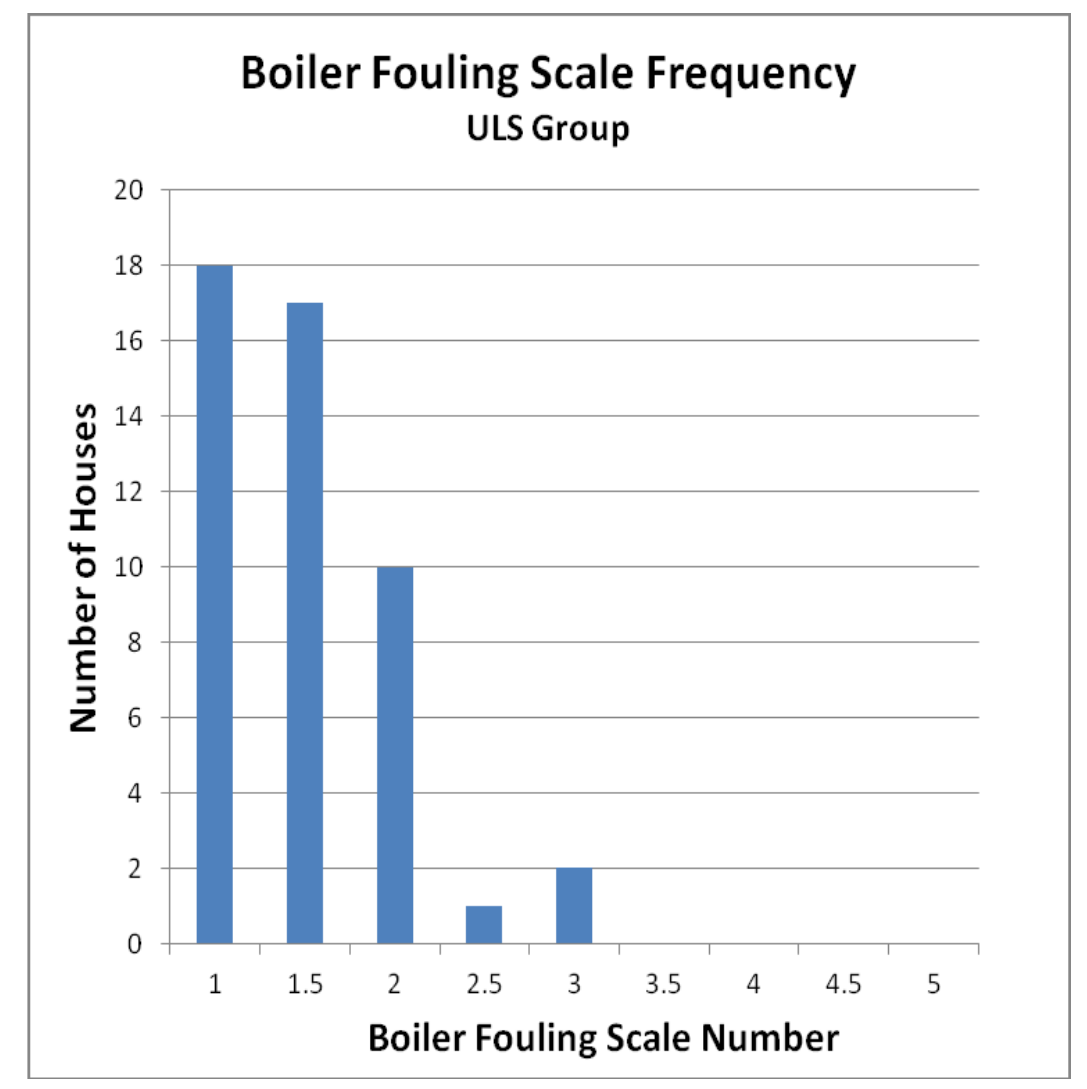

Figure 5-2. Boiler Fouling Scale Values for ULS Group

Most of the houses that were burning Ultra Low Sulfure heating oil had very low fouling rates of number 2 or less. Approximately 3 out of 4 of the ULS houses have a very low fouling scale number of 1 or 1.5. More than one-third of these boilers has a fouling rate of 1 which indicates no appreciable fouling of the heat transfer surfaces over an entire heating season. This is a remarkable result and demonstrates that lowering the sulfur content of heating oil can lower the boiler fouling rate to very low levels.

The chart for the boiler in the Control Group shows much higher fouling rates when compared to the ULS group. The chart below for the normal sulfur Control Group shows the number of houses at each of the boiler fouling rates (BFS) after the second year of field tests. 


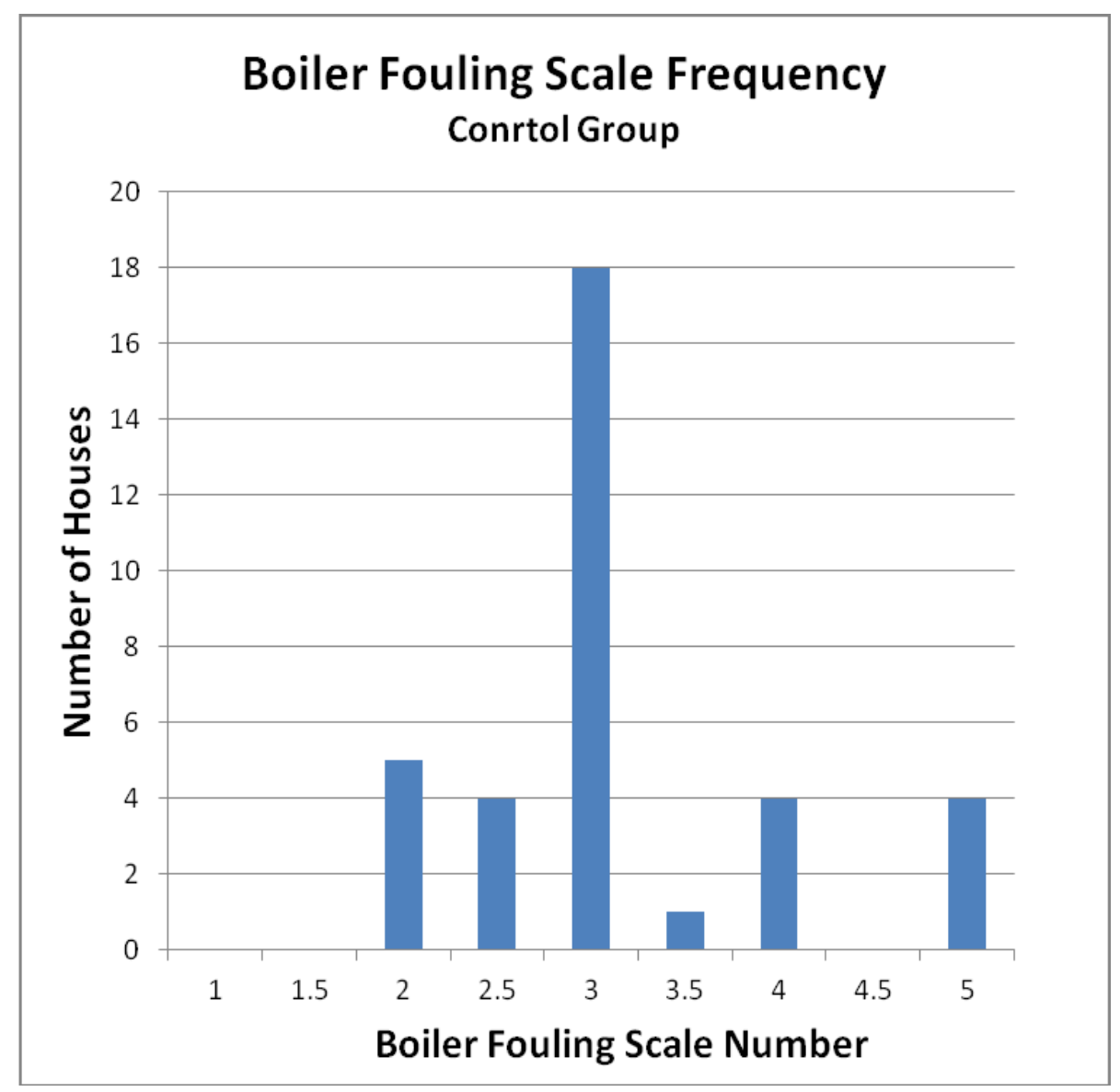

Figure 5-3. Boiler Fouling Scale Values for Normal Sulfur Control Group

The average fouling number for this higher sulfur content fuel is shifted to the right with an average fouling number of about 3 . None of these house produced a fouling number of 1 which was the predominate fouling number for the ULS test group. The Control Group also had houses with fouling numbers of 4 and 5, while the highest fouling number for the ULS group was 3 . These charts demonstrate the substantial reduction in boiler fouling rates when Ultra Low Sulfur heating oil is used in place of conventional heating oil with higher sulfur content.

The chart that follows overlays the ULS and Control Group plots so that they can be compared directly. It clearly demonstrates the much lower fouling numbers and 


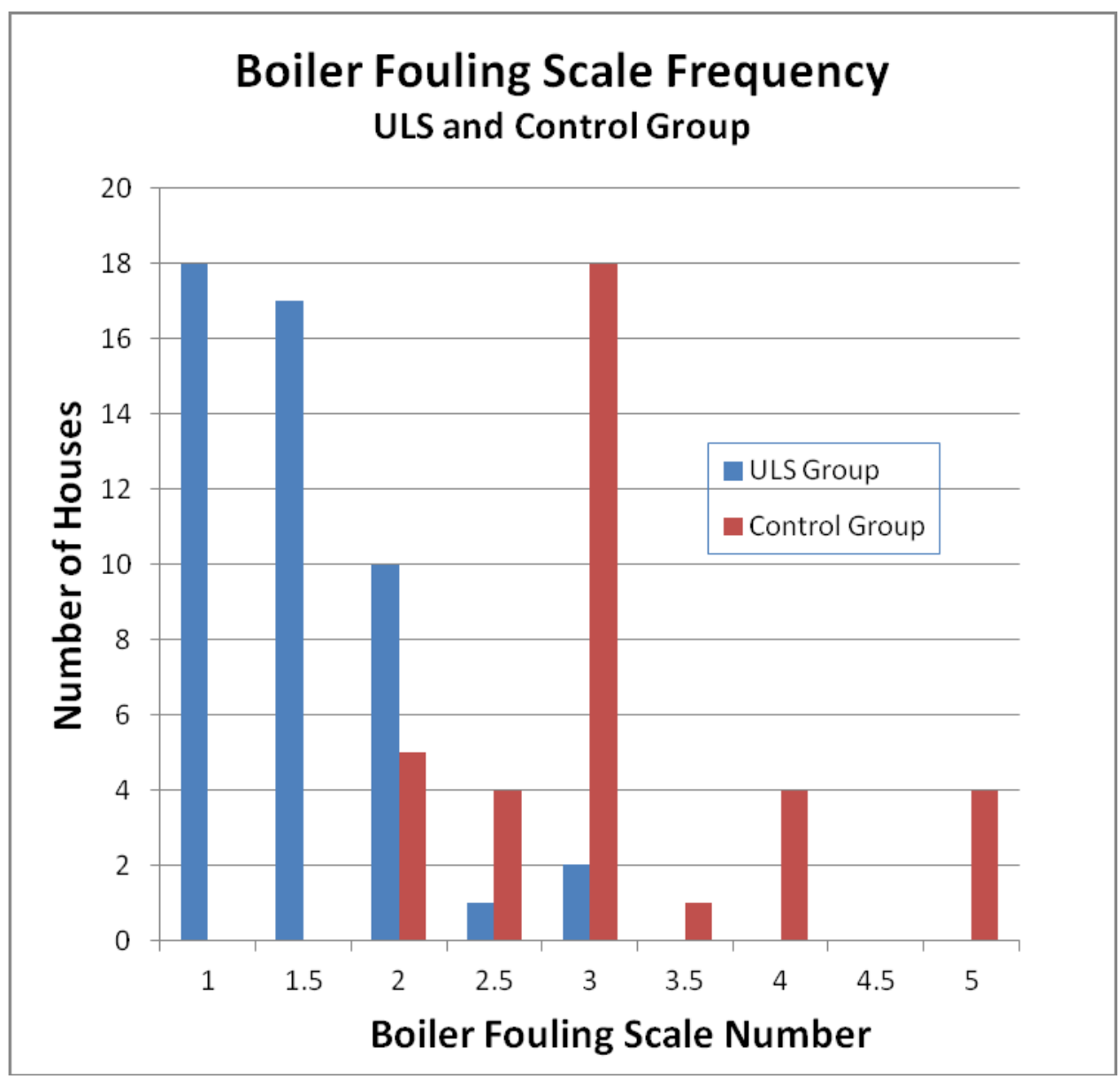

Figure 5-4. Comparison of Fouling Scale Values for ULS and Control Group

fouling rates for the Ultra Low Sulfur test group when compared to the normal sulfur Control Group. The fouling rate using the Boiler Fouling Comparison Scale that was developed by BNL is the primary metric for this study. These results quantify the reduction in boiler fouling rates by switching to Ultra Low Sulfur heating oil in homes.

These results can be compared to the prior field study of Low Sulfur (500 ppm or $0.05 \%$ sulfur) heating oil conducted by NYSERDA in the chart that follows. The normal sulfur heating oil produced an average fouling number of 3.1 in the prior Low Sulfur study and averaged 3.15 in this ULS field study. These are very consistent results and allow comparison of the Low Sulfur and Ultra Low Sulfur fouling rates (ref 13). 


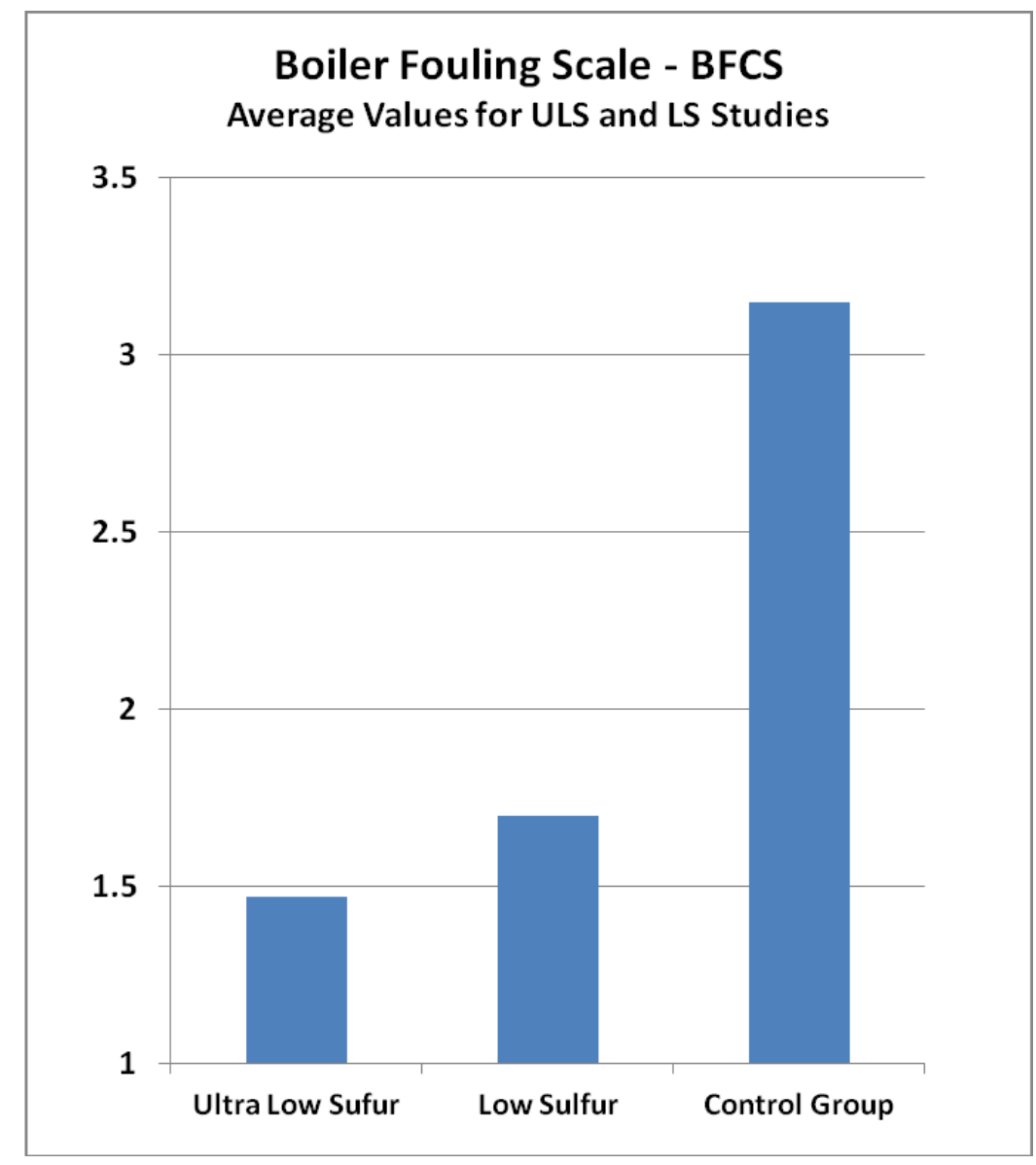

Figure 5-5. Comparison of ULS and LS Boiler fouling scales

The comparison of the Low Sulfur and Ultra Low Sulfur field studies demonstrate that the Boiler Fouling Scale developed for these field studies is an effective metric for evaluating the impact of sulfur content on boiler fouling rates. In both studies the average fouling number for the conventional heating oil was determined to be 3.1 and 3.15 which is excellent agreement. In addition, the reduction in fouling rates for the Low Sulfur (500 parts per million sulfur) and the Ultra Low Sulfur (15 parts per million Sulfur) are as expected based on the sulfur content of the fuels. Clearly, lowering fuel oil sulfur content directly reduces fouling rates in a linear way as predicted by past laboratory studies conducted at BNL. 


\section{c. Case Studies for the ULS and Control Groups}

Example cases are presented after the second year of field testing that show substantial differences in boiler fouling rates for the ULS and normal sulfur control groups that were part of this study. It supplies visual evidence of the reduction in fouling rates with the ULS heating oil compared to the higher sulfur fuel.

Several cases are presented and discussed.

\section{$\underline{\text { ULS Case Studies }}$}

\section{Case Study \#1 - Older Cast-Iron Boiler Using ULS Heating Oil}

This test house received ULS heating oil for two years and had an initial boiler cleaning in 2008, and follow-up inspection and cleaning in 2009 and a final inspection and cleaning in 2010.

House and heating system characteristics

House Height: 2 Story and Basement

Chimney: $\quad$ Brick, clay tile liner, good condition

Boiler: $\quad$ American Standard Cast Iron with Dry Base

Boiler Age: $\quad$ Approximately 40 years

Boiler Location: Basement

Burner: $\quad$ RW Beckett (newer)

Combustion Test Results for Final Cleaning in 2010

\begin{tabular}{|c|c|c|}
\hline & As Found & After Service \\
\hline Carbon Dioxide (\%): & 11.0 & 11.0 \\
\hline Flue Gas Temp (F): & 520 & 480 \\
\hline Smoke Number: & 0 & 0 \\
\hline Draft in Flue (in. w.c.): & -0.06 & -0.06 \\
\hline Boiler Fouling Scale: & 2.5 & 1.5 \\
\hline Pump Seal Leak & No & \\
\hline
\end{tabular}

Discussion:

This ULS test house operated for two years and had an inspection and service each year. The inspection and combustion test for the final year showed good combustion performance with a small reduction in flue gas temperature after cleaning which indicates minimal fouling on heat transfer surfaces. The "as found" fouling number was 2.5 and the after cleaning value was 1.5 , indicating a minor increase in fouling number over the second full heating season using the ULS heating oil. 


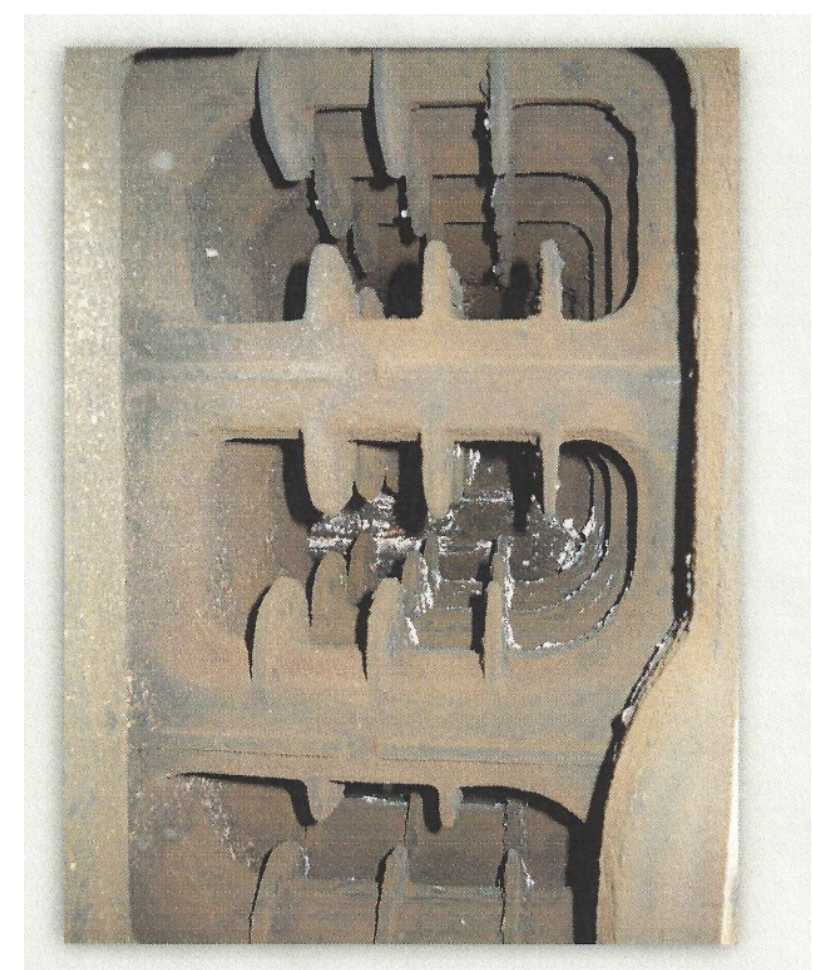

Boiler Inside Flue Passage Before Cleaning

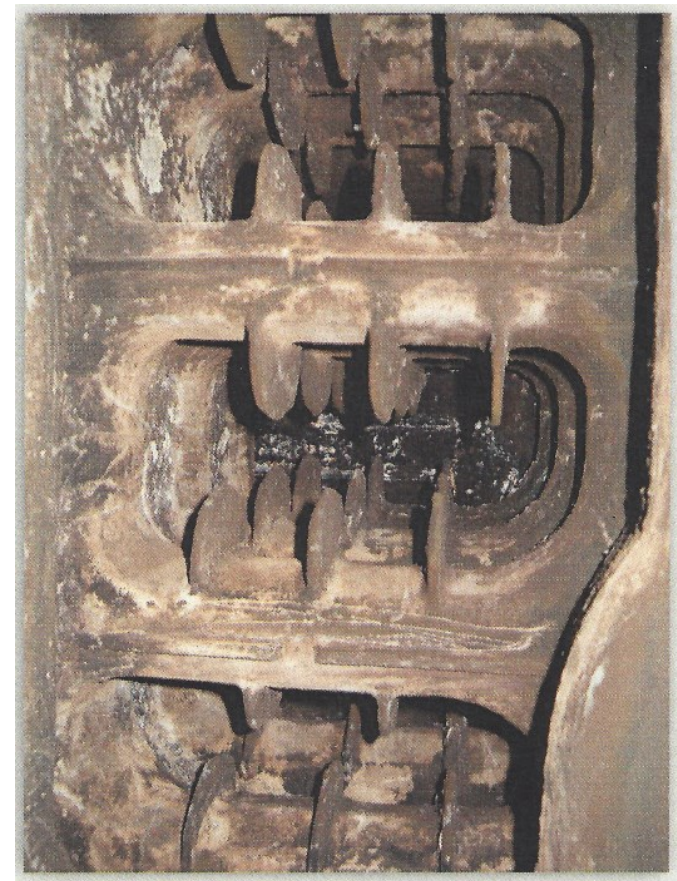

Boiler Inside Flue Passage After Cleaning 


\section{Case Study \#2 - Cast-Iron Sectional Boiler Using ULS Heating Oil}

This test house received ULS heating oil for two years and had an initial boiler cleaning in 2008, and follow-up inspection and cleaning in 2009 and a final inspection and cleaning in 2010.

House and heating system characteristics

House Height: 2 Story without Basement

Chimney: $\quad$ Brick, clay tile liner, good condition

Boiler: $\quad$ Peerless Cast Iron with Wet Base

Boiler Age: $\quad 15$ to 20 years

Boiler Location: Garage

Burner: Riello

Combustion Test Results for Final Cleaning in 2010

$\begin{array}{lccc} & \text { As Found } & & \text { After Service } \\ \text { Carbon Dioxide (\%): } & 10.0 & & 10.0 \\ \text { Flue Gas Temp (F): } & 505 & & 500 \\ \text { Smoke Number: } & 0 & & 0 \\ \text { Draft in Flue (in. w.c.): } & -0.04 & -0.04 \\ \text { Boiler Fouling Scale: } & 2.0 & & 1.0 \\ \text { Pump Seal Leak } & \text { No } & \end{array}$

\section{Discussion:}

This ULS test house operated for two years and had an inspection and service each year. The inspection and combustion test for the final year showed good combustion performance with a negligible $5 \mathrm{~F}$ reduction in flue gas temperature after cleaning which indicates very minor fouling on heat transfer surfaces. The "as found" fouling number was 2.0 and the after cleaning value was 1.0, indicating a minor increase in fouling number over the last heating season with the ULS heating oil. The photographs that were taken before and after cleaning are very similar indicating only minor deposition of fouling deposits over an entire year while using the ULS heating oil. The before cleaning photograph clearly indicates that the boiler could operate for several heating seasons without vacuum cleaning using ULS heating oil. 


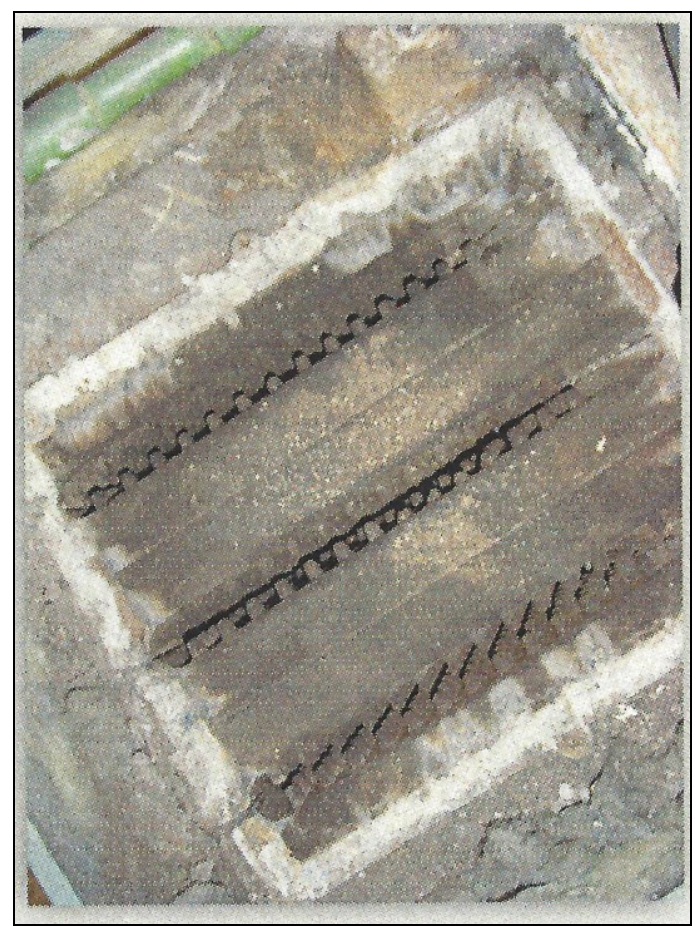

Boiler Inside Flue Passage Before Cleaning

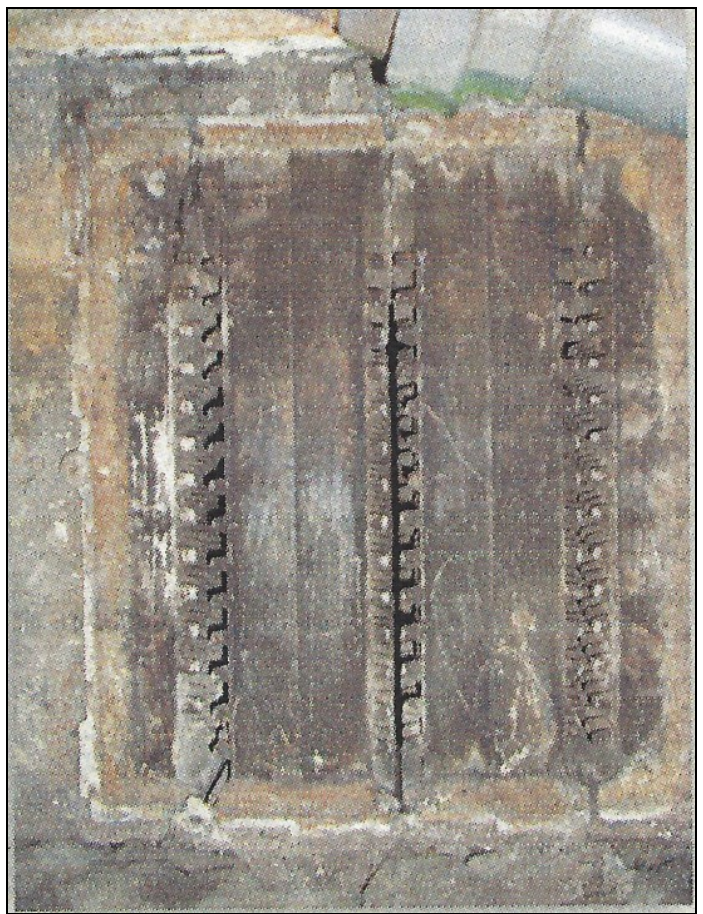

Boiler Inside Flue Passage After Cleaning 


\section{Case Study \#3 - Cast-Iron Sectional Boiler Using ULS Heating Oil}

This test house received ULS heating oil for two years and had an initial boiler cleaning in 2008, and follow-up inspection and cleaning in 2009 and a final inspection and cleaning in 2010.

House and heating system characteristics

House Height: 2 Story and Basement

Chimney: $\quad$ Brick, clay tile liner, good condition

Boiler: $\quad$ Slant Fin Cast Iron with Wet Base

Boiler Age: $\quad 5$ years

Boiler Location: Basement

Burner: $\quad$ RW Beckett AFG

Combustion Test Results for Final Cleaning in 2010

$\begin{array}{lccc} & \text { As Found } & & \text { After Service } \\ \text { Carbon Dioxide (\%): } & 10.0 & & 10.0 \\ \text { Flue Gas Temp (F): } & 500 & & 500 \\ \text { Smoke Number: } & 0 & & 0 \\ \text { Draft in Flue (in. w.c.): } & -0.04 & & -0.04 \\ \text { Boiler Fouling Scale: } & 1.0 & & 1.0 \\ \text { Pump Seal Leak } & \text { No } & \end{array}$

\section{Discussion:}

This ULS test house operated for two years and had an inspection and service each year. The inspection and combustion test for the final year showed good combustion performance with no reduction in flue gas temperature after cleaning which indicates only superficial fouling on heat transfer surfaces. The "as found" fouling number was 1.0 and the after cleaning value was 1.0, indicating no increase in fouling number over the last heating season with the ULS heating oil. The photographs that were taken before and after cleaning are very similar indicating very minor deposition over an entire year while using the ULS heating oil. The "before cleaning" photograph clearly indicates that the boiler could operate for several heating seasons without vacuum cleaning using ULS heating oil. This case supplies clear and compelling evidence that ULS heating oil can produce near-zero fouling of boiler heat transfer surfaces over an entire year of operation, and boiler vacuum cleaning intervals can be extended. 


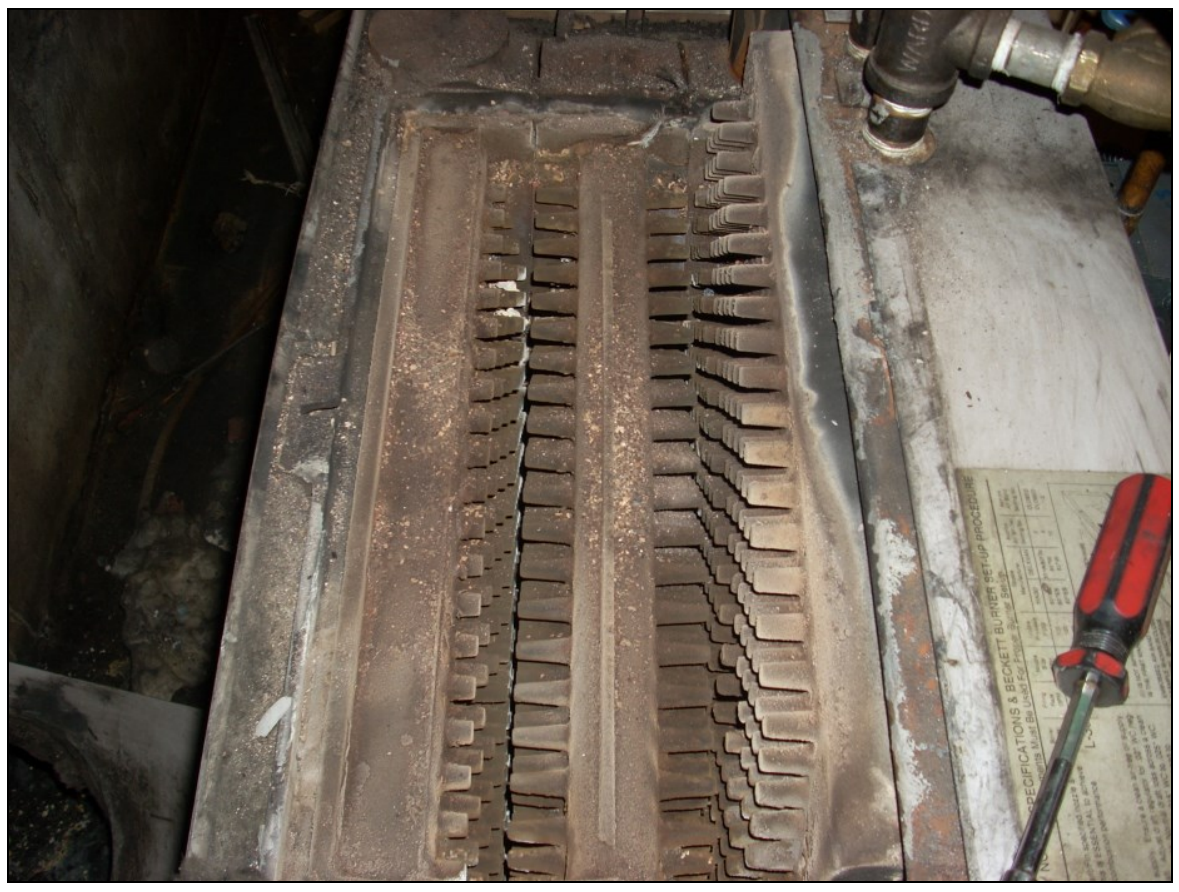

Boiler Inside Flue Passage Before Cleaning

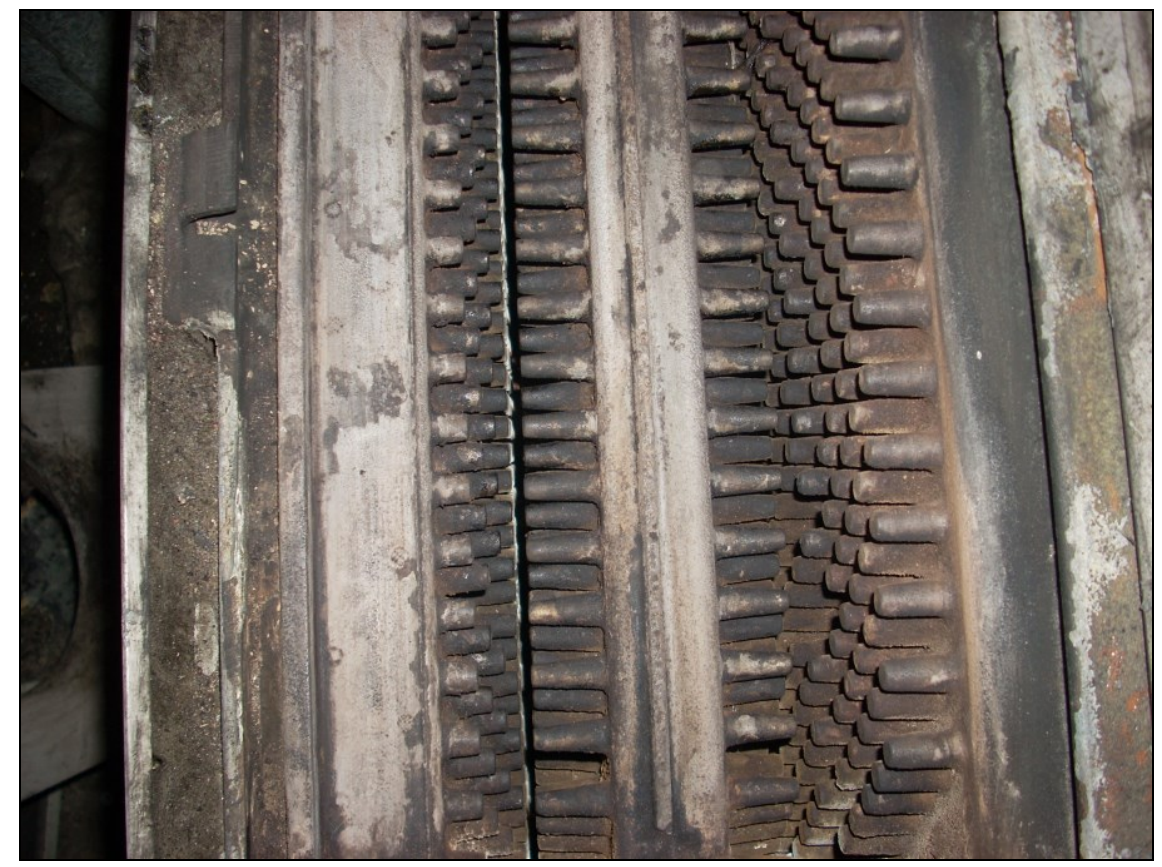

Boiler Inside Flue Passage After Cleaning 


\section{Case Study \#4 - Cast-Iron Sectional Boiler Using ULS Heating Oil}

This test house received ULS heating oil for two years and had an initial boiler cleaning in 2008, and follow-up inspection and cleaning in 2009 and a final inspection and cleaning in 2010.

House and heating system characteristics

House Height: 2 Story and Basement

Chimney: $\quad$ Brick, masonry liner, fair condition

Boiler: $\quad$ Slant Fin Cast Iron with Wet Base

Boiler Age: $\quad 5$ years

Boiler Location: Laundry Room

Burner: Riello

Combustion Test Results for Final Cleaning in 2010

$\begin{array}{lccc} & \text { As Found } & & \text { After Service } \\ \text { Carbon Dioxide (\%): } & 12.0 & & 12.0 \\ \text { Flue Gas Temp (F): } & 430 & & 430 \\ \text { Smoke Number: } & 0 & & 0 \\ \text { Draft in Flue (in. w.c.): } & -0.04 & & -0.04 \\ \text { Boiler Fouling Scale: } & 1.0 & & 1.0 \\ \text { Pump Seal Leak } & \text { No } & \end{array}$

\section{Discussion:}

This ULS test house operated for two years and had an inspection and service each year. The inspection and combustion test for the final year showed very good combustion performance with no reduction in flue gas temperature after cleaning which indicates no noticeable fouling on heat transfer surfaces. The "as found" fouling number was 1.0 and the after cleaning value was 1.0, indicating no increase in fouling number over the last heating season with the ULS heating oil. The photographs that were taken before and after cleaning show only very minor deposition over an entire year while using the ULS heating oil. The before cleaning photograph again clearly indicates that the boiler could operate for several heating seasons without vacuum cleaning using ULS heating oil. This case again clearly demonstrates that ULS heating oil can produce minimal fouling of boiler heat transfer surfaces over an entire year of operation. Boiler vacuum cleaning intervals can be extended, and this can lower annual service costs for homeowners by using ULS heating oil. 


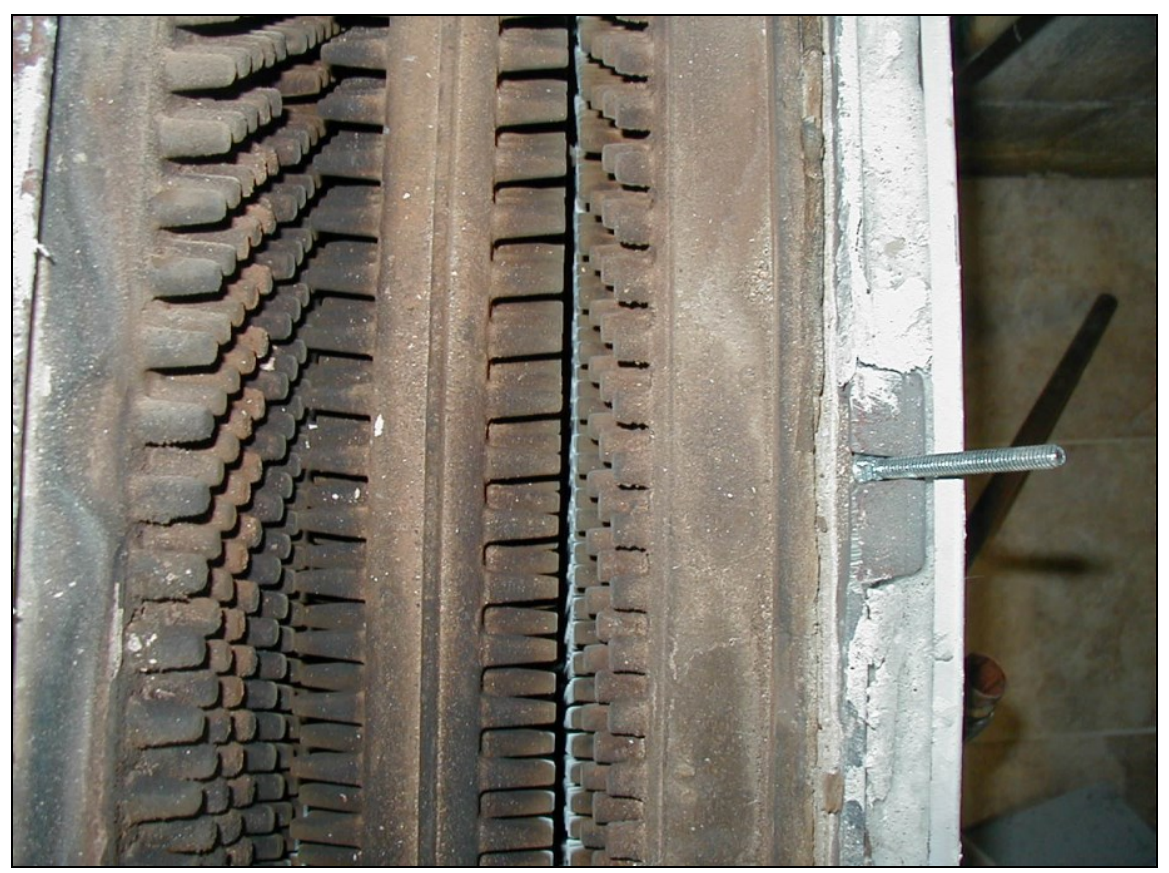

Boiler Inside Flue Passage Before Cleaning

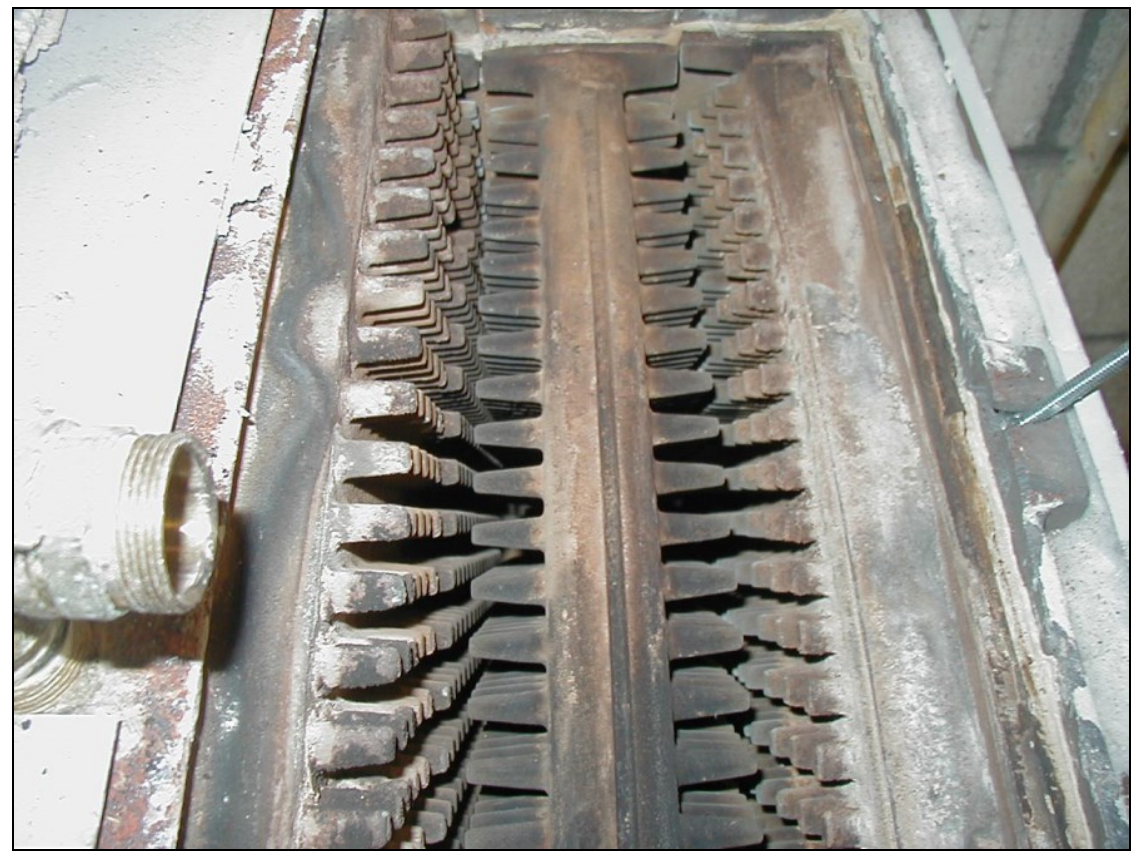

Boiler Inside Flue Passage After Cleaning 


\section{Case Study \#5 - Cast-Iron Sectional Boiler Using ULS Heating Oil}

This test house received ULS heating oil for two years and had an initial boiler cleaning in 2008, and follow-up inspection and cleaning in 2010 after two years of operation using ULS heating oil.

$\underline{\text { House and heating system characteristics }}$

House Height: 2 Story without Basement

Chimney: $\quad$ Brick, clay tile liner, excellent condition

Boiler: $\quad$ Slant Fin Cast Iron with Wet Base

Boiler Age: $\quad 4$ years

Boiler Location: Separate Room

Burner: $\quad$ Riello - F5

Combustion Test Results for Final Cleaning in 2010

\begin{tabular}{|c|c|c|}
\hline & As Found & After Service \\
\hline Carbon Dioxide (\%): & 11.0 & 11.0 \\
\hline Flue Gas Temp $(F)$ : & 400 & 400 \\
\hline Smoke Number: & 0 & 0 \\
\hline Draft in Flue (in. w.c.): & -0.04 & -0.04 \\
\hline Boiler Fouling Scale: & 2.0 & 1.0 \\
\hline Pump Seal Leak & No & \\
\hline
\end{tabular}

\section{Discussion:}

This ULS test house operated for two years and had an inspection and service only after two years of operation. The inspection and combustion test after two years showed very good combustion performance with no reduction in flue gas temperature after cleaning which indicates no appreciable fouling on heat transfer surfaces. The "as found" fouling number was 2.0 and the after cleaning value was 1.0, indicating only a minor increase in fouling number over two heating seasons with the ULS heating oil. The photographs that were taken before and after cleaning show only minor deposition on boiler surfaces over two years of operation. The "before cleaning" photograph once again clearly indicates that the boiler could operate for several heating seasons without vacuum cleaning using ULS heating oil. This case demonstrates that ULS heating oil can produce minimal fouling of boiler heat transfer surfaces over two years of operation. Boiler vacuum cleaning intervals can be extended to multiple years, and this can lower annual service costs for homeowners by using ULS heating oil. 


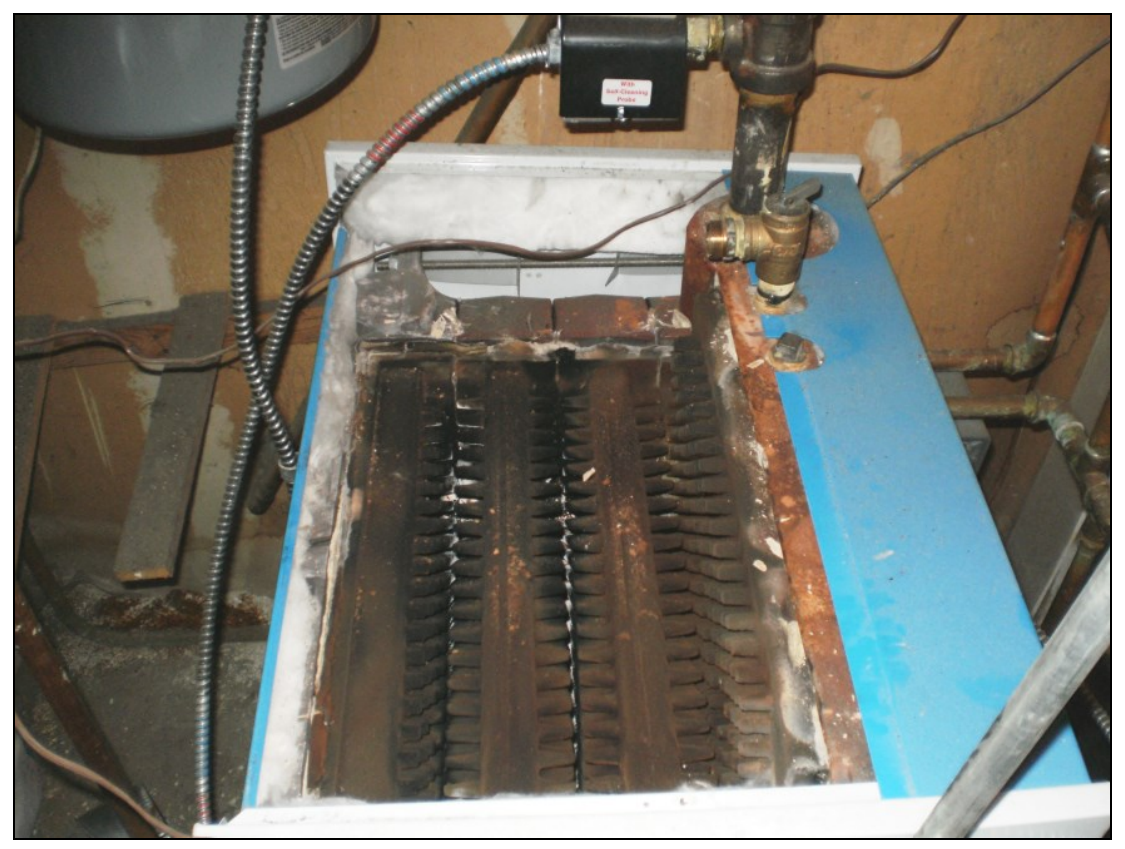

Boiler Inside Flue Passage Before Cleaning

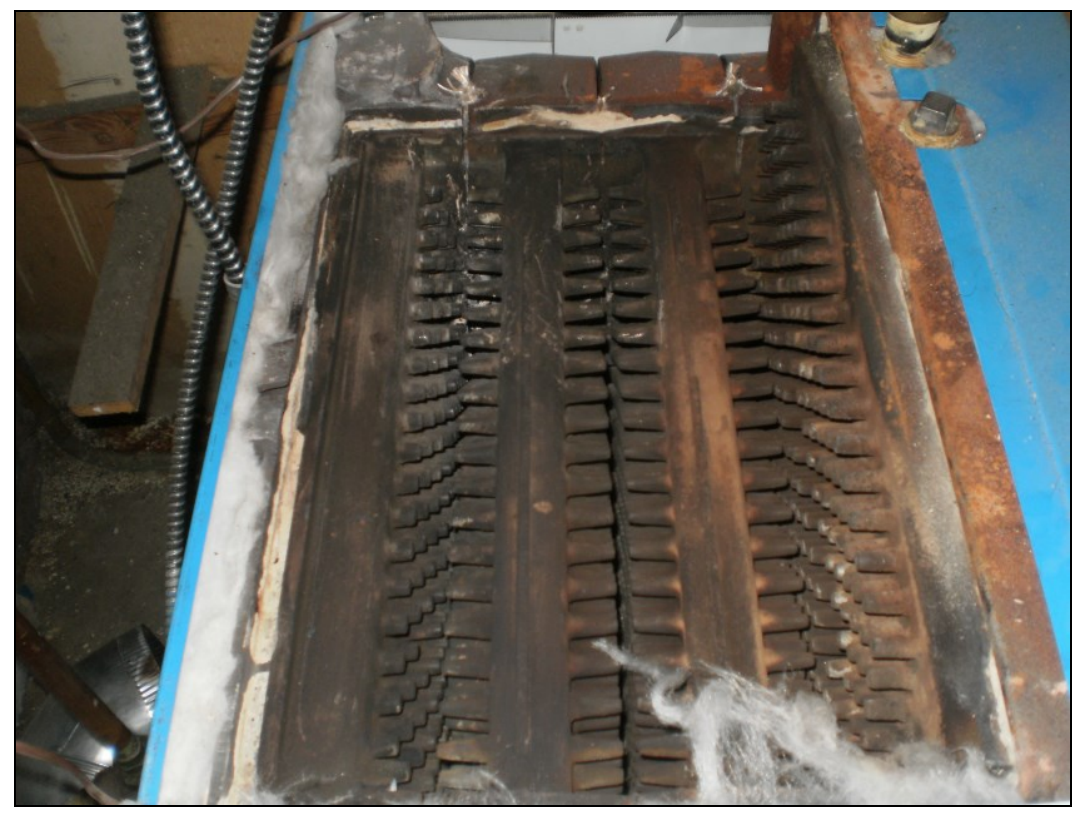

Boiler Inside Flue Passage After Cleaning 


\section{Conventional Sulfur Heating Oil - Control Group}

\section{Case Study \#6 - Cast-Iron Boiler Using Conventional Higher Sulfur Heating Oil}

This test house received conventional higher sulfur heating oil for two years and had an initial boiler cleaning in 2008, and follow-up inspection and cleaning in 2009 and a final inspection and cleaning in 2010.

$\underline{\text { House and heating system characteristics }}$

House Height: 1 Story without Basement

Chimney: Masonry, Metal liner, good condition

Boiler: $\quad$ Slant Fin Cast Iron with Wet Base

Boiler Age: $\quad 1$ year

Boiler Location: Basement

Burner: $\quad$ RW Beckett AFG

Combustion Test Results for Final Cleaning in 2010

$\begin{array}{lccc} & \text { As Found } & & \text { After Service } \\ \text { Carbon Dioxide (\%): } & 12.0 & & 12.0 \\ \text { Flue Gas Temp (F): } & 407 & & 401 \\ \text { Smoke Number: } & 0 & & 0 \\ \text { Draft in Flue (in. w.c.): } & -0.05 & & -0.05 \\ \text { Boiler Fouling Scale: } & 2.0 & & 1.0 \\ \text { Pump Seal Leak } & \text { No } & \end{array}$

\section{Discussion:}

This conventional oil Control Group house operated for two years and had an inspection and cleaning service each year. The inspection and combustion test for the final year showed good combustion performance, with an $6 \mathrm{~F}$ reduction in flue gas temperature after cleaning which indicates minor fouling on heat transfer surfaces. The "as found" fouling number was 2.0 and the after cleaning value was 1.0 , indicating a minor increase in fouling number over the last heating season with the ULS heating oil. The photographs that were taken before and after cleaning indicating visible deposition of fouling deposits over one year while using the conventional heating oil. The boiler fouling appears to be greater than for the ULS heating oil over one heating season. (See case studies 1, 2, 3 and 4.) The difference between the ULS and conventional sulfur heating oil is much more evident after two years of operation as shown in the cases that follow. 


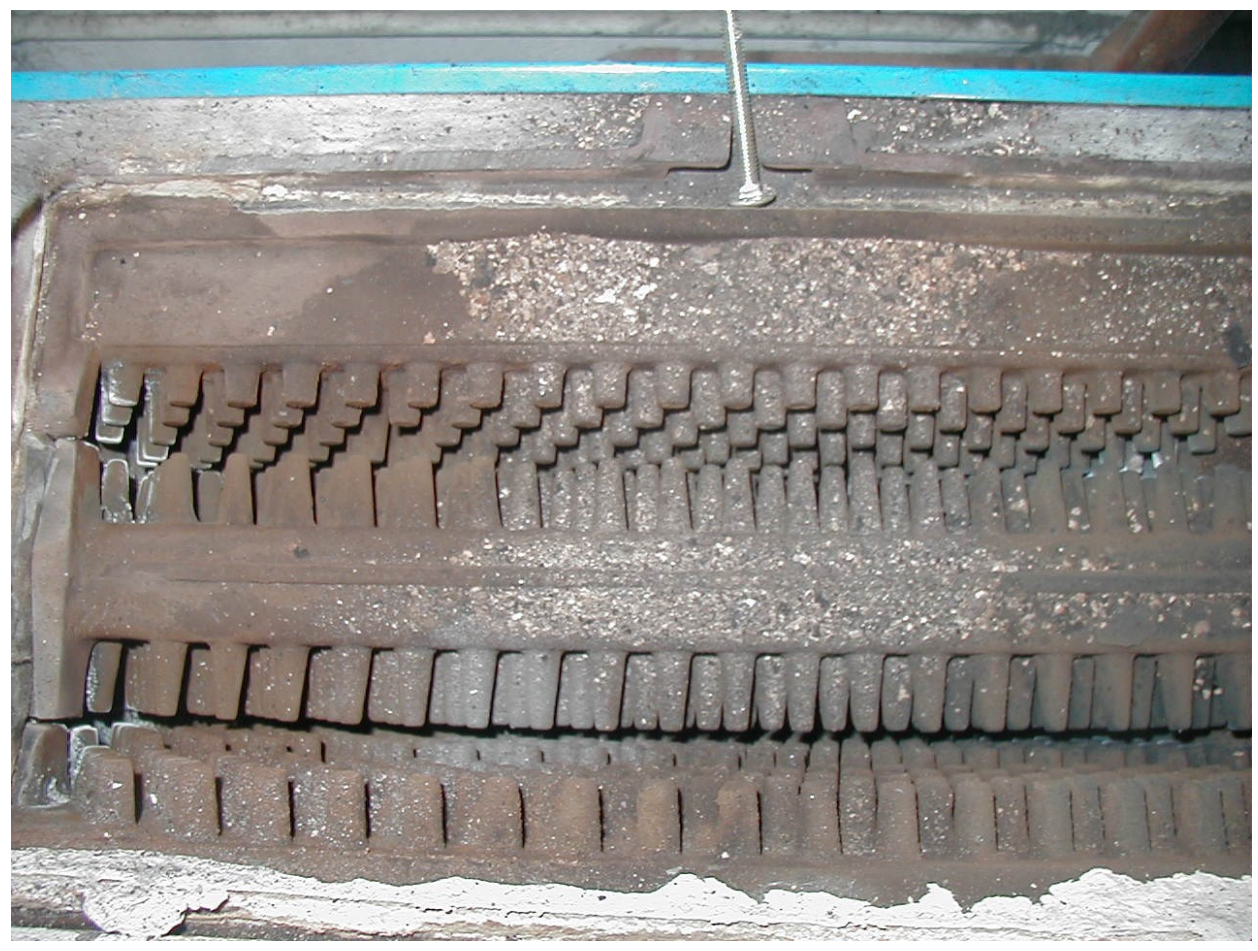

Boiler Inside Flue Passage Before Cleaning

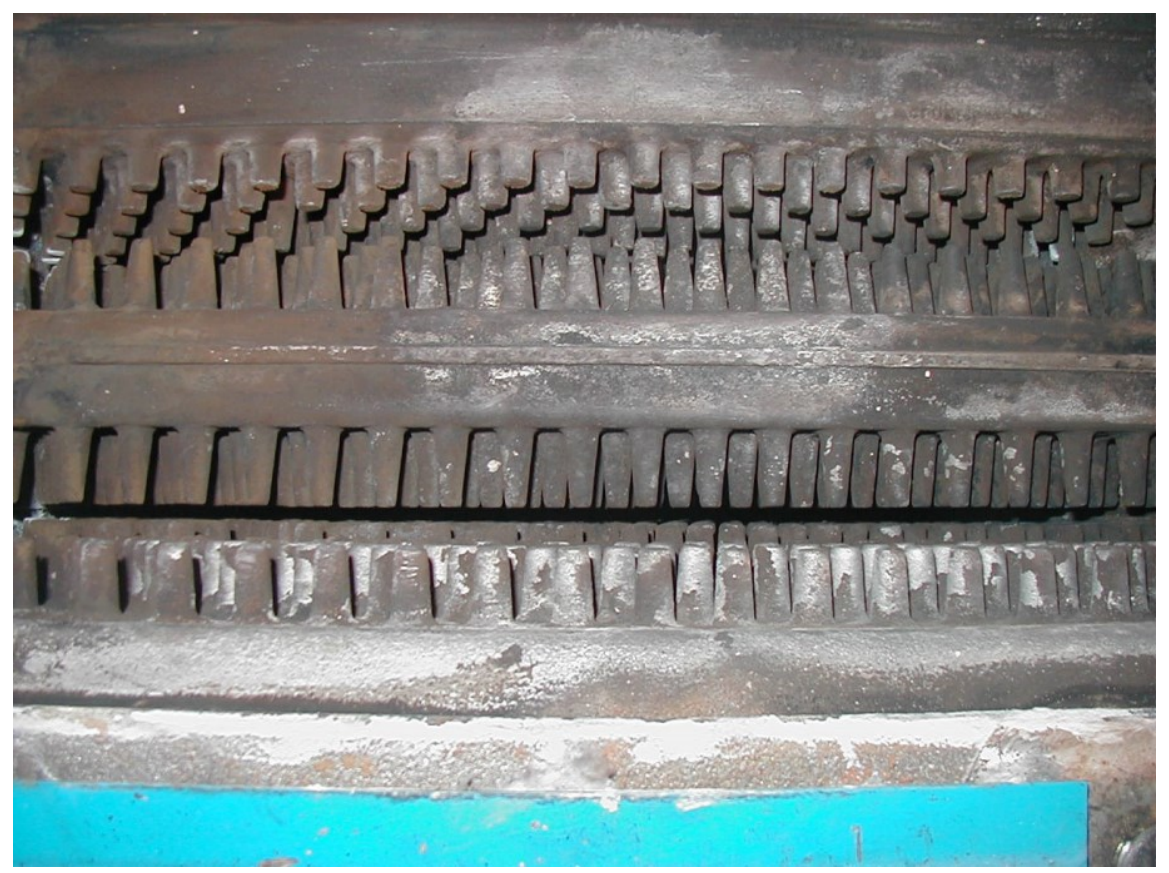

Boiler Inside Flue Passage After Cleaning 


\section{Case Study \#7 - Cast-Iron Boiler Using Conventional Higher Sulfur Heating Oil}

This test house received conventional higher sulfur heating oil for two years and had an initial boiler cleaning in 2008, with no follow-up inspection and cleaning in 2009 and a final inspection and cleaning in 2010.

House and heating system characteristics

House Height: 2 Story and Basement

Chimney: $\quad$ Brick, clay tile liner, good condition

Boiler: $\quad$ Burnham Cast Iron Boiler

Boiler Age: $\quad 20$ years

Boiler Location: Basement

Burner: Riello

Combustion Test Results for Final Cleaning in 2010

\begin{tabular}{lccc} 
& As Found & & After Service \\
\cline { 2 - 3 } Carbon Dioxide (\%): & 10.0 & & 10.0 \\
Flue Gas Temp (F): & 475 & & 435 \\
Smoke Number: & 0 & & 0 \\
Draft in Flue (in. w.c.): & -0.03 & & -0.04 \\
Boiler Fouling Scale: & 5.0 & & 2.0 \\
Pump Seal Leak & No &
\end{tabular}

\section{Discussion:}

This conventional oil Control Group house operated for two years and had an inspection and cleaning service after the end of the second year. The inspection and combustion test for the final year showed acceptable combustion performance, but a $40 \mathrm{~F}$ reduction in flue gas temperature after cleaning which indicates some fouling on heat transfer surfaces. The "as found" fouling number was 5.0 and the after cleaning value was 2.0, indicating a major increase in fouling number over the two heating season with the conventional heating oil. The number 5 on the Boiler Fouling Comparison Scale is the highest number indicating substantial fouling and deposition on boiler heat exchange surfaces. The photographs that were taken before and after cleaning clearly document substantial fouling deposits over the two years of operation while using the conventional heating oil. The fouling rate is much greater than for the ULS heating oil over two heating seasons. (See case study \#5.) 


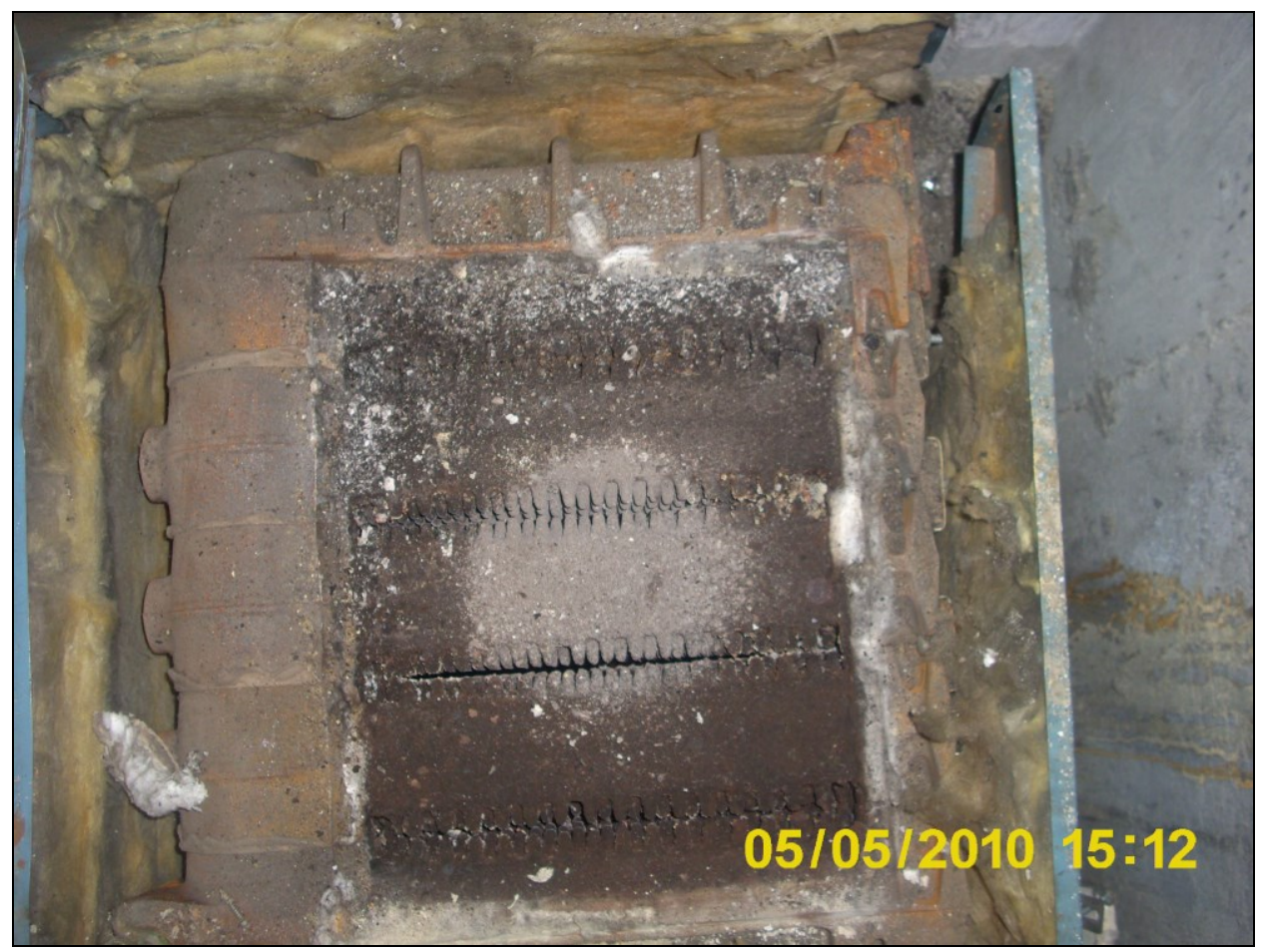

Boiler Inside Flue Passage Before Cleaning

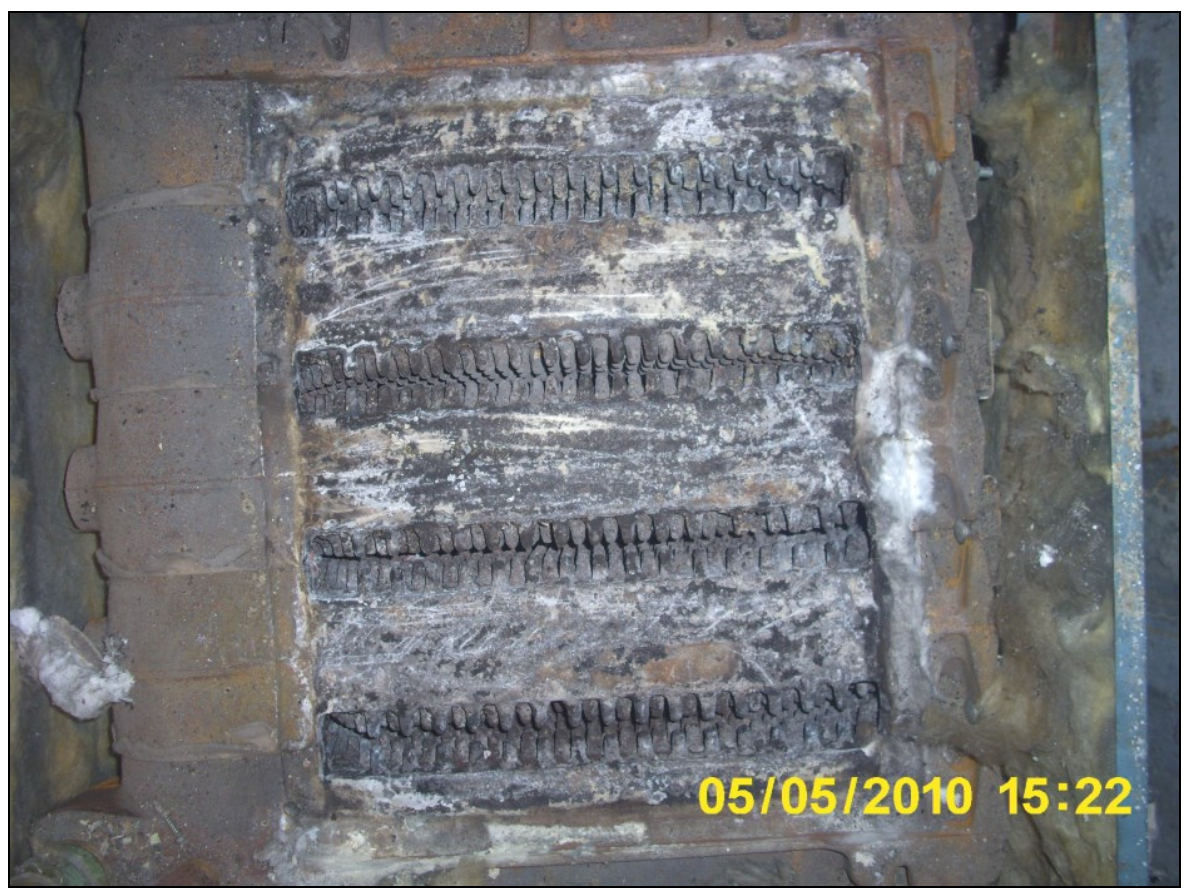

Boiler Inside Flue Passage After Cleaning 


\section{Case Study \#8 - Cast-Iron Boiler Using Conventional Higher Sulfur Heating Oil}

This test house received conventional higher sulfur heating oil for two years and had an initial boiler cleaning in 2008, with no follow-up inspection and cleaning in 2009 and a final inspection and cleaning in 2010.

House and heating system characteristics

House Height: 2 Story and Basement

Chimney: $\quad$ Brick, clay tile liner, good condition

Boiler: $\quad$ USA, Cast Iron, Dry Base

Boiler Age: $\quad 30$ years

Boiler Location: Basement

Burner:

RW Beckett AFG

Combustion Test Results for Final Cleaning in 2010

$\begin{array}{lccc} & \text { As Found } & & \text { After Service } \\ { } } & 11.0 & & 11.0 \\ \text { Flue Gas Temp (F): } & 540 & & 515 \\ \text { Smoke Number: } & 0 & & 0 \\ \text { Draft in Flue (in. w.c.): } & -0.05 & & -0.05 \\ \text { Boiler Fouling Scale: } & 4.5 & & 1.0 \\ \text { Pump Seal Leak } & \text { No } & \end{array}$

\section{Discussion:}

This conventional oil Control Group house operated for two years and had an inspection and cleaning service after the end of the second year. The inspection and combustion test for the final year showed good combustion performance, but a $25 \mathrm{~F}$ reduction in flue gas temperature after cleaning which indicates some fouling on heat transfer surfaces. The "as found" fouling number was 4.5 and the after cleaning value was 1.0 , indicating a major increase in fouling over the two heating season with the conventional heating oil. The number 4.5 on the Boiler Fouling Comparison Scale is near the top of the scale, indicating substantial fouling and deposition on boiler heat exchange surfaces. The photographs that were taken before and after cleaning clearly document major deposits on boiler heat transfer surfaces over the two years of operation while using the conventional heating oil. The fouling rate is much greater than for ULS heating oil over two heating seasons. (See case study \#5.) 


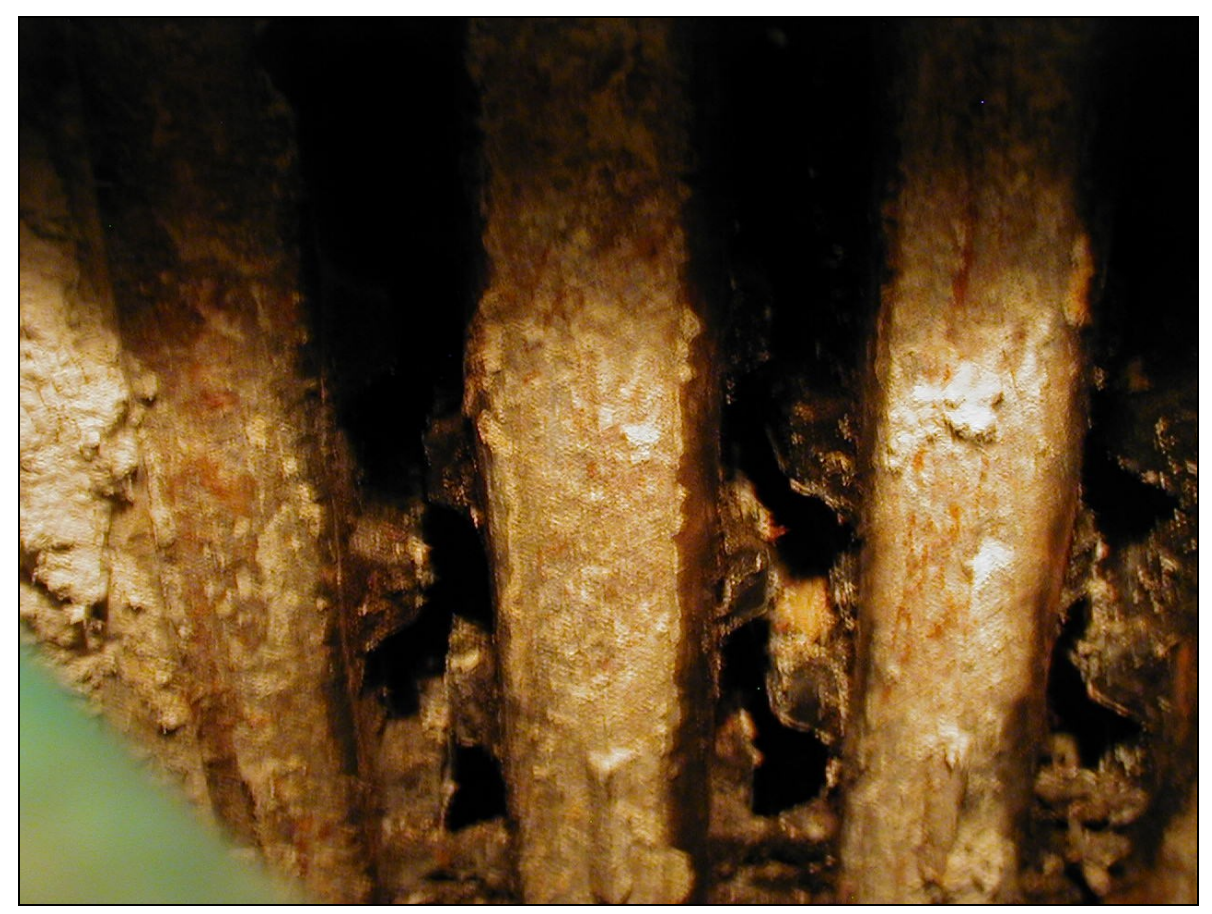

Boiler Inside Flue Passage Before Cleaning

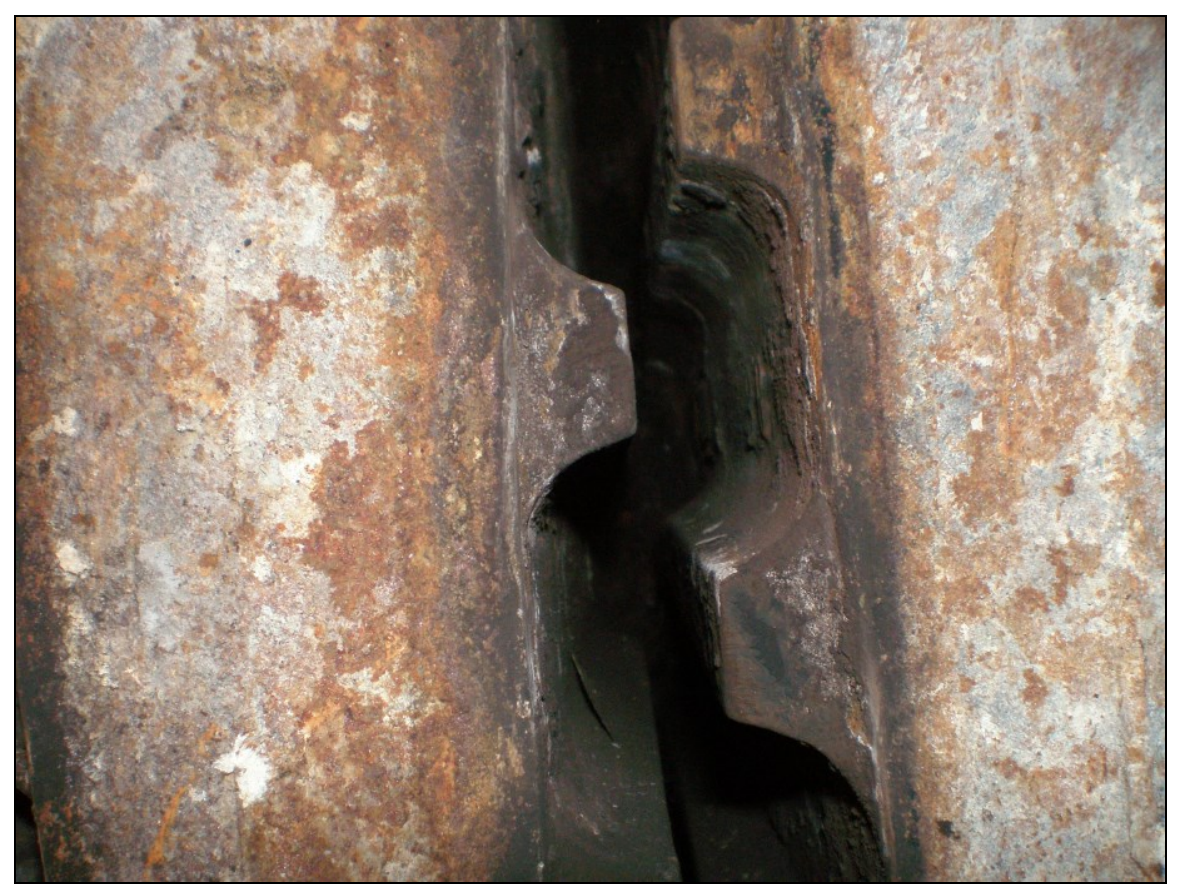

Boiler Inside Flue Passage After Cleaning 


\section{Case Study \#9 - Cast-Iron Boiler Using Conventional Higher Sulfur Heating Oil}

This test house received conventional higher sulfur heating oil for two years and had an initial boiler cleaning in 2008, with no follow-up inspection and cleaning in 2009 and a final inspection and cleaning in 2010.

House and heating system characteristics

House Height: 2 Story and Basement

Chimney: $\quad$ Brick, clay tile liner, good condition

Boiler: Weil McLain Gold, Cast Iron, Wet Base

Boiler Age: $\quad 5$ years

Boiler Location: Basement

Burner:

RW Beckett AFG

Combustion Test Results for Final Cleaning in 2010

\begin{tabular}{lccc} 
& As Found & & After Service \\
\cline { 2 - 3 } Carbon Dioxide (\%): & 11.0 & & 12.0 \\
Flue Gas Temp (F): & 585 & & 475 \\
Smoke Number: & 0 & & 0 \\
Draft in Flue (in. w.c.): & -0.04 & & -0.04 \\
Boiler Fouling Scale: & 5.0 & & 1.0 \\
Pump Seal Leak & No &
\end{tabular}

\section{Discussion:}

This conventional oil Control Group house operated for two years and had an inspection and cleaning service after the end of the second year. The inspection and combustion test for the final year showed good combustion performance, but a $110 \mathrm{~F}$ reduction in flue gas temperature after cleaning which indicates substantial fouling on heat transfer surfaces before cleaning. The "as found" fouling number was 5.0 and the after cleaning value was 1.0, indicating a major fouling over the two heating season with the conventional heating oil. The number 5.0 on the Boiler Fouling Comparison Scale is at the top of the scale, indicating substantial deposition on boiler heat exchange surfaces. The photographs that were taken before and after cleaning clearly document major fouling deposits over the two years of operation while using the conventional heating oil. The fouling rate is much greater than for the ULS heating oil over two heating season. (See case study \#5.) 


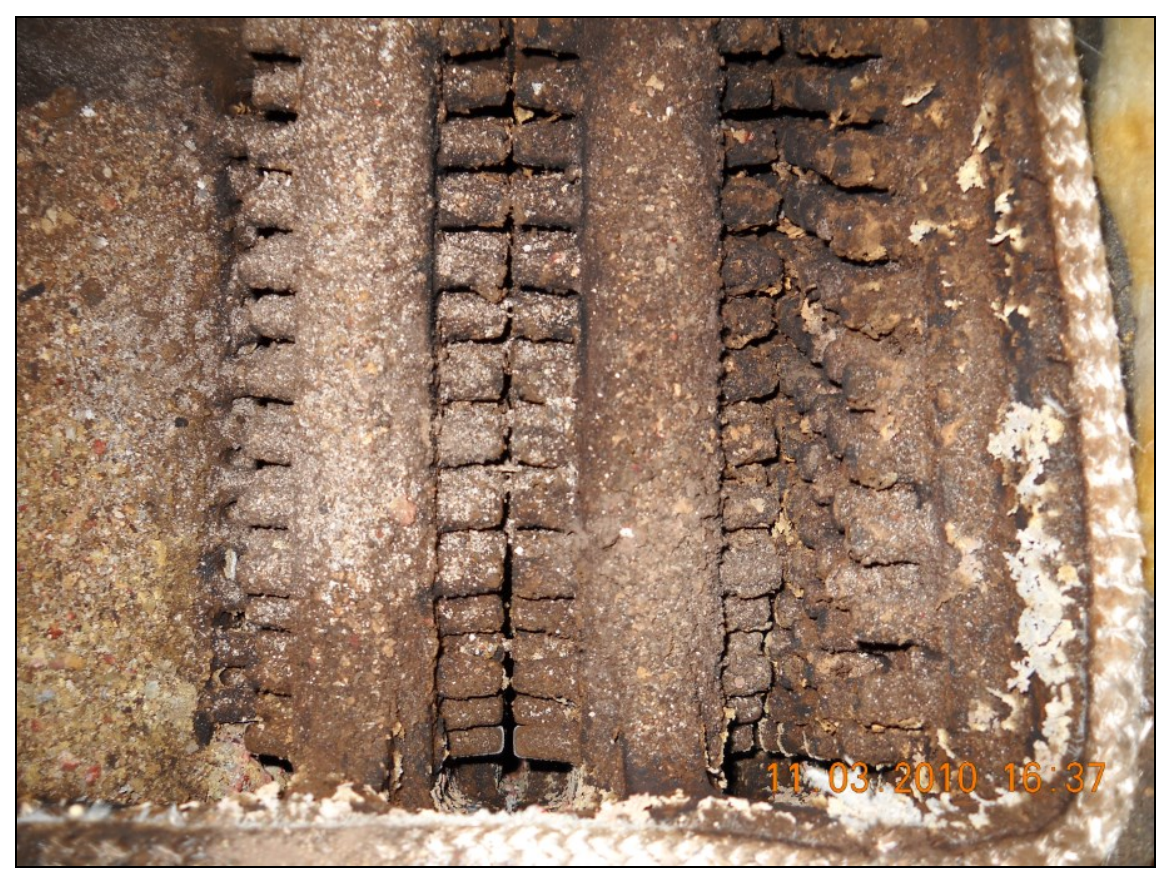

Boiler Inside Flue Passage Before Cleaning

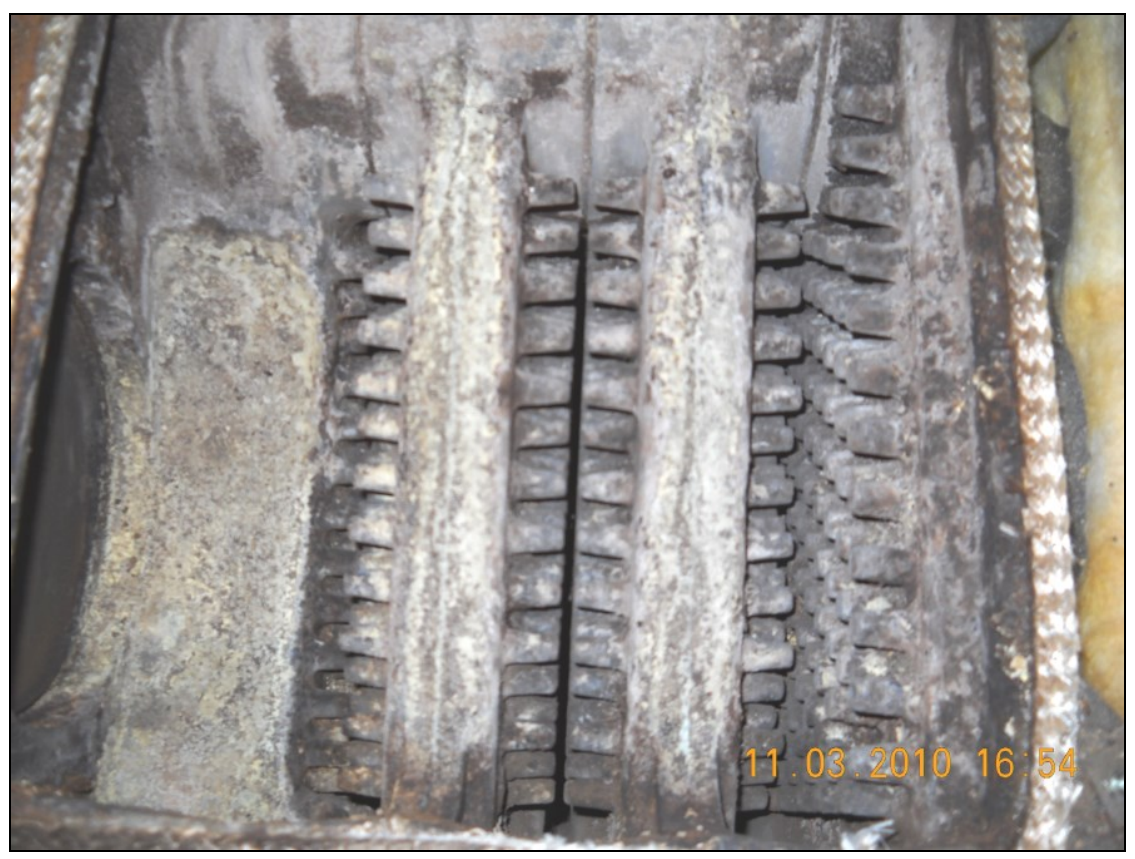

Boiler Inside Flue Passage After Cleaning 


\section{Case Study \#10 - Fire-tube Boiler Using Conventional Higher Sulfur Heating Oil}

This test house received conventional higher sulfur heating oil for two years and had an initial boiler cleaning in 2008, with no follow-up inspection and cleaning in 2009 and a final inspection and cleaning in 2010.

House and heating system characteristics

House Height: 2 Story and Basement

Chimney: $\quad$ Brick, masonry, good condition

Boiler: $\quad$ Cast Iron, Dry Base

Boiler Age: $\quad 45$ years

Boiler Location: Basement

Burner:

RW Beckett AF

Combustion Test Results for Final Cleaning in 2010

$\begin{array}{lccc} & \text { As Found } & & \text { After Service } \\ \text { Carbon Dioxide (\%): } & 11.0 & & 11.0 \\ \text { Flue Gas Temp (F): } & 520 & & 500 \\ \text { Smoke Number: } & 0 & & 0 \\ \text { Draft in Flue (in. w.c.): } & -0.04 & -0.04 \\ \text { Boiler Fouling Scale: } & 4.0 & 1.0 \\ \text { Pump Seal Leak } & \text { No } & \end{array}$

Discussion:

This conventional oil Control Group house operated for two years and had an inspection and cleaning service after the end of the second year. The inspection and combustion test for the final year showed good combustion performance, with a $20 \mathrm{~F}$ reduction in flue gas temperature after cleaning which indicates some fouling on heat transfer surfaces before cleaning. The "as found" fouling number was 4.0 and the after cleaning value was 1.0, indicating major fouling over the two heating season with the conventional heating oil. The number 4.0 on the Boiler Fouling Comparison Scale is near the top of the scale, indicating substantial deposition on boiler heat exchange surfaces. The photographs that were taken before and after cleaning clearly document major fouling deposits over the two years of operation while using the conventional heating oil. The fouling rate is much greater than for the ULS heating oil over two heating season. (See case study \#5.) 


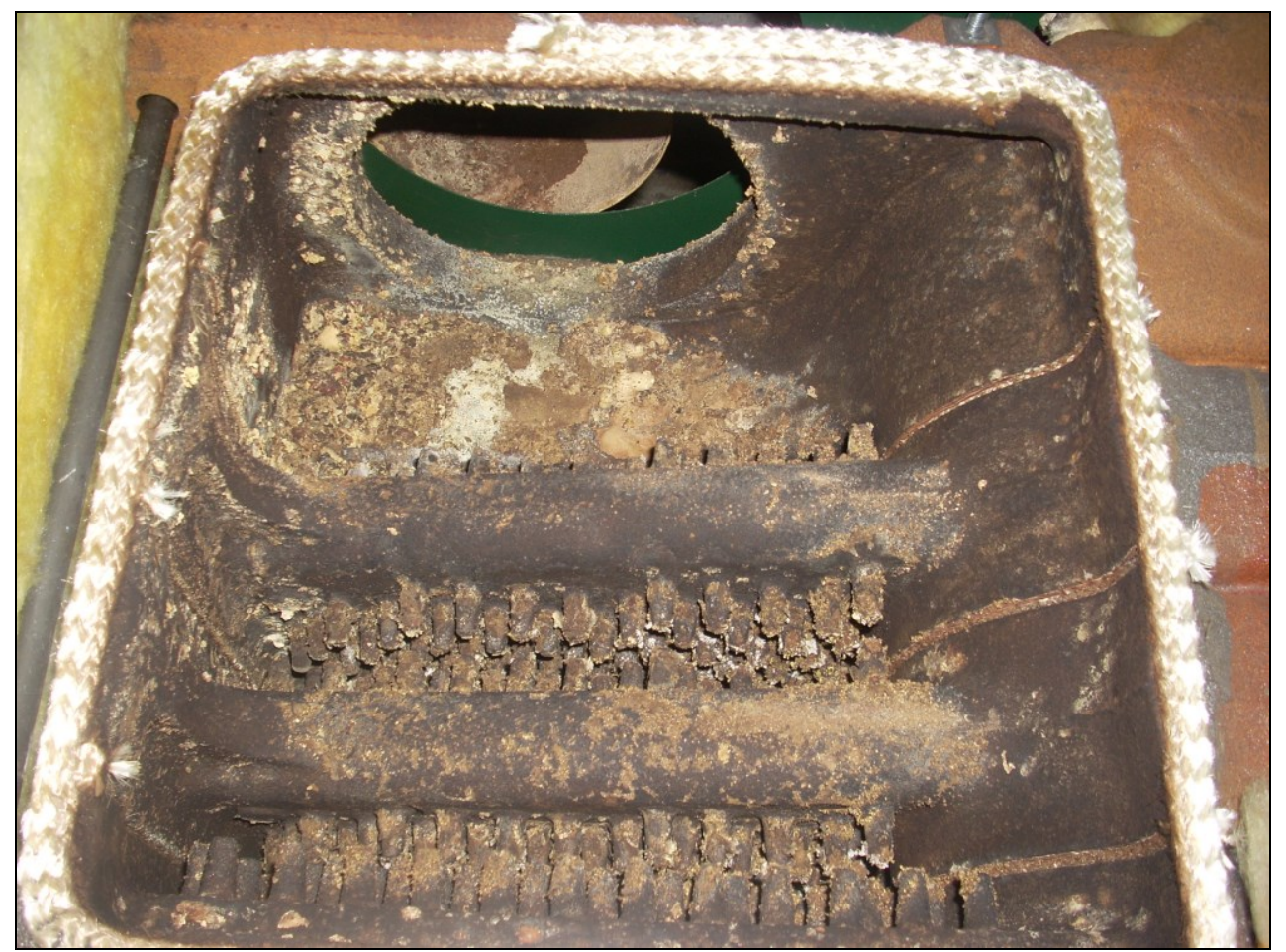

Boiler Inside Flue Passage Before Cleaning

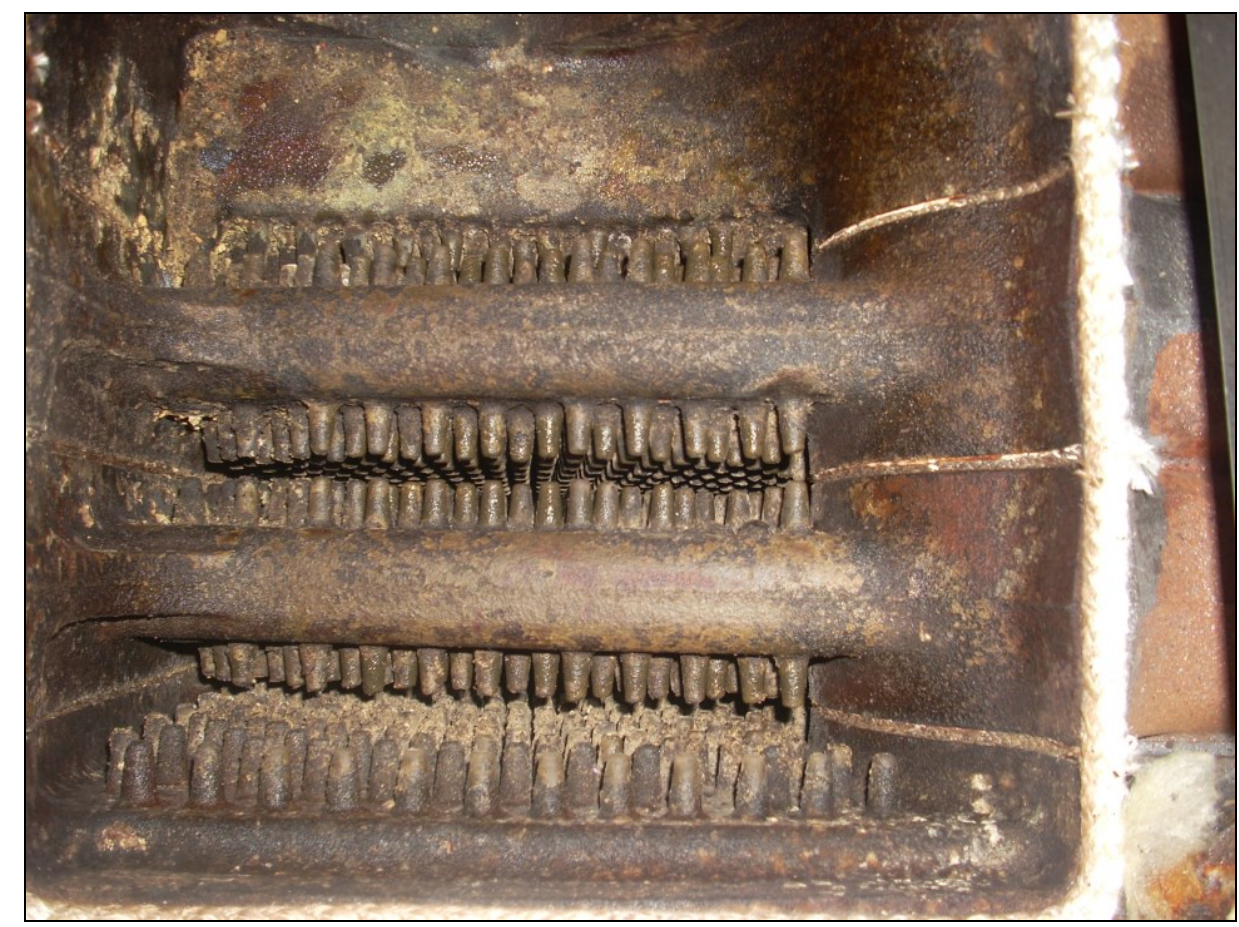

Boiler Inside Flue Passage After Cleaning 


\section{d. Service Record Review and Analysis for ULS Heating Oil and Control Group}

Service records are maintained by the fuel oil delivery and service company that participated in the field study which included all service calls made to the ULS and conventional sulfur oil houses. These records were used in this study to investigate any changes in service frequency and types of service required for ULS fuel compared to conventional higher sulfur heating oil. Increases in service frequency could indicate potential issues with compatibility of the ULS using conventional oil heating equipment.

Service records were examined for the entire duration of the ULS field study. All service calls for the ULS group and the control group were collected from the oil service company and were tabulated and analyzed to determine the cause for the service and the services that were performed. These service records were sent to ERC on a periodic basis. At the end of the field test project, all service records for the both the ULS test group and Control Group were collected and entered into two summary spreadsheets. Some of these data were in text message format, and these were converted to a digital spreadsheet format for comparison and analysis of services required. A database was established to track and compare the ULS and control groups and the results are summarized in this section of the report.

Two service spreadsheets were developed - one of the ULS test group and one for the normal sulfur control group. The service spreadsheet that was developed from the complete service records listing all ULS accounts and all service calls over the entire test period. Along the top of the spreadsheet all service call reasons were included. Each service call was recorded on the spreadsheet with a "1" in the appropriate call box indicating the reason for the service call. After all the service data were entered, the number and types of calls were tabulated and analyzed for the ULS group. The same procedure was used for the normal sulfur control group.

This project enabled a quantitative side-by-side comparison of service needs for the ULS and control groups using higher sulfur heating oil. The findings indicate that there was no significant change observed in overall service rates for the two groups.

\section{i. ULS Test Group Service Calls}

The ULS test group service spreadsheet included the following general call categories listed in the order of frequency from highest to lowest:

\section{- Oil Related Calls}


- No action / other

- Miscellaneous action

- No or insufficient Heat or Hot water

- Equipment install or adjust

- Water related

- Noise

- Set summer/winter

- Soot or smoke

- Fuel oil pump replacement

A primary category of interest shown above is Oil Related Calls that can be further separated into the services calls that follow:

- Oil burner check or clean

- Oil pump clean or replace

- Oil filter

- Oil Strainer

- Fuel oil nozzle

- Nozzle line or adapter

- Oil line clean or replace

- Oil odor

- Oil leak

- Install oil line

- Primed oil pump

All the service calls for each ULS house over the test period were entered into the service spreadsheet and the number of calls of each type and category were tabulated and analyzed. The results of that analysis are summarized in the chart that follows for the ULS test group of houses. 


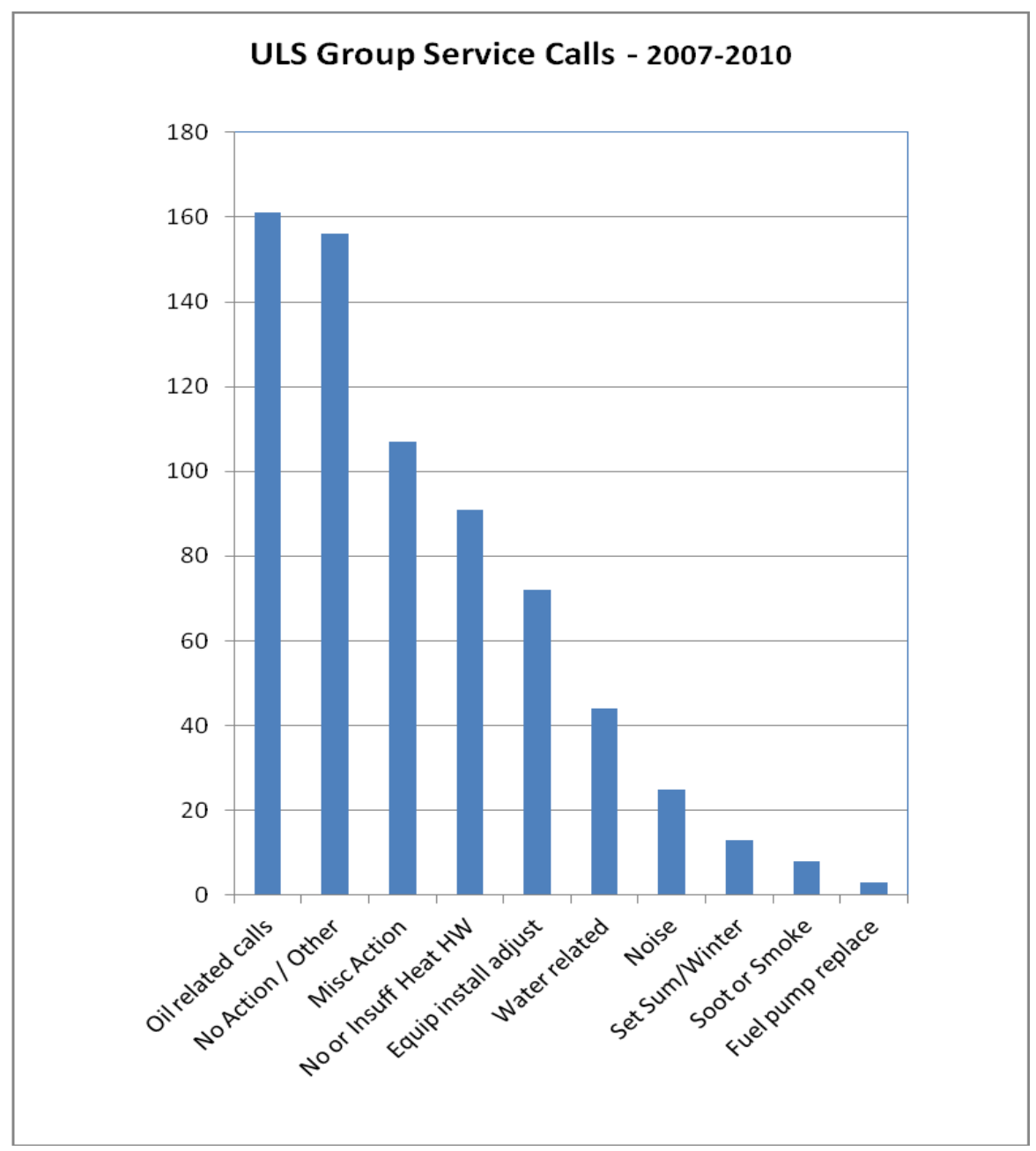

Figure 5-6. Service Call Type and Frequency

Oil related calls were the most frequent service category for the ULS group that accounted for the 161 of the 680 total service calls or 23.7 percent of all calls. No Action and Other was the next most frequent service type and generally indicates that no adjustments, repairs, or other actions were needed. Miscellaneous was next highest, followed by No or Insufficient Heat or Hot water, Equipment Install/Adjust, Water Related (boiler or piping leaks), Noise, Set Boiler for Summer or Winter Operation, Soot or Smoke, and Fuel Pump Replacement. Oil related calls will be discussed in more detail and compared to the control group service record later in this section. 
The ULS group service data are presented in the table that follows that includes the number of calls, and the percentage of calls for each call category for the field test program. A total of 680 service calls were recorded for the test period for a total of 106 original accounts using the ULS test fuel including annual burner tune-ups. This equals 6.4 calls per account, or 2.1 calls per account per year. If annual tune-ups are subtracted, this totals 1.1 service calls per year for each ULS account.

Oil related service calls totaled 161 for the test period, or 23.7 percent of all service calls as shown in the table that follows. In addition, three fuel oil pump replacements for the ULS test group during the test period.

\begin{tabular}{|ccc|}
\hline ULS Accounts & & $\%$ \\
Number of service calls & $\mathbf{6 8 0}$ & \\
Number of accounts & $\mathbf{1 0 6}$ & \\
Oil related calls & 161 & 23.7 \\
No Action / Other & 156 & 22.9 \\
Misc Action & 107 & 15.7 \\
No or Insuff Heat HW & 91 & 13.4 \\
Equip install adjust & 72 & 10.6 \\
Water related & 44 & 6.5 \\
Noise & 25 & 3.7 \\
Set Sum/Winter & 13 & 1.9 \\
Soot or Smoke & 8 & 1.2 \\
Fuel pump replace & 3 & 0.4 \\
& & \\
& & \\
Service calls / acct & & $\mathbf{6 . 4}$ \\
Service calls / acct / yr & & $\mathbf{2 . 1}$ \\
\hline
\end{tabular}

Figure 5-7. Table of Service Call Type and Frequency 


\section{ii. Control Group Service Calls}

The Control Group service spreadsheet included the following general call categories listed in the order of frequency from highest to lowest:

- No or insufficient Heat or Hot water

- Oil Related Calls

- Equipment install or adjust

- Miscellaneous action

- Water related

- Set summer/winter

- Noise

- No action / other

- Soot or smoke

- Fuel oil pump replacement

A primary category of interest shown above is Oil Related Calls that can be separated into the services calls that follow:

- Oil burner check or clean

- Oil pump clean or replace

- Oil filter

- Oil Strainer

- Fuel oil nozzle

- Nozzle line adapter

- Oil line clean or replace

- Oil odor

- Oil leak

- Install oil line

- Primed oil pump

- Oil valves

All the service calls for each Control Group (house higher sulfur oil) over the test period were entered into the service spreadsheet and the number of calls of each type and category were tabulated and analyzed. The results of that analysis are summarized in the chart that follows for the control group of houses. 


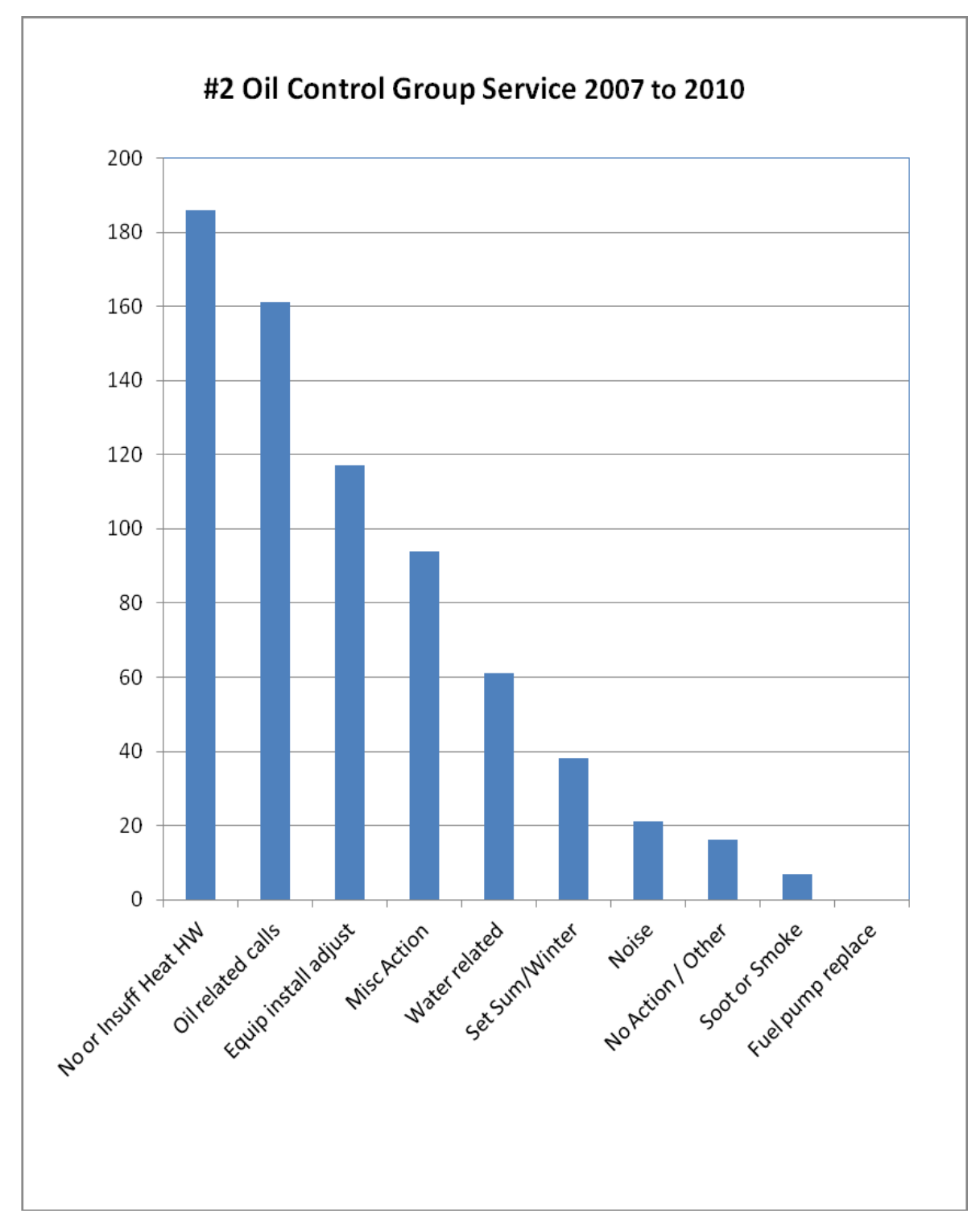

Figure 5-8. Service Call Type and Frequency

Oil related calls were the second most frequent service category for the control group that accounted for the 186 of the 701 total service calls or 23.0 percent of all calls. No heat of Insufficient Heat or Hot Water was the most common call type. After Oil Related calls the most frequent were: Equipment Installation or Adjustment, Miscellaneous Action, Water Related, Set Boiler for Summer or Winter Operation, Noise, No Action or Other, and Soot or Smoke. No fuel oil pumps were replaced for the control group during the test period. 
The Control Group service data are presented in the table that follows which includes the number of calls, and the percentage of calls for each call category for the field test program. A total of 701 service calls were recorded for the test period for a total of 101 original accounts which includes annual burner tune-ups. This equals 6.9 calls per account, or 2.3 calls per account per year. If annual tune-ups are subtracted, this totals 1.3 service calls per year for each Control Group account.

Oil related service calls totaled 161 for the test period, or 23.0 percent of all service calls as shown in the table that follows. There were no fuel oil pump replacements for the Control Group during the test period.

\begin{tabular}{|ccc|}
\hline \#2 Oil & & $\%$ \\
Number of serv calls & 701 & \\
Number of accounts & $\mathbf{1 0 1}$ & \\
No or Insuff Heat HW & 186 & 26.5 \\
Oil related calls & 161 & 23.0 \\
Equip install adjust & 117 & 16.7 \\
Misc Action & 94 & 13.4 \\
Water related & 61 & 8.7 \\
Set Sum/Winter & 38 & 5.4 \\
Noise & 21 & 3.0 \\
No Action / Other & 16 & 2.3 \\
Soot or Smoke & 7 & 1.0 \\
Fuel pump replace & 0 & 0.0 \\
& & \\
& 701 & \\
Serv call / acct & & $\mathbf{6 . 9}$ \\
Serv call / acct / yr & & $\mathbf{2 . 3}$ \\
\hline
\end{tabular}

Figure 5-9. Table of Service Call Type and Frequency 


\section{iii. Comparison of Service Calls for ULS and Control Groups}

The service frequency for the ULS test group and the control group houses were similar, with the ULS group showing slightly lower $(7.5 \%$ less) service requirements during the test period. A summary of these findings follows.

\begin{tabular}{lcc} 
& ULS & Control \\
\cline { 2 - 3 } Average calls per account each year & 2.1 & 2.3 \\
Average calls excluding tune-ups & 1.1 & 1.3 \\
Oil Related service calls & 161 & 161 \\
Percentage oil related calls & 23.7 & 23.0 \\
Fuel oil pump replacements & 3 & 0
\end{tabular}

The summary table above shows remarkable similar results for both he ULS and conventional higher sulfur heating oil examined in this field demonstration. The average calls per year for each account including annual tune-ups were 2.1 and 2.3 for the ULS and Control groups, respectively. This study found a small reduction in the number of service calls for the ULS test group. This indicates that the ULS heating oil used in houses did not impact the number of service calls, and if anything slightly lowered the number of calls each year when compared to conventional higher sulfur home heating oil.

The number of Oil-Related-Calls were exactly the same for the ULS and Control Group examined as part of this study at 161. The percentage of calls for the ULS group was slightly higher than the Control group at 23.7 percent and 23.0 percent, respectively.

One potentially significant difference in the service records for the ULS and Control Groups was the number of oil burner pump replacements which were 3 for the ULS group and zero for the Control Group. One of the fuel pump replacements for the ULS involved a pump seal failure and leakage for a fuel pump that was only two years old and had been exposed to the ULS fuel for only about one year. The pump seal on this unit was a brown Viton seal material that was developed for use with biofuel blends. Concurrent lab tests at BNL on pump seal compatibility with different fuel types, also found a potential compatibility problem with the Viton oil pump seals and ULS heating oil. More details on this finding are presented in a later section of this report. 


\section{e. Tracking Flue Gas Temperatures Using Data Loggers}

Flue gas temperature measurement which is a part of combustion testing is an indicator of the internal condition of heat transfer surfaces in boilers. Fouling deposits that include sulfates that are produced from fuel bound sulfur can build up on these surfaces and the flue gas temperature rises. Tracking flue gas temperature over time is one way to determine the amount of deposition on a boiler's internal heat transfer surfaces.

Ten houses were selected for detailed monitoring of flue gas temperatures over time as part of this ULS field demonstration project. Battery powered data loggers with temperature sensor were installed in the flue pipes of the test houses. The dataloggers were left in the field for several month, and were then collected and returned to BNL for data retrieval and analysis. This permitted tracking of flue gas temperature over time in these ULS and control group test houses that included 5 ULs and 5 Control Group. The resulting flue gas temperature data were analyzed and the results follow.

The flue gas temperature tracking did not produce significant results on the overall findings of this study. Boiler flue gas temperatures change slowly over time and the test duration with the dataloggers was only several months. in addition, the ULS houses generally experienced only minor increases in flue gas temperature over the dataloggers test period. Tracking flue gas temperature over time is more meaningful in cases where sooting or heavy fouling occurs so that corrective action can be taken before the boiler flue gas passages becomes fully plugged. The Boiler Fouling Scale proved to be a much better measure of boiler condition and the relative fouling rates each year.

A brief summary and example cases of the flue gas tracking results follow. Cases 1, 2, and 3 show results for the control group using higher sulfur heating oil, and cases 4,5 , and 6 are for the ULS test group.

Case 1 is a Control Group house using conventional \#2 heating oil in which a Flue Gas Datalogger was installed from December 4, 2009 to March 12010 . The flue gas temperature rises slowly from December 4 to December 23 . The flue gas temperature then drops consistent with an annual tune-up that was performed and then remains fairly steady for the next two months. A plot of the output from data logger follows. The initial upper "burner on" temperature is about $480 \mathrm{~F}$ and increases to about $500 \mathrm{~F}$. It then drops to about $470 \mathrm{~F}$ and remains steady. The "burner off" temperature are at the bottom of the plot in the of about $150 \mathrm{~F}$ to $160 \mathrm{~F}$. This is expected as the Site Characterization Form for this boiler showed a boiler water set point of $160 \mathrm{~F}$, and off- 
cycle air flow exiting the boiler flue is expected to be close to the boiler water temperature.

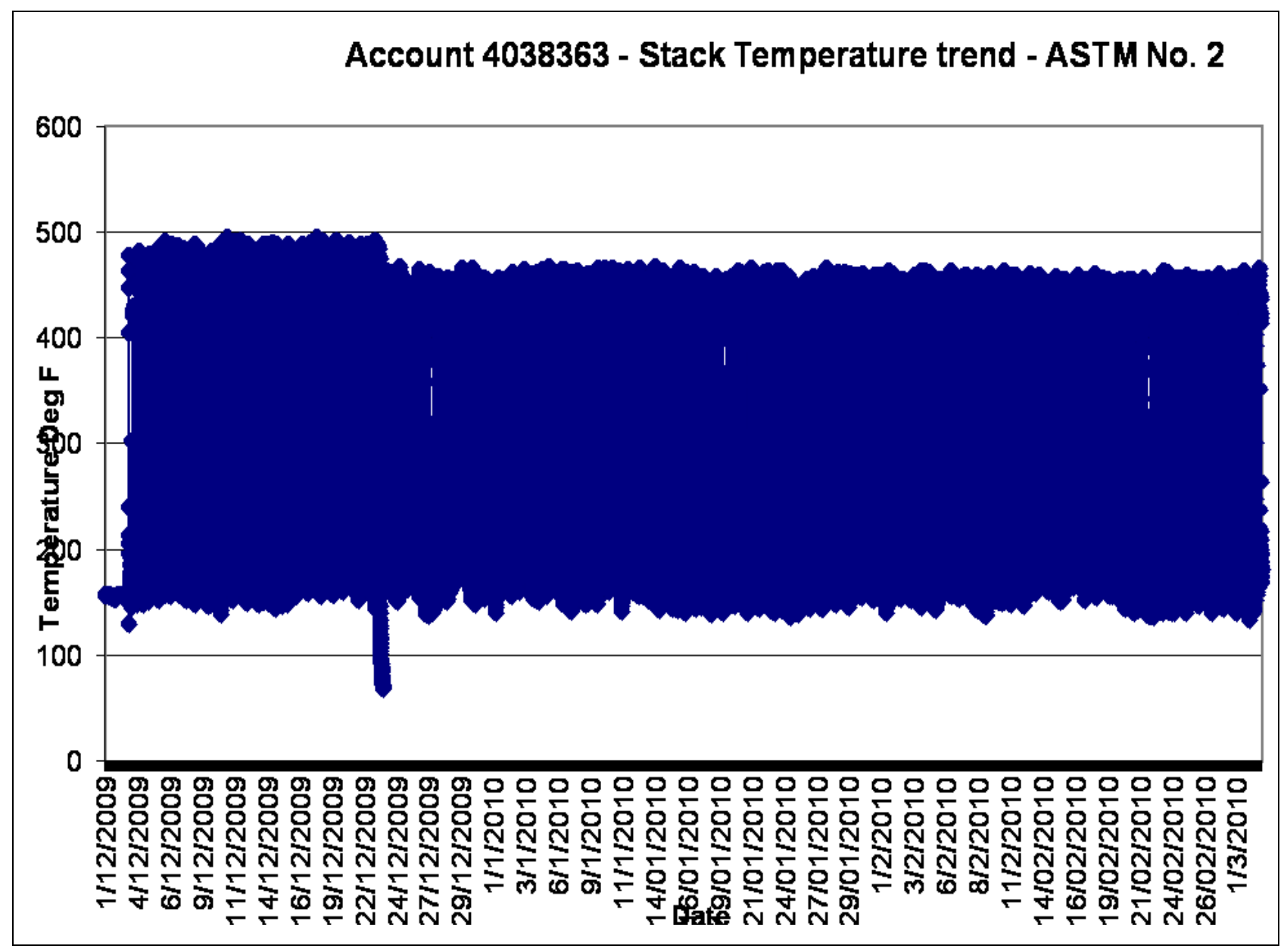

Figure 5-9. Case \#1 - Control Group (higher sulfur heating oil)

Case 2 is a Control Group house in which a Flue Gas Datalogger was installed from November 16, 2009 to March 1, 2010. The flue gas temperature remained steady for the entire test period. A plot of the output from data logger follows. This plot demonstrates that the flue gas temperature increases slowly, even for the higher sulfur fuel oil used in the Control Group. The results presented earlier for the Boiler Fouling Scale, however, suggest that over longer time periods on the order of two years or more, boiler fouling with conventional higher sulfur heating oil can cause substantial fouling. The fuel gas temperature is expected to rise noticeably in these cases. 


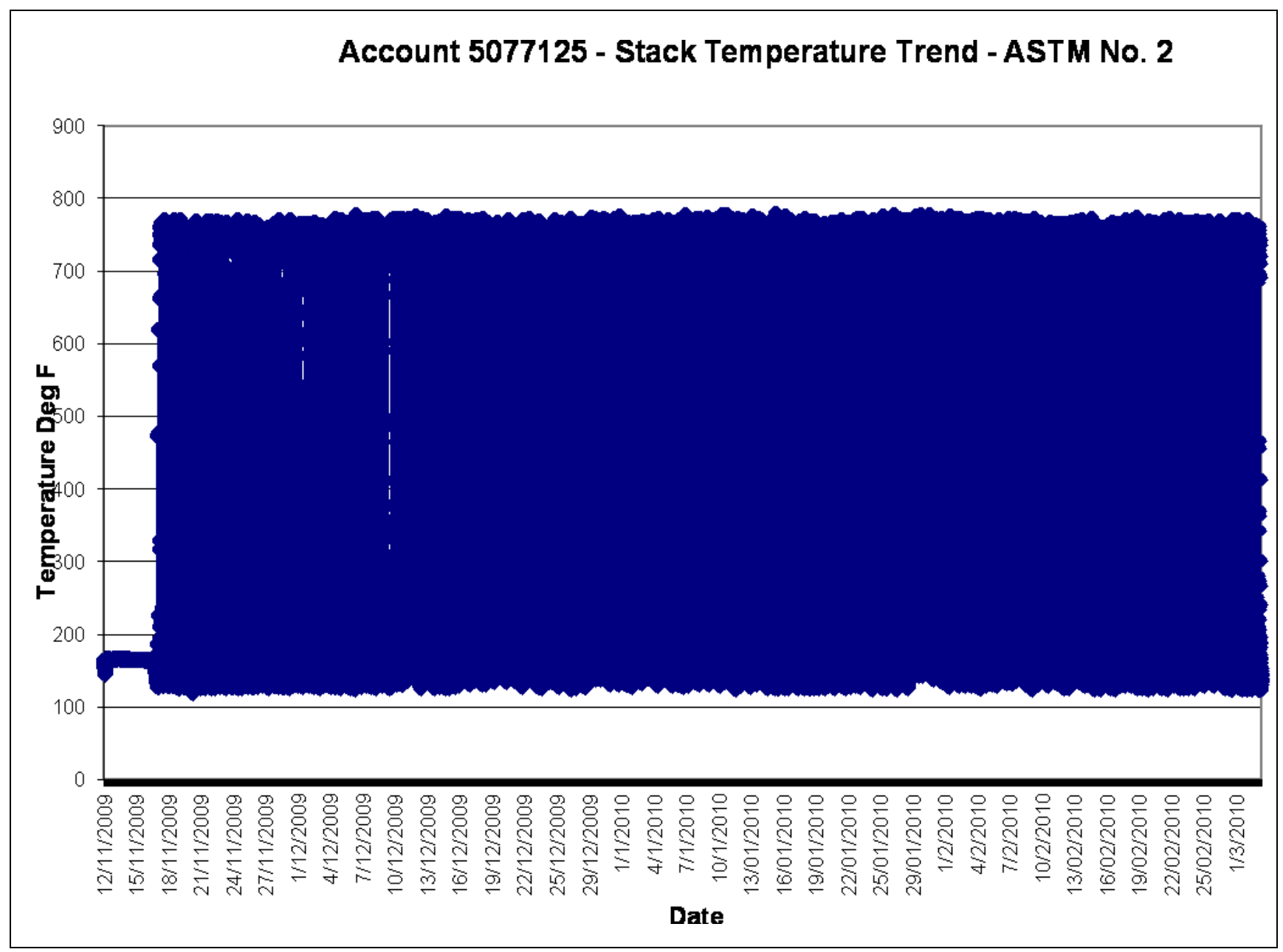

Figure 5-10. Case \#2 - Control Group (higher sulfur heating oil)

Case 3 is a Control Group house in which a Flue Gas Datalogger was installed from November 29, 2009 to March 3, 2010. The flue gas temperature increased gradually over the test period which includes most of the heating season that runs from October through April. A plot of the output from data logger follows. The boiler in this case is a 25 year old cast iron boiler with flame retention oil burner that is typical of the general population of hot water boilers. The gradual increase in flue gas temperature is expected after boiler cleaning and burner tune-up that occurred when the data logger was installed. 


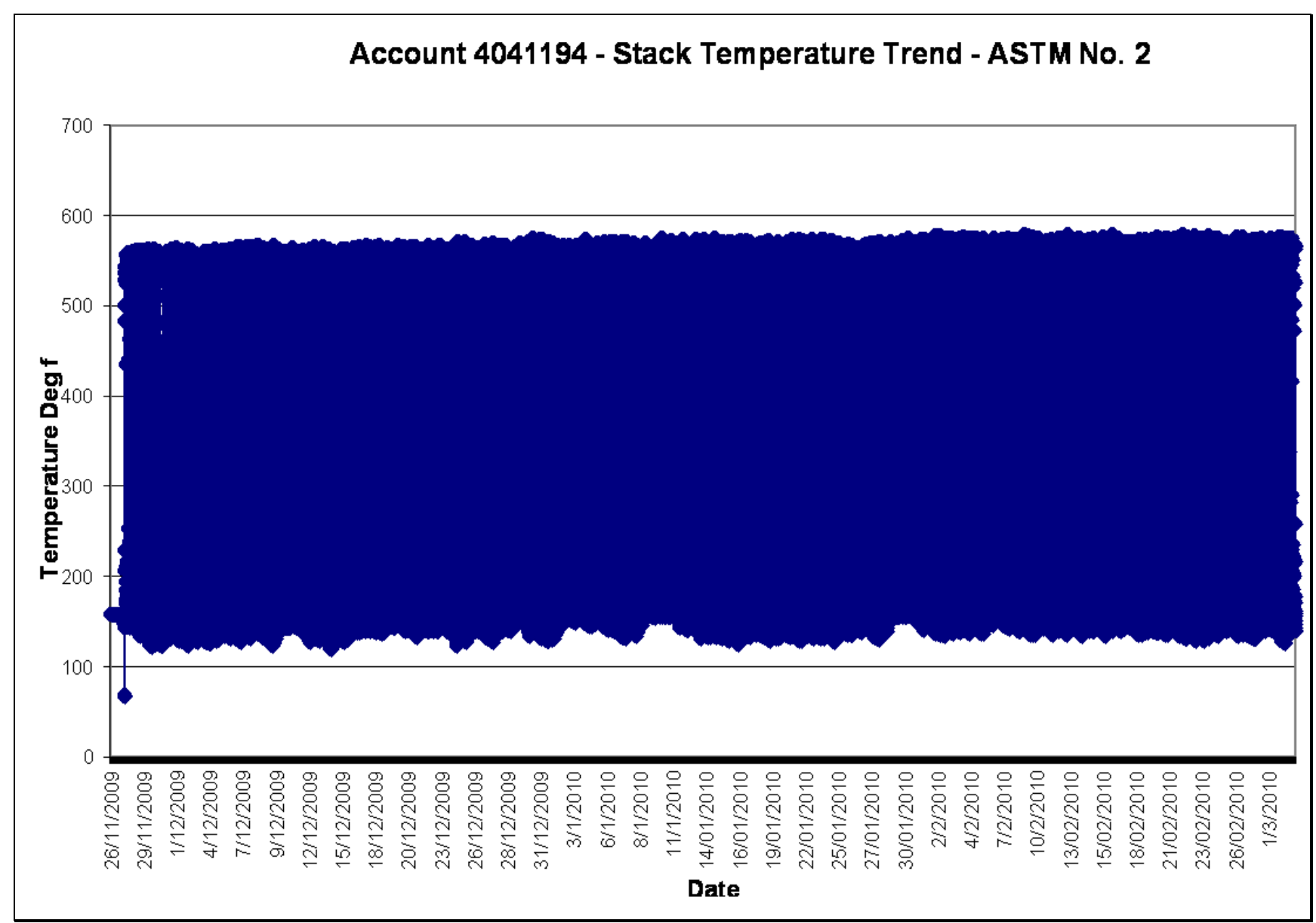

Figure 5-11. Case \#3 - Control Group (higher sulfur heating oil)

Case 4 is a ULS fueled test house in which a Flue Gas Temperature Datalogger was installed from November 29, 2009 to March 3, 2010. The flue gas temperature remained flat over the test period which includes most of the heating season that runs from October through April. A plot of the output from data logger follows. The boiler in this case was an older cast iron boiler ( 40 or 50 years old) with an older flame retention oil burner that is one of the oldest types of boilers in operation today. The steady flue gas temperature is indicative of minimal deposition on boiler heat transfer surfaces that is consistent with burning ULS heating oil. 


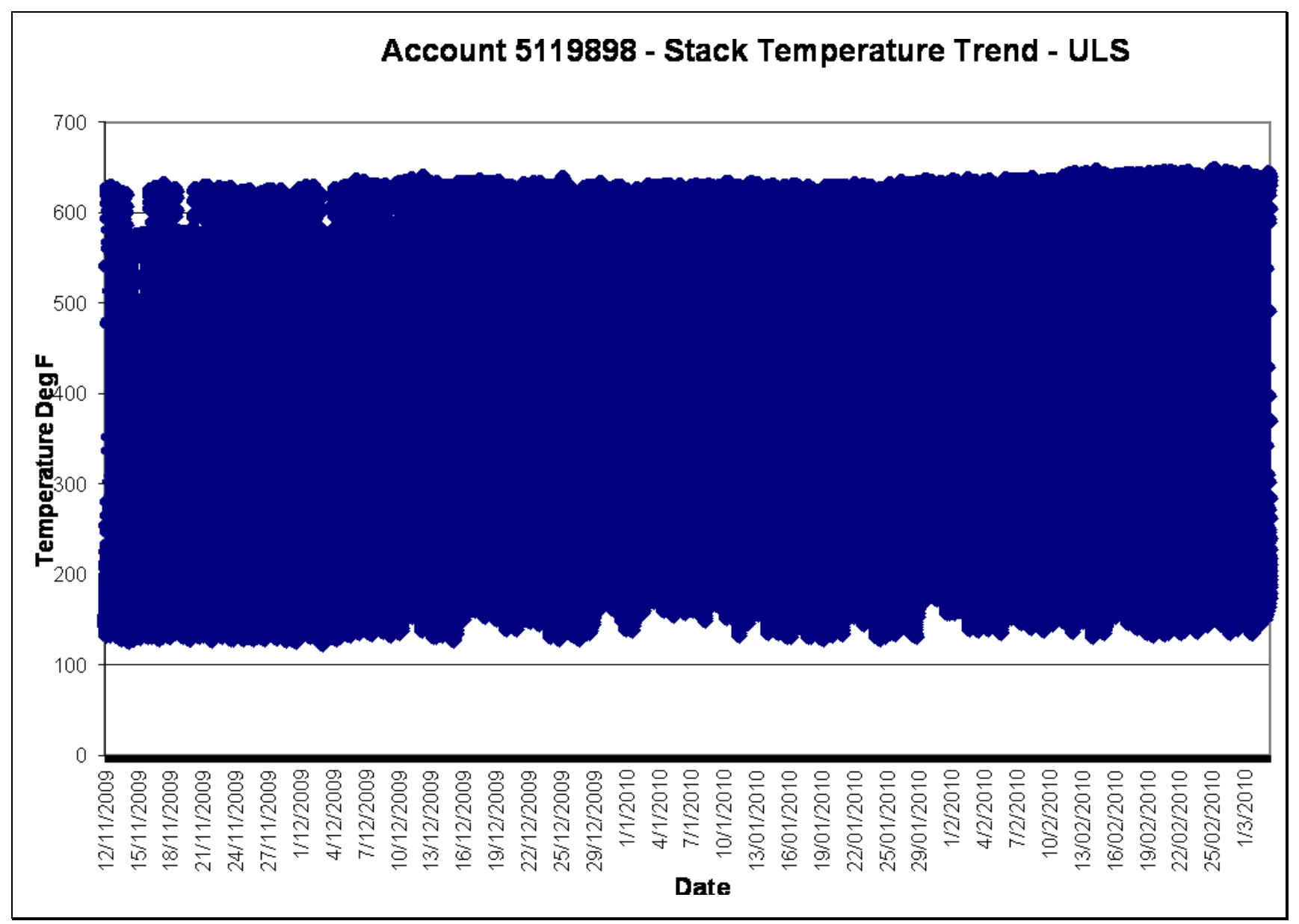

Figure 5-12. Case \#4 - Ultra Low Sulfur Group

Case 5 is a ULS group house in which a Flue Gas Temperature Datalogger was installed from November 29, 2009 to March 3, 2010. The flue gas temperature remained fairly level over the test period which includes most of the heating season that runs from October through April. A plot of the output from data logger follows. The boiler in this case was an older cast iron boiler (40 or 50 years old) with an older flame retention oil burner that is one of the oldest types of boilers in operation today. The steady flue gas temperature in indicative of minimal deposition on boiler heat transfer surfaces that is consistent with burning ULs heating oil. 


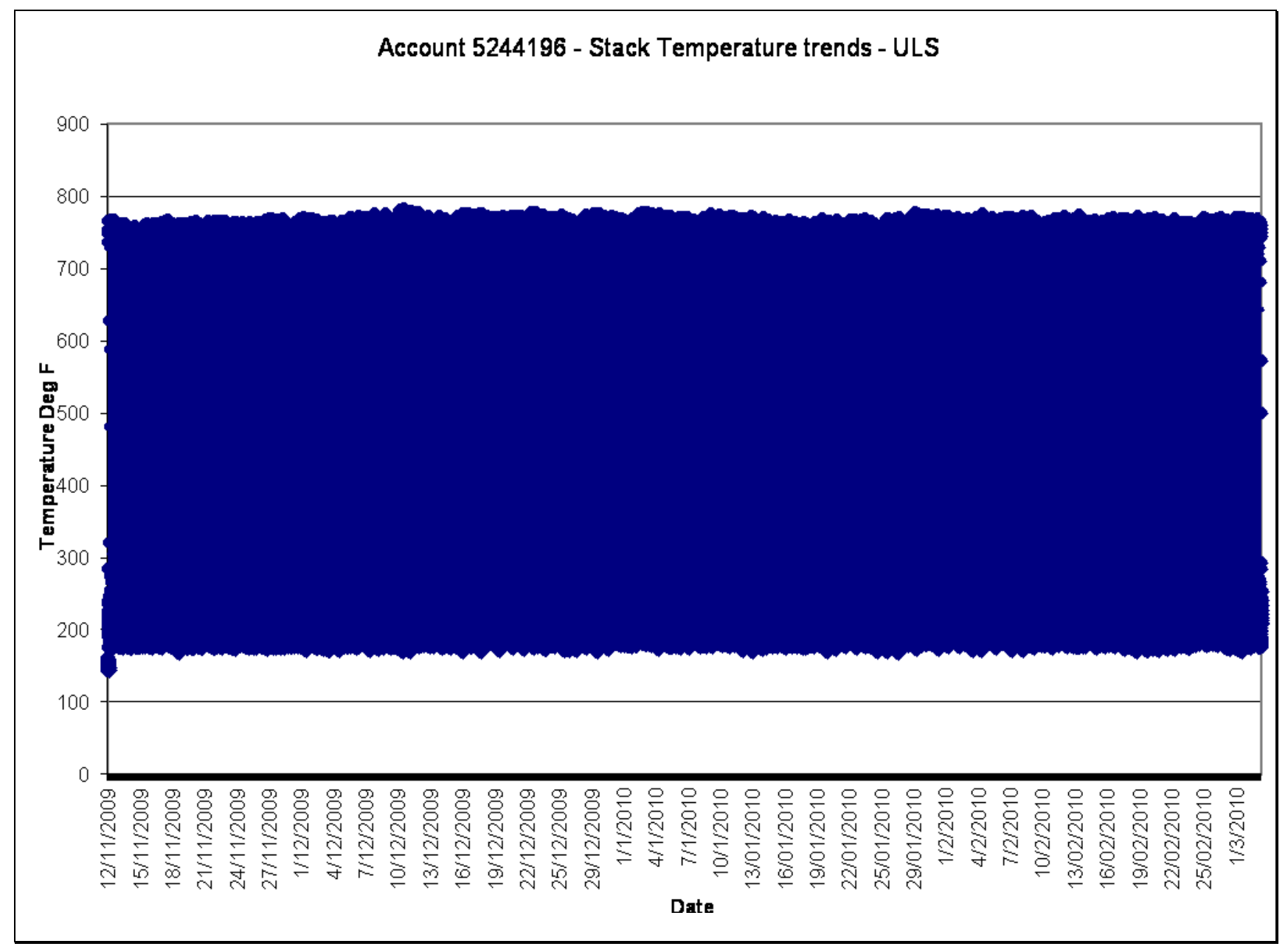

Figure 5-13. Case \#5 - Ultra Low Sulfur Group

Case 6 is a ULS group house in which a Flue Gas Temperature Datalogger was installed from November 29, 2009 to March 3, 2010. The flue gas temperature remained fairly level and gradually decreased over the test period which includes most of the heating season that runs from October through April. Decreasing flue gas temperature over time is unusual and suggests a decrease in boiler fouling over the heating season. A plot of the output from data logger follows. The boiler in this case was an older cast iron boiler (40 or 50 years old) with an older flame retention oil burner that is one of the oldest types of boilers in operation today. The steady flue gas 
temperature in indicative of minimal deposition on boiler heat transfer surfaces that is consistent with burning ULs heating oil.

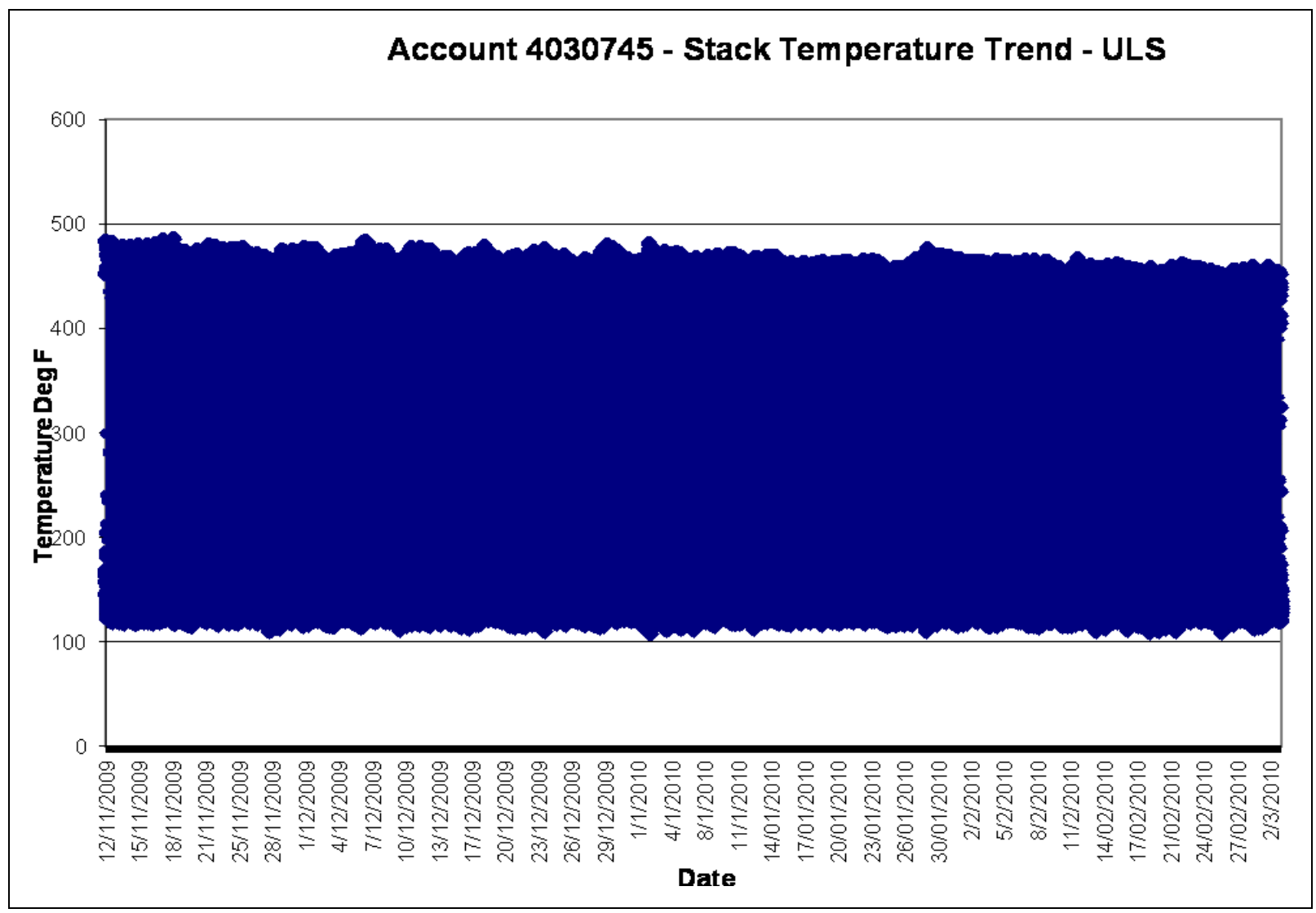

Figure 5-14. Case \#6 - Ultra Low Sulfur Group

These datalogger results for both the ULs and Control groups do not show significant changes in flue gas temperature over the time interval in which they were installed. Flue gas temperatures typically change slowly over the year and the time interval for these data logger tests was only4 or five months. Therefore, tracking flue gas temperature may not be a reliable measure for assessing the benefits of using ULS heating oil. 


\section{f. Energy Tracking and Control Analysis Results}

One additional measure that was applied for this field study was Energy Tracking and Control analysis that was developed by the ERC and uses fuel oil delivery records and heating load factors based on heating degree days to accurately track fuel use in houses. ETC can predict changes in fuel tank levels and can measure changes in heating equipment efficiency on the order of one percent.

\section{Tank Level Prediction for Maximum ULS Fuel Deliveries}

At the start of the project ETC fuel use profiles were developed for each ULS account to more accurately predict the amount of fuel remaining in each tank each day. Fuel deliveries were then delayed by the participating fuel oil supplier until fuel tank levels were low, so that a larger volume of the ULS heating oil could be delivered to each tank. In this way, larger volumes of Ultra Low Sulfur heating oil were delivered to the ULS test tanks so that very low sulfur levels could be achieved in each of the ULS fuel tanks much more rapidly than by following normal fuel delivery methods.

Testing conducted by ERC has demonstrated that during the early Spring and early Winter when the ULS fuel delivery started for this project, fuel delivery volumes often account for only about half of the tank or about 138 gallons for 275 gallon oil tanks. This is due to the uncertainly in the conventional heating degree day tracking method that is used by most fuel oil delivery companies. Fuel deliveries frequently are made before the tank level is low to avoid customer fuel run-outs. ETC supplies more precise fuel tank level tracking and helped the participating fuel oil company to make the initial and subsequent ULS fuel oil deliveries when the fuel tank levels were closer to empty. This allowed the sulfur levels in the tank to reach very low levels faster than when using conventional degree-day delivery methods.

By using ETC to assist scheduling fuel deliverers, the average delivery to 275 tanks was 188 gallons which is about 50 gallons higher than the typical deliveries using heating degree days.

\section{Tracking Changes in Fuel Use and Efficiency}

ETC analysis was also used in this field demonstration as one of the measures to track changes in fuel use efficiency (caused by boiler fouling) over time for both the ULS houses and the Control group. This allowed accurate evaluation of efficiency changes for houses that were part of the study. The results of several example cases follow. 


\section{ETC Case 1. ULS House Efficiency Change Over Two Years without Cleaning}

This case shows a ULS test house that operated for two years without boiler cleaning and ETC was used to measure the change in efficiency over time. The ETC plots show how the Fuel Use Factor (y-axis) changes in relation to the Heat Load Factor (x-axis). Each point on the plot is for a single fuel delivery. The fuel use factor is a modified heating degree day. As the outdoor temperature drops, the heat load increase, and the fuel use also increases. The unique feature of ETC analysis is the highly linear and precise nature of the plots with an uncertainty of approximately 1 percent. In contrast, Heating Degree Day- based analysis has an uncertainty of 30 to 40 percent. The plots that follow for the two year test project clearly demonstrate no change in fuel use factors, indicating no change in efficiency over the two year period.

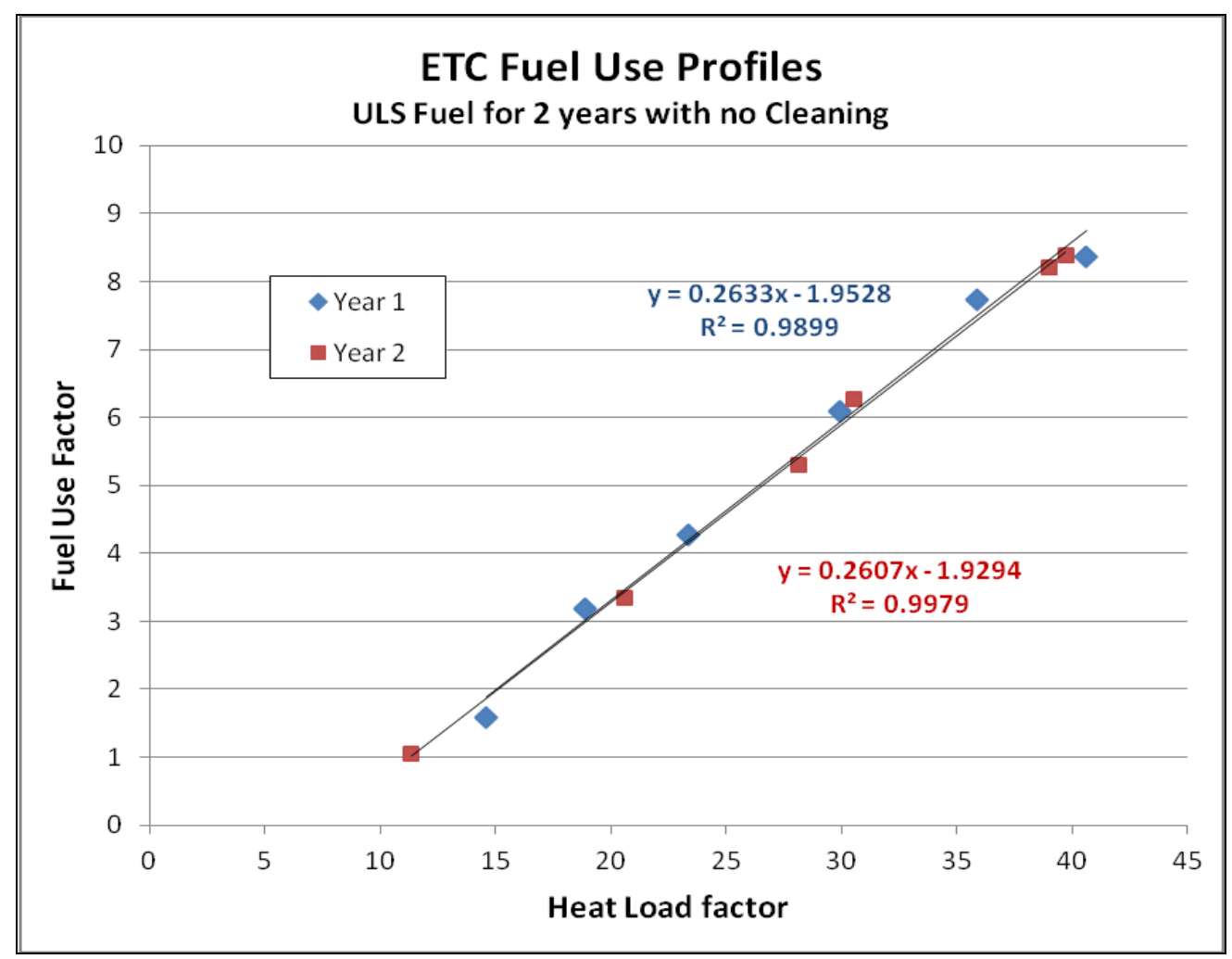

Figure 5-16. ETC Plot for ULS house over 2 years

This is typical for the ULS test houses and shows no measurable change in efficiency or fuel use over two years of operation without cleaning. This is consistent with the Boiler Fouling Scale results and photographs. 


\section{ETC Case 2. Control Group - Boiler Efficiency Loss after 2 years of Operation}

The case shows results for a control group house supplied with 2000 ppm sulfur heating oil that operated for two years without cleaning and the ETC-measured change in efficiency over time. The ETC plot shows how the Fuel Use Factor (y-axis) changes in relation to the Heat Load Factor (x-axis). The upper plot shows the Fuel Use profile for the last deliveries at the end of the 2 year period after boiler fouling has occurred. Note that it is above the single data point for fuel use immediately after the boiler was cleaned and shows a reduction in fuel use. This single point shows lower fuel use while the upper plot shows the increase in fuel usage from efficiency loss due to boiler deposits.

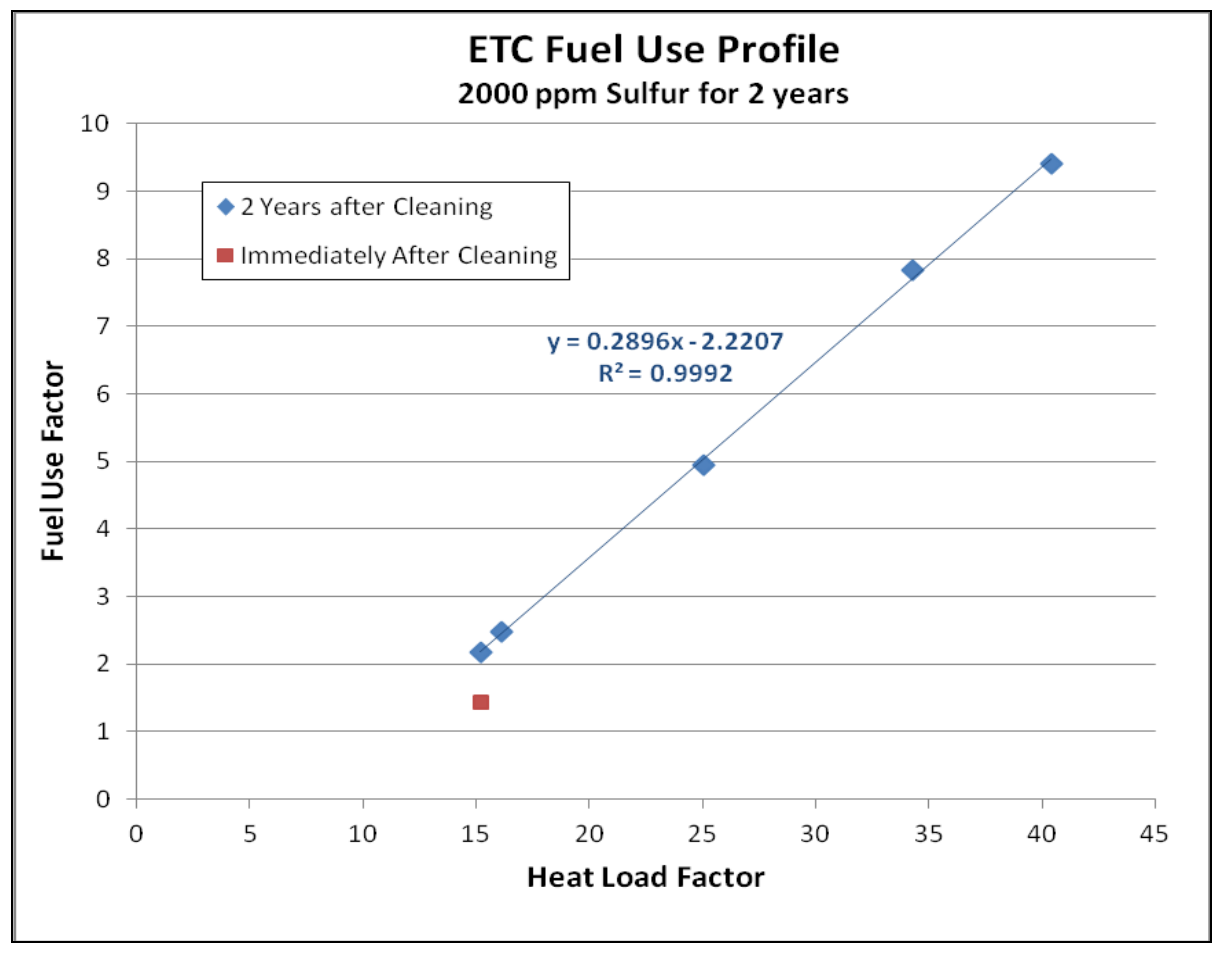

Figure 5-17. ETC Plot for ULS house over 2 years

The analysis demonstrates that fuel use increases by 12 percent after boiler fouling due to 2 years of operation with heating oil containing $2000 \mathrm{ppm}$ of sulfur. This is an important finding that documents efficiency loss by using higher sulfur heating oil for only two years between boiler cleanings. This loss is higher than expected and it was evaluated by the ETC method. 


\section{ETC Case 3. Control Group - Boiler Efficiency Loss after 2 years of Operation}

This is another case that shows results for a Control Group house supplied with 2000 ppm sulfur heating oil that operated for two years without cleaning and the ETCmeasured change in efficiency over time. The ETC plot shows how the Fuel Use changes in relation to the Heat Load Factor. The upper plot shows the Fuel Use profile for the last deliveries at the end of the two-year period without boiler cleaning and after boiler fouling has occurred. The lower plot shows after boiler cleaning, and the lowest point is for first fuel delivery immediately after cleaning. In this case, the fuel use for this point is 11 percent lower than the upper plot after two years of operation without cleaning. Only four deliveries cleaning, the boiler becomes fouled and the average efficiency difference decreases to 4.4 percent.

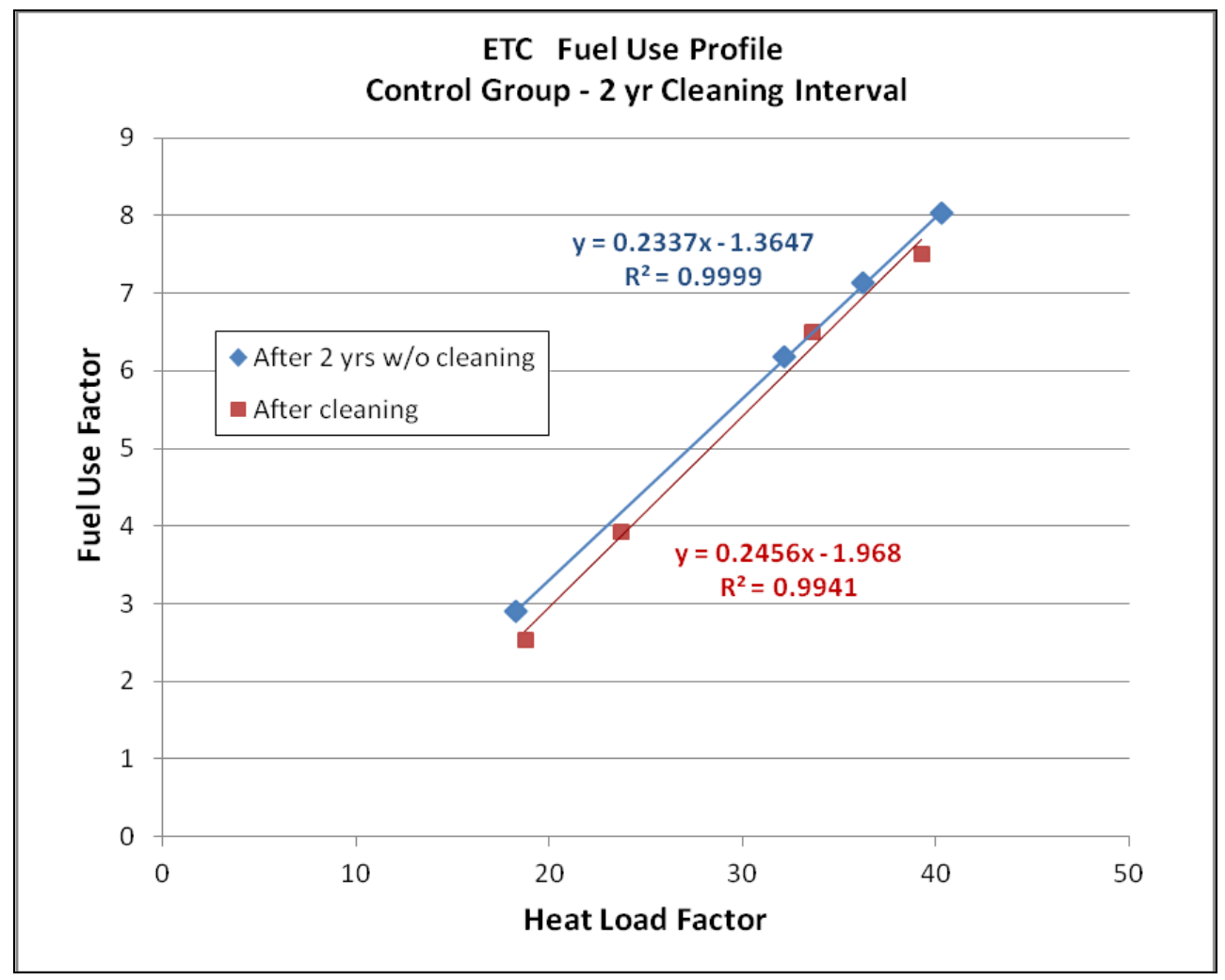

Figure 5-18. ETC Plot for Control Group house over 2 years

These plots again clearly demonstrate an increase in fuel use as the boiler becomes fouled with 2000 ppm sulfur heating oil over a two year period between boiler cleanings. This example case was for the boiler in Visual Fouling Scale Case \#9 with substantial deposition on boiler heat transfer surfaces. 


\section{ETC Case 4. ULS Group - Moderate Boiler Sooting}

This case study shows results for a test house receiving ULS heating oil but with moderate soot deposits in the boiler over a one-year boiler cleaning interval. The upper ETC plot shows the Fuel Use profile for the last deliveries at the end of the 1 year period after boiler cleaning and after boiler fouling has occurred. The single point below the line shows the first fuel delivery immediately after cleaning. By comparing the point on the upper line to the "clean boiler" point boiler we find an efficiency drop of 12 percent after boiler sooting.

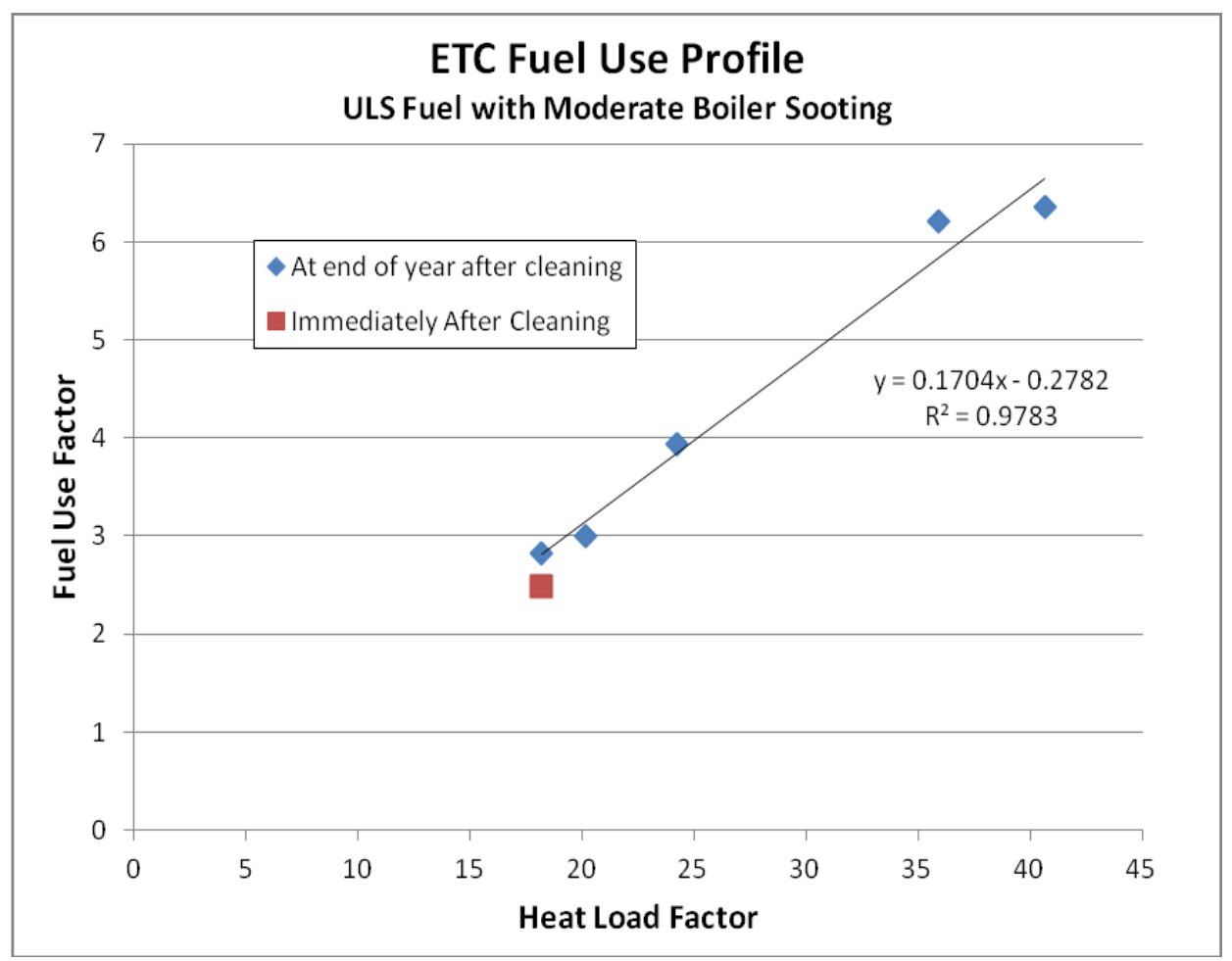

Figure 5-19. ETC Plot for ULS house with Sooting over 1 year

If the sooting occurs evenly over the year, then the loss in boiler efficiency and increased fuel use is expected to be about 6 percent. If the fouling is more severe or the cleaning interval is longer than one year, the fuel use can increase by much more than 6 percent. Clearly, proper burner tuning and assuring an adequate supply of combustion air is important for preventing soot deposits and avoidable increases in fuel use and heating costs. 
The figures that follows show photographs of the boiler in this case study before and after cleaning. It demonstrates that even moderate soot deposits can adversely impact heat transfer rate, lower boiler efficiency, and increase fuel oil use.

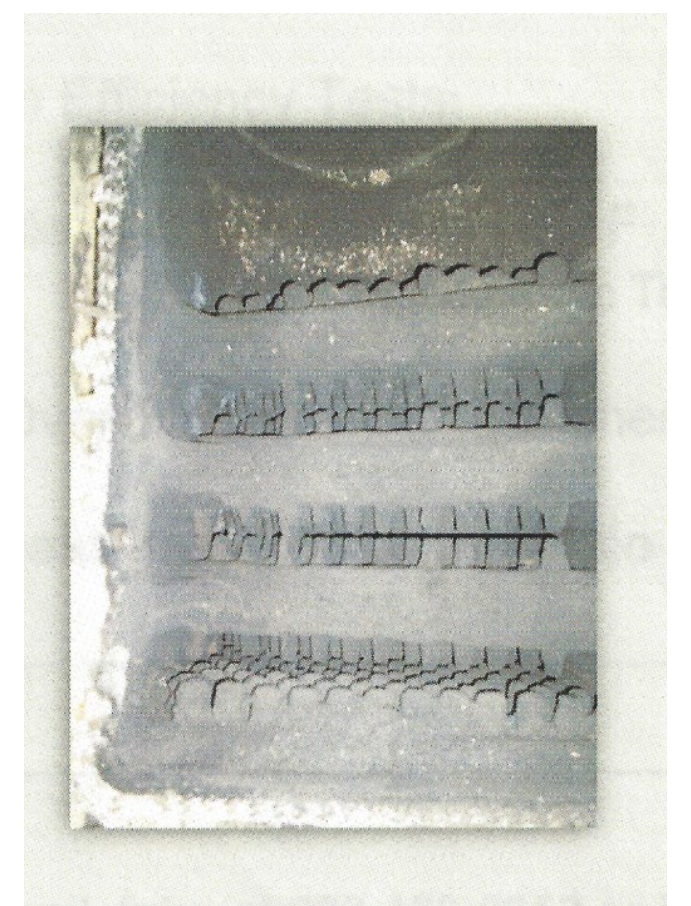

Figure 5-20. Boiler with soot deposits

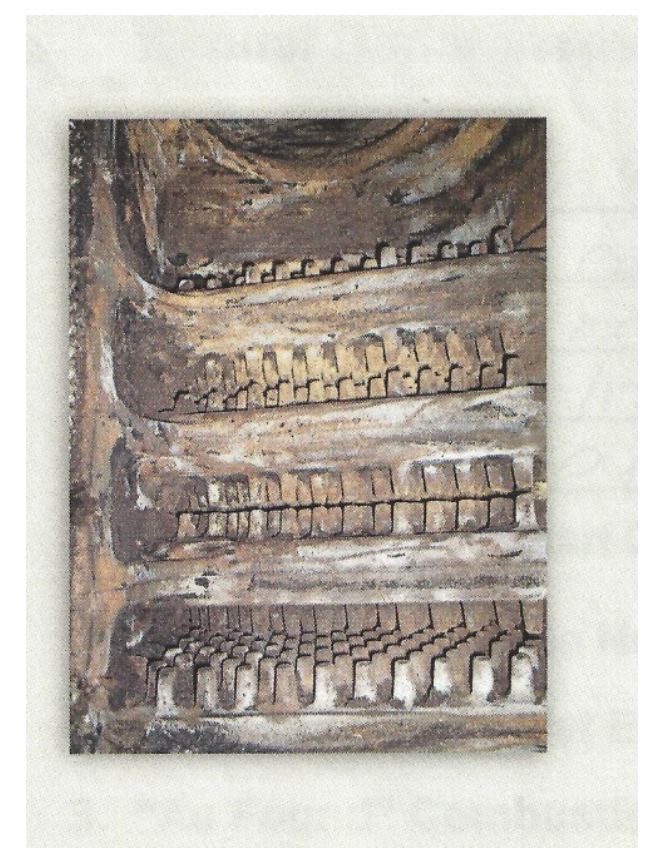

Figure 5-21. Boiler after Cleaning 


\section{ETC Case 5. ULS Group - Heavy Soot deposition one year}

This case study shows results for a test house receiving ULS heating oil but with more severe soot deposits in the boiler over a one-year boiler cleaning interval. ETC was again used to measure the change in efficiency over time. The upper ETC plot shows the Fuel Use profile for the last deliveries at the end of the one- year period after boiler soot fouling had occurred. The two point below the line shows the fuel delivery soon after cleaning, and the fuel use is 11 percent lower than the "after fouling" upper line in the figure. By comparing the upper line (after sooting) to the "clean boiler" points (lower line) equations, we find a maximum efficiency increase of 20 percent after boiler cleaning.

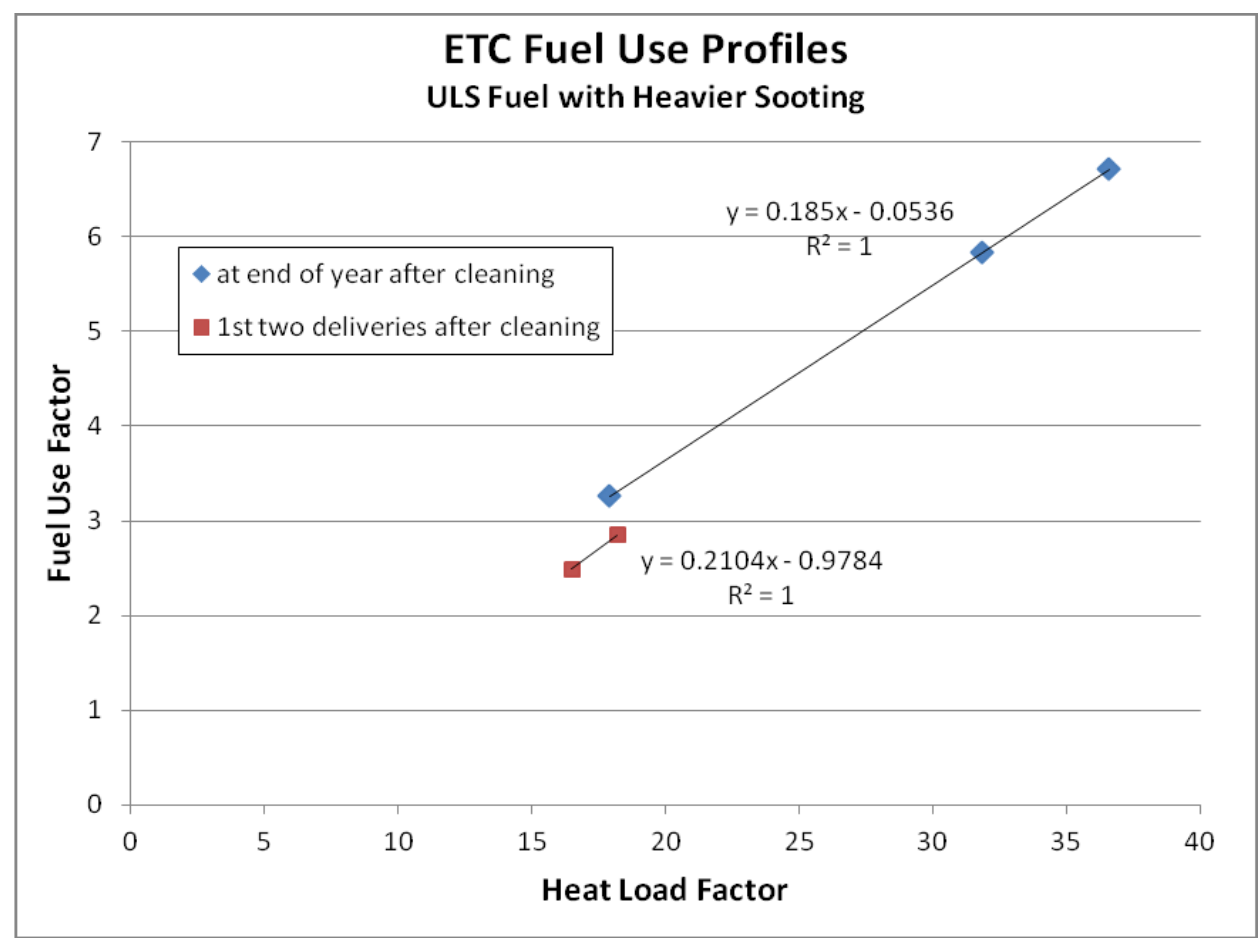

Figure 5-22. ETC Plot for ULS house with Sooting Over 1 year

If the sooting occurs evenly over the year for this heavier sooting case, then the loss in boiler efficiency and increased fuel use is expected to be about 10 percent. Again, if the fouling is more severe or the cleaning interval is longer than one year, then the fuel use can increase by much more than 10 percent. Clearly, proper burner tuning and assuring an adequate supply of combustion air are important for preventing unneeded fuel use and costs resulting from soot deposits, and more frequent service calls. 
The figures that follows show photographs of the boiler in this case study before and after cleaning. The photograph at the right of the figure is the boiler with substantial sooting visible on the outside of the cast-iron boiler sections. This soot forms an insulating layer that reduces the rate of heat transfer from the hot flue gases to the boiler water inside the cast iron sections. This increases the exhaust gas temperature and lowers the efficiency of the boiler as a smaller fraction of the available heat from the flame is transferred as useful heat to the boiler. This in turn increases fuel use. demonstrates that even moderate soot deposits adversely impact heat transfer rate, lower boiler efficiency, and increase fuel oil use.

The photograph at the left of the of the figure shows the same boiler section after the boiler is cleaned and soot deposits are removed.

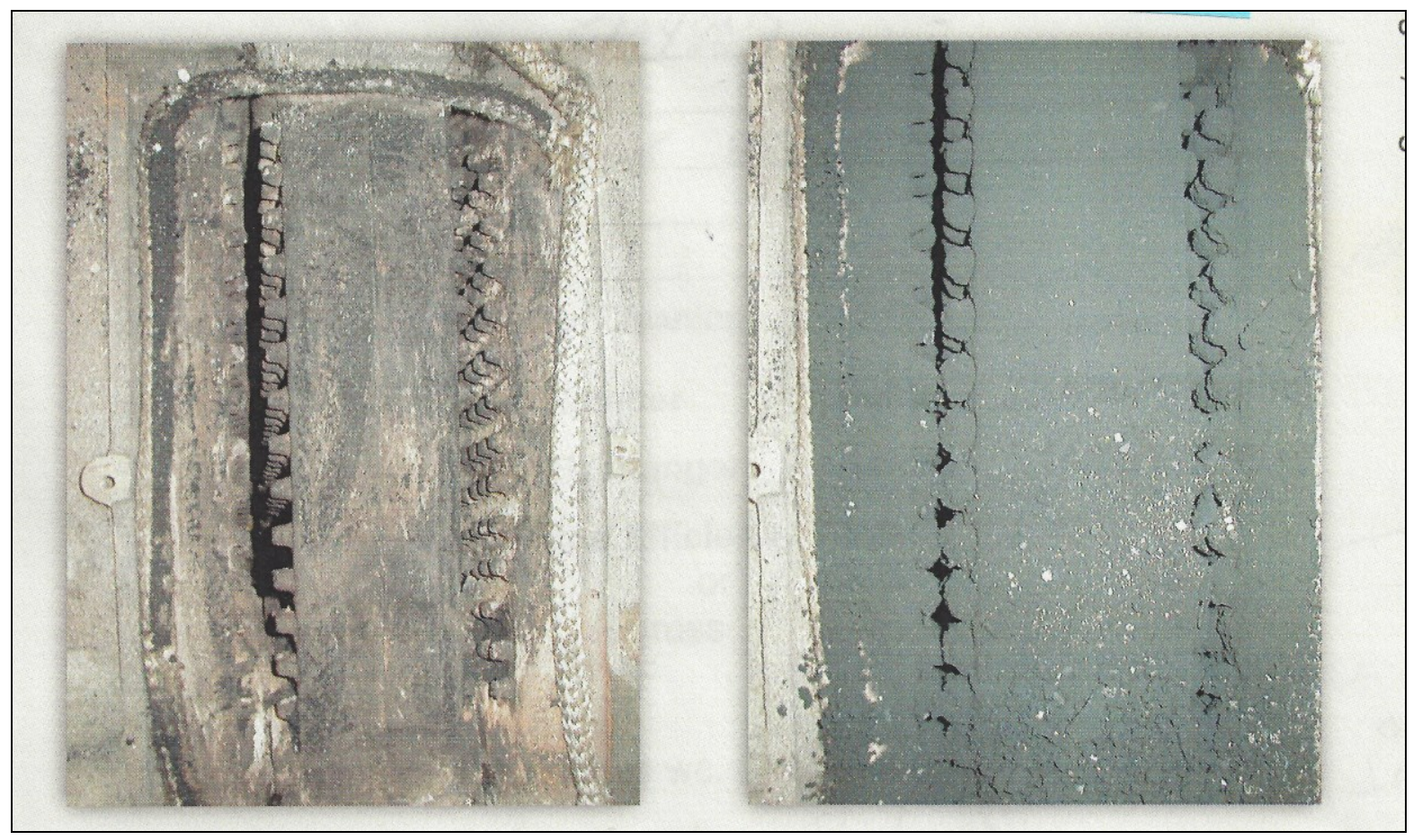

Figure 5-23. Photographs showing soot covered and clean boiler section.

This case study graphically shows soot deposits within a boiler, and the ETC analysis finds that these deposits can lower fuel use efficiency by as much as $10 \%$ to $20 \%$ of the annual fuel use. This is a remarkable finding that demonstrates the important impact of burner tuning and boiler cleaning on fuel use and costs. 


\section{ETC Case 6 - ULS Group - Boiler Replacement}

This case study shows results for a ULS test house in which a boiler was replaced after the start of the field demonstration. The upper ETC plot shows the Fuel Use profile for the older less efficient boiler that was in place at the start of the project. The lower line shows the fuel use for the new higher efficiency boiler that was installed at the house. Fuel savings were by comparing the fuel use plots for the upper and lower lines, and produced an average savings of 23.7 percent using the mean winter heat load.

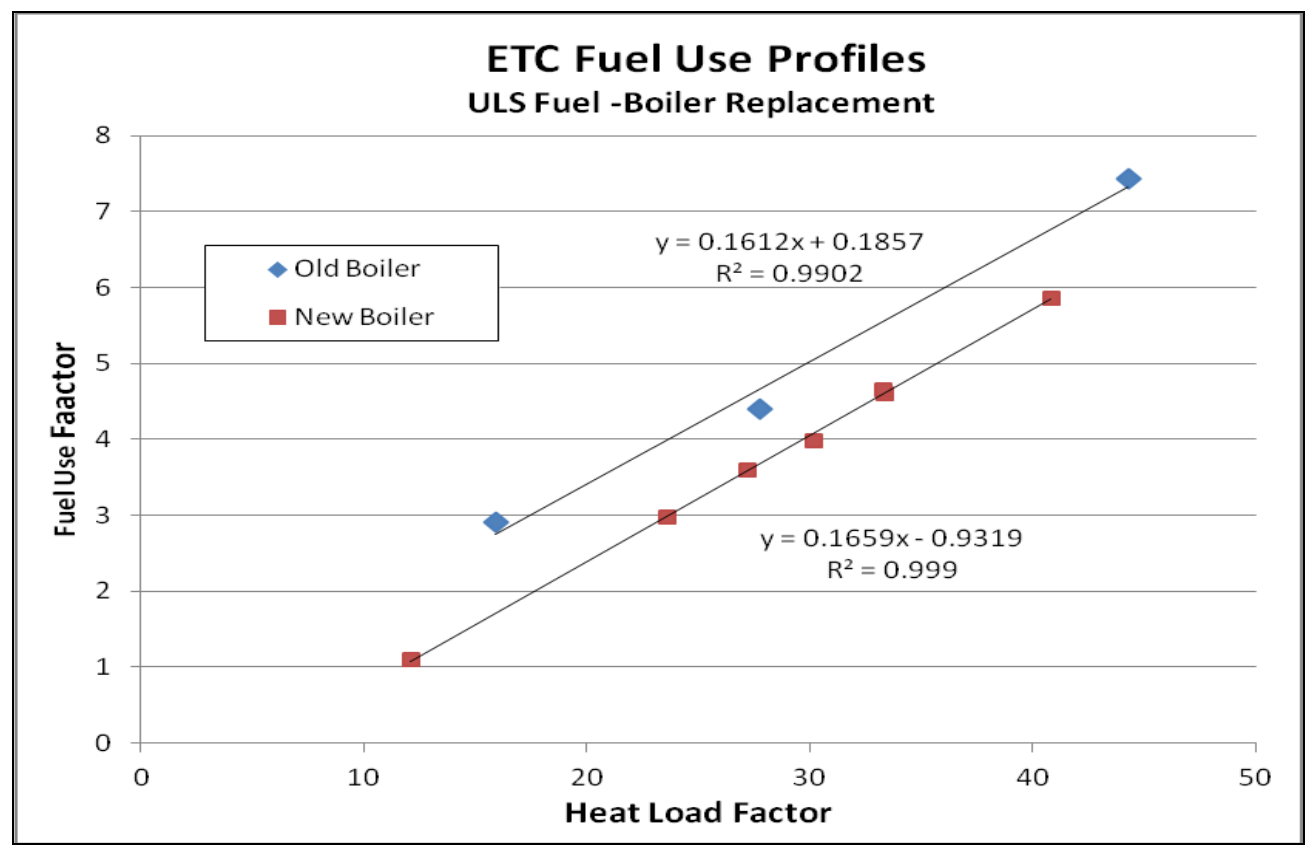

Figure 5-24. ETC Plot for ULS house with Boiler Replacement

ETC analysis has been used in past studies to measure fuel savings produced by new boilers, including a prior research study for NYSERDA, where the average savings were 25.9 percent for ten highly efficient new boilers were installed in houses. This case study is consistent with prior studies using the Energy Tracking and Control method. An important observation based on the case studies above is the efficiency improvement that is available by replacing an outdated boiler with a more efficient model can be partially negated by soot accumulation, if the burner is not properly adjusted, if sufficient combustion air is not supplied to the burner, or if the boiler is not cleaned on a regular basis. These are important findings from this field demonstration project for Ultra Low Sulfur heating oil. 


\section{Summary and Conclusions}

Efficiency tracking systems such as Energy Tracking and Control offer a way to change from scheduled cleaning of heating equipment to "as needed" cleaning by tracking changes in equipment efficiency using only fuel delivery data and modified heating degree day data. This can be especially useful in houses using ULS heating oil where the vacuum cleaning intervals are extended to two, three, four, or more heating seasons. This can substantially lower the cost of annual equipment service for boiler or furnace vacuum cleaning, and lower homeowner service costs. However, annual burner tune-ups are recommended to assure adjustment of low smoke numbers and soot-free operation.

Fuel delivery data for houses receiving ULS heating oil and for houses in the Control group were analyzed using ETC. Only minor efficiency changes are expected in the ULS test houses over a single heating season, but it is possible to detect changes in the normal sulfur Control group houses in some cases. These findings also provided insight as to how boiler efficiencies can decrease over time due to fouling from sulfurbased deposits and from soot deposits in boilers. These directly impact fuel use efficiency and annual heating costs. It is important to detect changes in efficiency quickly so that corrective action can be taken to avoid excessive fuel use and equipment breakdown. 


\section{g. Fuel Pump Seals and ULS Heating Oil}

An unexpected result was discovered while testing ULS heating oil in residential oil burners during both the laboratory and field studies that were funded by the New York State Energy Research and Development Authority. Some shaft seals on the oil burner pumps experienced shortened lifetimes when compared to operation with normal sulfur heating oil as used in the control group. This could require more frequent replacement of oil burner fuel pumps in homes, which needs to be fully evaluated.

Some oil burner pumps use elastomeric lip seals that fit around the fuel oil pump shaft to prevent fuel from leaking from the pump. The most common type of seal that is found in residential fuel pumps in the United States is a Nitrile seal that is black in color. This is used in the vast majority of existing home oil burners that use lip seals. A newer seal that has been introduced into some residential oil burners is a brown-colored Viton lip seal. One other type of pump seal used in home oil burners is a mechanical carbon face seal. Tests of each of these seals were conducted by BNL in the laboratory to examine their compatibility with Ultra Low Sulfur heating oil.

This section of the report summarizes the results of NYSERDA-funded laboratory tests at BNL and the ULS field tests which is the subject of this report related to potential seal leaking and shortened pump seal lifetimes.

\section{i. BNL Laboratory Tests of Fuel Pumps}

At the same time that the NYSERDA-funded field study of ULS fuel oil in test homes was underway, a laboratory study was being conducted at BNL concurrently to evaluate the operation of fuel pumps using ULS heating oil. These laboratory tests were conducted by Roger McDonald who also collaborated with the Energy Research Center on the field demonstration of ULS heating oil in homes. An overview of these lab test findings are presented here.

The goal of the BNL Laboratory Testing of Ultra-low Sulfur Heating Oil was to evaluate the energy, environmental and economic implications of ultra-low sulfur heating oil for the oilheat industry and consumers in New York State. The project included study the environmental benefits of ultra-low sulfur heating oil in reducing gaseous and particulate emissions; determine the technical feasibility of using ultra-low sulfur heating oil in existing-oil-fired heating systems. This included issues related to fuel compatibility, mixing, and storage stability, and evaluate economic costs and supply availability of ultra-low sulfur heating oil for oilheat customers in New York State. 
A brief description of the oil pump tests procedures carried out at BNL follows. Residential fuel oil pumps were tested in the lab during long term cycling under realistic conditions. The pumps were installed in oil burner chassis frames and powered by oil burner motors. The oil was pumped in a single pipe arrangement and the fuel is sprayed through a conventional oil burner nozzle at 100-140 pounds per square inch pressure. The fuel quantity was approximately 2 and a half gallons and it was sprayed into a fuel reservoir and recycled backed to the pump under test. Pump operation was controlled by a cycle timer that turned the motor and pump on for ten minutes and then off for ten minutes, and then repeated this cycle for the duration of the tests.

The BNL laboratory test program of fuel oil pumps continued for more than two years and the key results from progress reports are summarized in this section is based on Progress Reports from the lab tests. More detailed information can be obtained from monthly progress reports of the BNL Lab test program for ULS heating oil that was also funded by NYSERDA.

A BNL Lab test summary report from October 23, 2009 presented the following results. Lubricity tests indicated that that the ULS diesel samples presented no concern with meeting the minimum required levels of lubricity for diesel fuels. Further, there is no lubricity requirement for heating oil. The results of the tests performed indicated that while all fuel samples satisfied the minimum requirement, the poorest fuel tested with regard to lubricity was the sample of normal ASTM No. 2 fuel used for comparison purposes. A Technical Advisory Group was established for the lab and field studies and agreed that a seal lifetime of 7,000 hours would be considered acceptable for the ULS heating oil in conventional oil burner pumps.

The two primary pump designs under consideration used elastomeric lip seal designs one made from Viton (brown seal) and one made from Nitrile (Black seal) materials. The two pumps with Viton seals that were evaluated in the lab both failed to operated for 7,000 hours without leakage. One failed after 3,720 running hours. The failure resulted in several fluid ounces of fuel leakage into the secondary containment in the lab. Figure 5-25 illustrates the condition of the viton seal upon failure. The second pump exhibited a minor leak at 3396 running hours but it was getting worse with time. The test was terminated because the same type of seal deterioration observed with the first pump using a Viton seal was evident. Pumps using the brown colored Viton seals were not commonly used in oil burner pumps except for a brief time in the early 2000's, and do not represent the majority of pump seals that are currently in the field. 


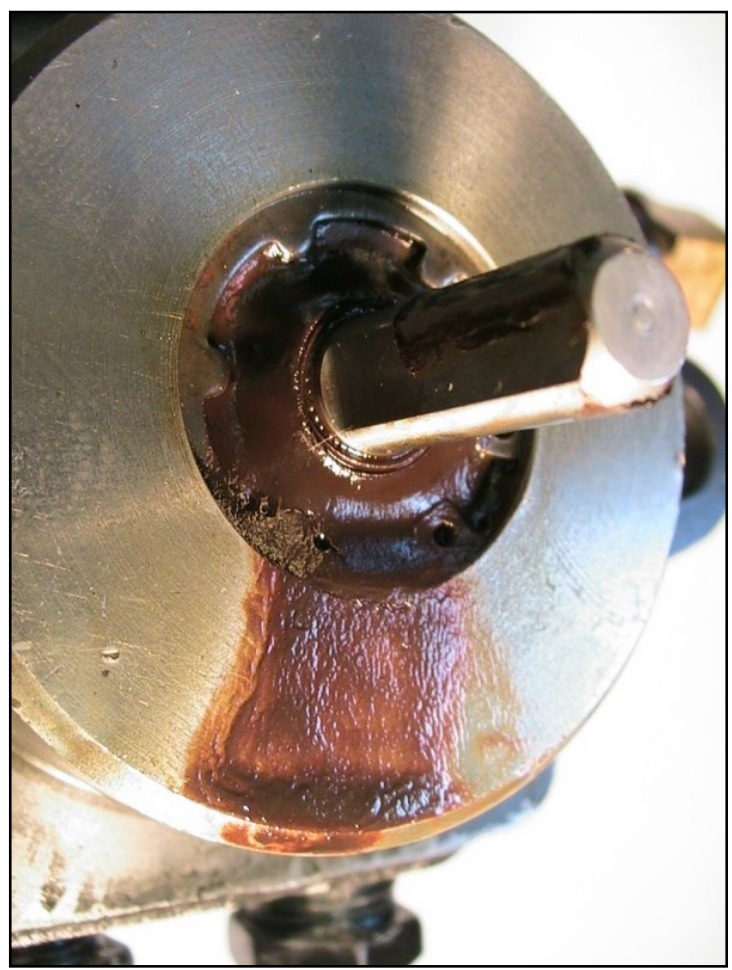

Figure 5-25. Oil pump with Viton seal failure

The conventional and more commonly used material of choice for the last several decades has been Nitrile (black material) that is used to make the fuel pump lip seals.

One additional oil burner fuel pump design that uses a carbon face seal was also tested and did not show any signs of leakage. The BNL Progress Report indicated that the Viton seal design is not recommended when using ULS fuel based on lab test results, and other tests of pumps using a Nitrile seal lip seal were conducted.

A summary of BNL Lab test progress report from March 12, 2010 follows. BNL continued to test oil burner pumps of various different makes using ULS heating oil in the accelerated endurance tests. The ULS fuel being used in these tests was checked and verified to make sure it satisfied the minimum lubricity requirement as stated in ASTM D-975 for diesel fuels. BNL obtained samples of the most commonly sold pumps made for use on oil burners for its testing. In all, three different seal materials were represented including Viton lip seals, Nitrile lip seals, and Carbon face seals. The Nitrile lip seal is the one most frequently used and represent an estimated 85 percent of all existing residential fuel pump seals. 
On average an oil burner operates for about 1,000 hours per year, and the accelerated testing protocol used in the lab requires roughly 20 months to reach 7,000 hours of operation is considered as passing the test. The tests are summarized in the Table that follows.

\begin{tabular}{|c|c|c|c|}
\hline \multicolumn{4}{|c|}{ Table 2 Oil Pump On-off Cyclic Indurance Testing } \\
\hline Pump & Seal Design & Hours & Status \\
\hline 1 & Viton Lip Seal & $\mathbf{3 , 3 9 6}$ & Failed \\
\hline 2 & Viton Lip Seal & $\mathbf{3 , 7 2 0}$ & Failed \\
\hline 3 & Carbon Face Seal & $\mathbf{7 , 5 1 2}$ & Passed \\
\hline 4 & Nitrile Lip Seal & $\mathbf{6 , 6 0 0}$ & Failed \\
\hline 5 & Nitrile Lip Seal & 5,988 & Ongoing \\
\hline 6 & Nitrile Lip Seal & 5,652 & Ongoing \\
\hline
\end{tabular}

The two oil pumps with viton seals that were tested (pumps 1 and 2) both failed after 3396 hours and 3720 hours of operation respectively. The carbon face seal operated for 7,512 hours, when testing stopped and passed the test bases on the 7000 operating hour criterion. One Nitrile seal pump seal leaked after 6,600 hours of operation.

Other components in a residential oil installation contain elastomeric materials. One example is the oil safety valve (OSV) used in many but not all homes. The OSV prevents the fuel siphoning from the oil storage tank when the burner is located below the fuel level in the tank. If a line leaks or is broken this would prevent the fuel from spilling from the tank. This valve is designed with a Buna-N diaphragm which may also be susceptible to early failure due to constant exposure to ULS fuel. Oil filters are used in most oil heated homes and are another potential concern as most filters depend on an elastomeric o-ring to seal the unit. Fortunately, these filters are changed out periodically and new seals can be used whenever the filter is replaced. More testing is needed to evaluate the compatibility of these components with ULS heating oil.

BNL investigated at other heating system components and has found no other issues associated with the storage or burning of ULS fuel. The fuel mixes very readily with conventional fuel oil. Combustion testing with ULS fuels was very successful. There are no concerns with regard to the normal operation of the oil burner safety controls. These controls sense the presence of a flame during normal combustion by using a Cadmium sulfide detector cell during operation. These "CAD" cells behaved normally throughout 
all of the burner tests. Also, long-term oxidative stability during storage also appears to be slightly improved based on available literature.

A summary of BNL's Final Monthly Laboratory Test Report including some excerpt from the report follows, and shows end results of the lab evaluation of oil burner pump seals when using ULS heating oil.

\begin{tabular}{|c|c|c|c|c|c|c|}
\hline $\begin{array}{c}\text { Pump } \\
\text { Identification } \\
\text { number labeled }\end{array}$ & \multicolumn{2}{|c|}{ ULS } & \multicolumn{2}{c|}{ ULS B5 } & \multicolumn{2}{c|}{ no.2 oil } \\
\cline { 2 - 7 } & Pass & Fail & \multicolumn{2}{|c|}{ Pass $\quad$ Fail } & Pass & Fail \\
\hline Nitrile Seal & $5 \& 6$ & 4 & 8 & $7 \& 10$ & 12 & \\
\hline Viton Seal & & $1 \& 2$ & & & & \\
\hline Carbon Face Seal & 3 & & 9 & 11 & & \\
\hline
\end{tabular}

Table 1: Success and failure of pump cycling with respect to fuel and seal type

\begin{tabular}{|r|l|}
\hline $\begin{array}{l}\text { Pump } \\
\text { Number }\end{array}$ & Mode of Failure \\
\hline 1 & Moderate visible leak at seal \\
\hline 2 & Major Leak observed at seal \\
\hline 4 & Major Leak observed at seal \\
\hline 7 & Complete seal failure \\
\hline 10 & Complete seal failure \\
\hline 11 & Pump shaft seized \\
\hline
\end{tabular}

Table 2: Mode of failure of failed pumps

The pump cycling tests included three fuel types and three different pump seal designs utilizing Viton, Nitrile, and a mechanical carbon face seal. Table 1 above summarizes the twelve pumps by pass or fail as well as categorizing each pump identification number with the pump seal material and the fuel type. The criteria used for successful operation was completing 7,000 hours of cyclical operation without severely leaking/dripping, or seizing. It should be noted that certain pumps did present a slight weep at the seal during the cycling operation. These observations are all documented 
in the Oil Pump Seal Testing Observations that follow. Table 2 summarizes the mode of failure for the 6 pumps that did not meet 7,000 hours of cyclical runtime.

The 12 pump tests at BNL showed results in which both of the viton seal pumps failed and one of the three Nitrile pump seals also did not reach the 7,000 hour leak-free goal while operating with ULS fuel oil. Additionally, the carbon face seal pump passed with ULS. The six Nitrile seal pumps were evaluated on ULS fuel and ULS B5 (5\% Biofuel) blends, and three failed on ULS or ULS B5 fuels.

\section{iii. Field Demonstration Results Related to Fuel Pumps Using ULS Heating Oil}

The information presented in this section summarizes fuel pump seal seepage or leakage and fuel pump replacements in the field based on service records for the houses in both the ULS and \#2 fuel oil control groups. It is also based on review of the Annual Boiler Inspection and Burner Tune-up Checklist reports that were completed by service technicians during this demonstration project. These findings are consistent with the laboratory tests related to potentially shortened pump seal lifetimes when using ULS heating oil.

The service records that are summarized in a prior section of the report for the ULS test group and the Control Group houses were nearly the same. One difference was the number of fuel pump replacements - three for the ULS group, and none for the \#2 fuel oil control group. In addition, review of the Annual Boiler Inspection and Burner Tuneup forms showed two additional fuel pump replacements for the ULS group, for a total of five fuel pump replacements over the field test program. A summary of these cases follows.

\section{Case 1. Fuel Pump Replacement}

Fuel: $\quad$ Ultra Low Sulfur Heating oil

Boiler : $\quad 45$ year old steel fire-tube

Burner: $\quad$ Flame retention with newer replacement oil pump

Pump Seal: viton (brown)

Date: $\quad$ Replaced with new fuel unit on April 20, 2010

Notes: $\quad$ Seal blown - needs replacements 


\section{Case 2. Fuel Pump Seal Leak}

Fuel: $\quad$ Ultra Low Sulfur Heating oil

Boiler : $\quad 30$ year old Cast Iron

Burner: $\quad$ Flame retention (newer)

Pump Seal: viton (brown)

Date: $\quad$ Replaced with new fuel unit on April 9, 2009

Notes: $\quad$ Pump seal leak found and fuel pump was replaced.

Pump that leaked had been installed on March 26, 2007 - two years old Viton seal leaked only one year after ULS fuel deliveries were started

\section{Case 3. Fuel Pump Lock Up}

Fuel: $\quad$ Ultra Low Sulfur Heating oil

Boiler : $\quad 30$ year old Cast Iron

Burner: $\quad$ Flame retention (newer

Pump Seal: Unknown

Date: $\quad$ Replaced with new fuel unit on June 23, 2010

Notes: $\quad$ Replaced A pump

\section{Case 4. Fuel Pump Seal Leak}

Fuel: $\quad$ Ultra Low Sulfur Heating oil

Boiler : $\quad 10$ year old Cast Iron

Burner: $\quad$ Flame retention

Pump Seal: Unknown

Date: $\quad$ Replaced with new fuel unit on September 9, 2010

Notes: $\quad$ Pump seal leak found and fuel pump was replaced.

\section{Case 5. Fuel Pump Seal Leak}

Fuel: $\quad$ Ultra Low Sulfur Heating oil

Boiler : $\quad 50$ year old Cast Iron

Burner: $\quad$ Flame retention (newer)

Pump Seal: viton (brown)

Date: $\quad$ Replaced with new fuel unit on March 13, 2009

Notes: $\quad$ Pump seal leak found and fuel pump was replaced 
Four of the five cases requiring fuel pump replacement were for fuel leakage, and one case was fuel pump lock-up on an older pump. Three of the four pumps using ULS heating oil that were replaced due to fuel leakage had a viton (brown) pump seal. This strongly suggests a potential fuel compatibility issue with the viton seal when using ULS heating oil. Case 2 is particularly of interest because a new fuel pump with a viton seal had been installed in March 2007. ULS heating oil delivery began in 2008, and after only about one year of operation with ULS heating oil, the viton seal leaked and had the fuel pump was replaced. This shortened lifetime for the viton pump seal is consistent with BNL laboratory test results.

Although the sample size for the field study was small, the number of viton seal leaks suggests that these seals may not be compatible with the ULS heating oil. This finding is substantiated by laboratory testing at BNL. Therefore, it is recommended that when ULS heating oil is used in houses, that the pumps seal be inspected. If a brown viton seal is found, then the pump should be replaced with a unit that uses a Nitrile or carbon face seal that have been found to have longer lifetimes with ULS heating oil. Annual inspection of fuel pump seals is also recommended so that pumps with seal seepage can be replaced promptly. Additional testing of pump seals including the viton seals is needed to fully evaluate their compatibility with ULS heating oil.

\section{Summary}

An unexpected finding of both the laboratory tests and field demonstration of ULS heating oil was shortened lifetimes for some of the fuel pump lip seals, especially the brown seals that were made from viton. These seals exhibited some seal seepage earlier than conventional pumps materials during the accelerated testing at BNL. This was observed at a time that is equivalent to about 2 years of operation. ASTM tests of lubricity of ULS fuel sample using a High Frequency Reciprocating Rig (HFRR) found that the shaft seal weeping is apparently unrelated to lubricity as the ULS fuel passes these tests.

The fuel oil pumps that use Nitrile seals performed better than those with Viton seals with ULS heating oil, but some of these also exhibited somewhat shortened lifetime, but lasted longer than the viton seals. The fuel pump that was tested with a carbon face seal passed the tests and operated for more than 7,000 hours without fuel weeping or leakage with ULS heating oil. Pump seal inspection should be part of the annual burner check-up and whenever any service is performed on houses using ULS heating oil. One method for checking for seal leaks is to examine for wetness or drips at the bottom 
of the burner housing below the pump or at the weep hole that deigned to allow the oil to escape from the housing.

Further testing of all fuel oil pump seal materials including Nitrile, Viton, and carbon seals is strongly recommended as the widespread use of ULS heating oil is now underway. In addition, examination of the fuel pumps that were removed from the ULS test houses is recommended to determine seal condition, and the nature or cause of the fuel leakage that occurred. Once determined, actions can be taken to reduce fuel seepage when using ULS heating oil. Simply replacing the fuel pump with a unit that has a seal that is more compatible with ULS heating oil is a simple and relatively low cost option. The substantial air emissions improvements and reductions in cleaning cost by using ULS oil appear to outweigh any minor costs related to potentially equipment upgrades needed to address shortened fuel pump seal lifetimes when using ULS heating oil. 


\section{Benefits of ULS Heating Oil and Potential Barriers to Widespread Use}

Using Ultra-Low Sulfur (ULS) heating oil in homes and small commercial applications in place of conventional higher sulfur home heating oil containing on the order of 2,000 parts per million sulfur offers a number important advantages. These include: substantially reduced sulfur oxide emissions, reduced PM emissions, and reduced boiler and furnace cleaning costs due to much lower particulate and sulfate fouling deposits inside furnace and boiler heat exchangers. These benefits appear to be far greater than any potential obstacles to widespread use of ULS heating oil. This section of the report summarizes key advantages and it also discusses some potential obstacles to widespread acceptance of ULS heating oil.

\section{a. Environmental Benefits of ULS Heating Oil - Reduced Sulfur Oxides and PM}

Historically, the sulfur content of heating oil used in homes has been on the order of 0.5 percent or 5,000 parts per million based on ASTM limits, but has been as high as $1.0 \%$ $(10,000 \mathrm{ppm})$ in some oil heat states in the past. Figure 3-1 of this report shows the percentage of sulfur in home heating oil from 1987 through 2002, with a range of 0.12 to 0.28 percent with a mean value of approximately 0.20 percent which equals $2,000 \mathrm{ppm}$ sulfur. The laboratory test report for fuel used in the control group of this field indicate a value was 0.20 percent $(2,000 \mathrm{ppm})$. Therefore, the results of this project are expected to be representative of typical results in oil heated homes in the New York State and other oil-heated regions of the US.

Combustion of fuel oil containing sulfur produces sulfur oxides primarily in the form of Sulfur Dioxide $\left(\mathrm{SO}_{2}\right)$ which is released into the atmosphere with the flue gases. This is a criterion air pollutant that is controlled by the USEPA. In addition to being a primary air pollutant, sulfur oxides react with boiler and furnace heat exchangers to form sulfate fouling which requires regular cleaning of heat transfer surfaces by oil heat service technicians which is a time-consuming and costly process. BNL established a direct relationship between fuel oil sulfur content and fouling rates and a direct relationship between fuel sulfur content and PM production. PM is a second primary air pollutant, and a criteria pollutant identified by the USEPA. It also contributes directly to boiler and furnace fouling. 
Using ULS heating oil containing less than $15 \mathrm{ppm}$ Sulfur (0.0015 percent) lowers sulfur oxide emissions in the flue gas by more than 99 percent compared to heating oil with $2000 \mathrm{ppm}$ sulfur, and produces sulfur oxide emissions that are comparable to natural gas heating equipment. This is shown in Figure 6-1 which is based on BNL laboratory tests of sulfur oxide emissions and standard emission factors presented in USEPA Publication AP-42 (ref 3).

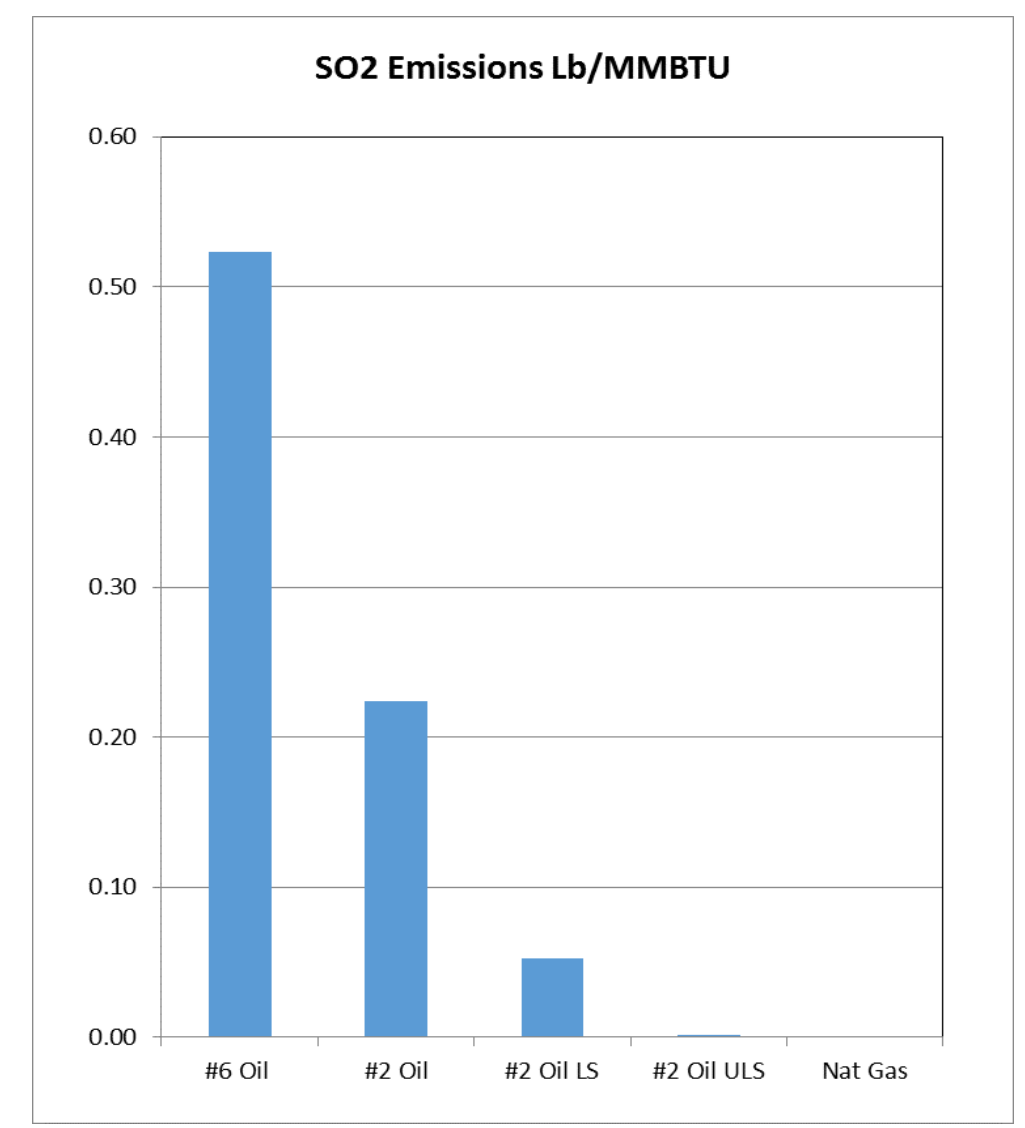

Figure 6-1. Sulfur Oxide Emissions for Various Fuels

The highest $\mathrm{SO}_{2}$ emissions in the chart are for \#6 heating oil with a sulfur content of 0.5 percent followed by \#2 oil with 0.2 percent sulfur. \#2 Oil LS is Low Sulfur heating oil with 0.05 percent $(500 \mathrm{ppm})$ sulfur. The lowest emissions are for ULS heating oil and natural gas burners that are both near zero. 
Similarly, Figure 6-2 shows that particulate matter (PM) emissions are linearly related to fuel sulfur content, and PM emissions also approach zero as the fuel oil sulfur content is lowered toward zero as it is in ULS heating oil. Laboratory testing conducted by BNL in collaboration with the USEPA and published in 2009 (Ref 14) compares the PM emissions for range of home heating fuels including ULS heating oil. While PM emissions vary for different boiler/burner combinations, the BNL report shows a typical value for oil burners using ULS heating oil of 0.00006 pounds of PM emissions for every million BTU of fuel oil consumed. This is 50 times less than conventional heating oil with 2000 ppm sulfur. This is shown in Figure 6-2 which is based on BNL laboratory tests of PM emissions (ref 14) and USEPA publication AP-42 (ref 3).

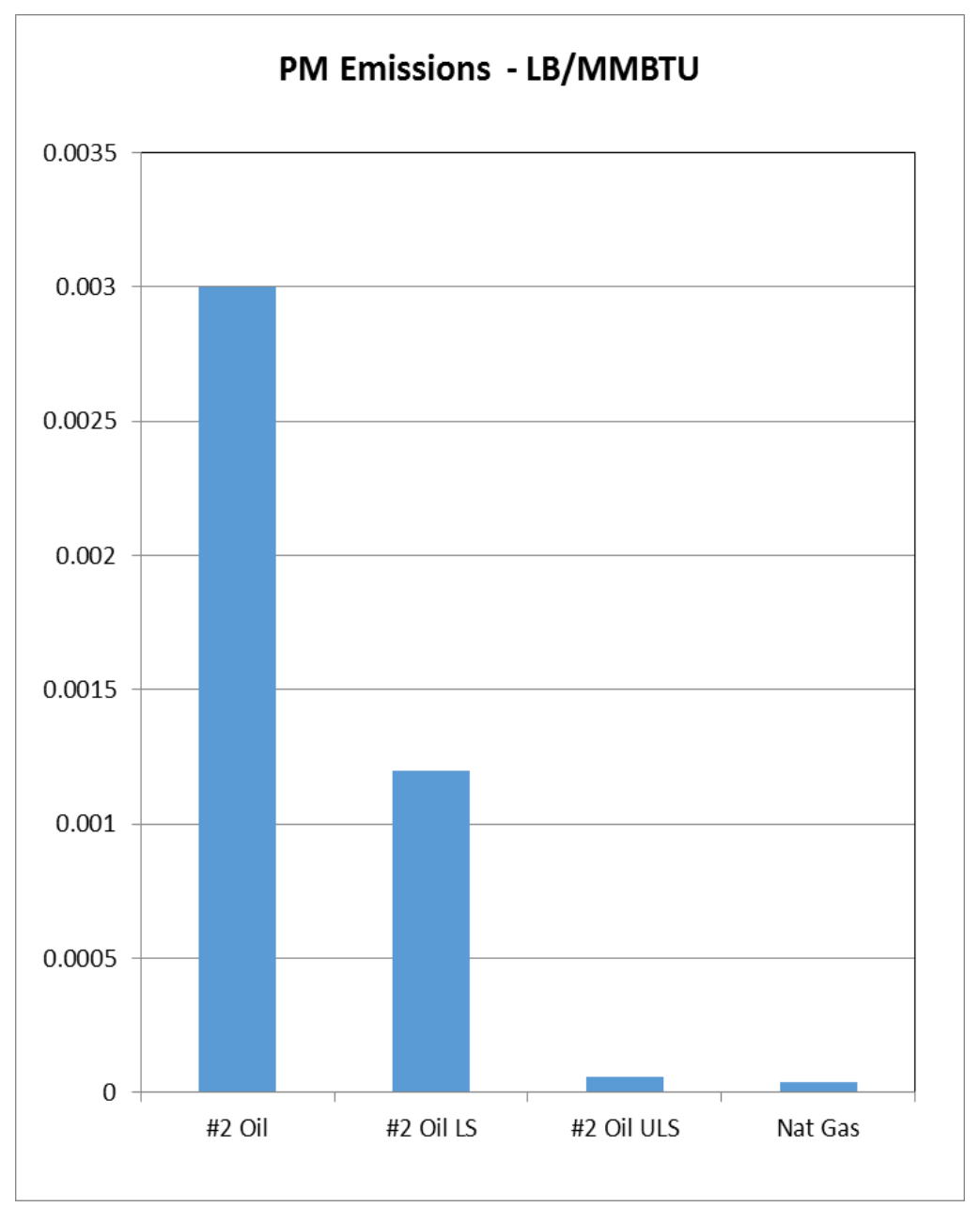

Figure 6-2. PM Emissions for Various Fuels 
The highest PM emissions in the chart are for \#2 heating oil with a sulfur content of 0.2 percent (\#6 oil is not shown in this chart). \#2 Low Sulfur heating oil with 0.05 percent (500 ppm) sulfur is next, and the lowest emissions are for ULS heating oil and natural gas burners, both with near zero emission levels.

The environmental benefits of using ULS heating oil in place of higher sulfur conventional fuel oil is clearly demonstrated by Figures $6-1$ and $6-2$ which is based on work conducted by BNL and the USEPA.

\section{b. Reduced Costs for Oil Heating Equipment Cleaning}

The reductions in Sulfur Oxide and PM air emissions by using ULS heating oil have another important benefit which is reduced fouling rates of oil-powered boiler and furnace heat exchangers, producing lower equipment cleaning costs. Research over the past 15 years at Brookhaven National Laboratory with Low Sulfur and ULS heating oil has demonstrated substantial reductions in fouling rates with the lowest sulfur heating fuels. Figure 3-4 produced by BNL shows residential boiler fouling and corrosion rates for a typical heating season as the sulfur content of the fuel is changes. Note that at $1.08 \%$ sulfur there is substantial accumulation of boiler scale over one heating season. In contrast as the sulfur level is reduced to $0.04 \%$ ( $400 \mathrm{ppm}$ sulfur) the following rates decrease dramatically. For comparison, current heating fuels are often restricted to 0.2 $\%$ to $0.3 \%$ sulfur which is shown in the bottom left photo in Figure $3-4$.

Clearly, lowering sulfur content of the heating fuel by using oil ULS heating oil with $0.0015 \%$ Sulfur substantially lowers corrosion and fouling rates of boilers, and extends boiler heat exchanger cleaning intervals. This is an important operational and environmental improvement. ULS heating oil now is required for use in New York State starting in the year 2012. ULS heating oil produces fouling rates that are even lower than the upper left photo shown in Figure 3-4 which is $0.04 \%$ (400 ppm) sulfur. Case studies 1 through 10 shown in Chapter 6 of this report clearly demonstrate that reduced fouling rates occur with ULS heating oil compared to higher sulfur fuels.

The prior NYSERDA-funded report of the Low Sulfur (LS) heating oil demonstration project (ref 13) addressed in detail the cost benefit of using Low Sulfur (500 ppm) in terms of reduced costs for cleaning the heat transfer surfaces of oil boiler and furnaces compared to higher sulfur heating oil. It showed potential service cost savings by extending cleaning intervals as a function of original sulfur content of the fuel for a range of hourly labor rates. These findings are applicable to ULS heating oil also, with even longer potential interval between cleanings and larger savings. 
We applied these findings for LS heating oil to ULS heating oil with a 20 percent increase for the lower PM and sulfate emissions with ULS heating oil compared to LS oil. Annual cleaning cost savings in New York State range from $\$ 54$ million to $\$ 108$ million, for replacing fuel oil with 2000 ppm sulfur content with ULS heating oil statewide. Nationwide, the potential annual cost savings are $\$ 240$ million to $\$ 470$ million, for service costs ranging from $\$ 50$ to $\$ 100$ per hour. The increased cost of the ULS heating oil is not considered in this analysis as Ultra-Low Sulfur heating oil use is now required in New York State.

Heating equipment cleaning costs by using ULS heating oil can be reduced by hundreds of millions of dollars a year by extending the intervals between cleanings. This has been demonstrated by the research at BNL and by the current and prior NYSERDA-funded demonstration projects. Information transfer to heating oil companies and oil heat customers is needed, however, to fully achieve these potential savings.

\section{c. Potential Barriers to Widespread Use of ULS Heating Oil}

Potential obstacles to use of ULS heating oil were identified during this demonstration project that could slow down widespread acceptance of ULS in the field. None of these appear to be insurmountable, but additional work is needed to assure long-term successful use of ULS heating oil in homes and small commercial applications. A brief summary follows.

\section{Added Cost for ULS heating Oil}

At the start of the project, the price differential for ULS heating oil compared to higher sulfur residential heating oil was in the range of $\$ 0.20$ to $\$ 0.40$ a gallon, but the fuel was not readily available for residential use at that time. This price differential has appeared to narrow over time as residential ULS heating oil use has increased. In addition, heating oil prices have been rising and falling over the past few years which makes direct comparison with ULS heating oil more difficult. Most importantly, however, New York State mandated the use ULS heating oil in 2012, which eliminates price differentials between ULS and higher sulfur heating from the discussion, and several other oil heat states are also requiring ULS heating oil use within the next several years. It appears that price differentials are not a major obstacle to widespread use of ULS heating oil at this time. 


\section{Fuel Pump Seal Compatibility}

An unexpected finding of this field demonstration project is potentially shortened lifetimes on some oil burner pump seals which may occur with ULS heating oil when compared with higher sulfur heating oil. This was observed during the field study and verified by laboratory testing at BNL. This could require more frequent oil burner pump replacement especially with the Viton pump seals, and it needs to be fully evaluated.

The precise mechanism for the reduced pump seal lifetime with ULS oil is not understood at this time. Additional testing and research is needed to fully evaluate and investigate the compatibility of conventional oil pump seals with ULS heating oil for a full range of seal materials and designs to identify the scope of the problem and develop solutions. For example, carbon face seals that were tested at BNL did not appear to be impacted and modified lip seal materials and designs can reduce the impact of ULS fuel oil on seal lifetimes.

The fuel pump and seal are replaceable parts on oil heat systems and are replaced as needed as part of normal service. Fuel pump replacement is a moderately low-cost modification, and it is outweighed by the environmental and cost savings benefits produced by conversion to ULS heating oil. Therefore, in the long term, fuel pump materials compatibility with ULS heating oil should not pose a serious problem related to expanded use of ULS heating oil, but additional testing, seal development, and demonstration is needed.

\section{Education and Training Needs}

Expanded information transfer to all interested parties of the benefits of ULS heating oil is needed to improve market acceptance of the fuel. The environmental and cost savings benefits are not fully understood by users at this time. Targets for education outreach include homeowners, fuel marketers, oil heat service groups, and policy makers at all levels of government. Recent work by NYSERDA clearly demonstrates that ULS heating oil is an environmental attractive option for homeowner with sulfur oxide and particulate matter emissions that are now comparable to natural gas. In addition, the use of ULS heating oil blended with biofuel can reduce the global warming potential of home heating oil lower than any other home heating fuel. However, many homeowners and fuel marketers and service technicians are not aware of these recent findings. 
NYSERDA has served an important role in New York State and all heat regions by supporting oil heat research, and can include this information in future outreach programs for Ultra Low Sulfur fuel oil and biofuels blends. 


\section{References}

Ref 1. Heating Oils, 2003, Cheryl L. Dickson, August 2003, NGMS-221 PPS 2003/4 Note: Northrop Grumman Mission Systems was formerly TRW Petroleum that was formerly the National Institute for Petroleum and Energy Research (NIPER) funded by the American Petroleum Institute and the US Department of Energy - Energy Information Administration.

Ref 2. Proceedings of the 2002 National Oilheat Research Alliance technology Symposium, BNL report 52670, August 2002, Paper No. 02-13, Assessing $\mathrm{PM}_{2.5}$ Emissions from Distillate Fuel Oil Heating, S. Win Lee, I He, T. Herage, E. Kelly and B. Young, CANMET Energy Technology Center-Ottawa, Natural resources Canada

Ref 3. AP 42, Fifth Edition, Compilation of Air Pollutant Emission Factors, Volume 1: Stationary Point and Area Sources, Chapter 1: External Combustion Sources, United States Environmental Agency, Table 1.3-1 Criteria Pollutant Emission Factors for Fuel-oil Combustion, Table 1.3-2 Condensable Particulate Matter Emission Factors for Fuel-Oil Combustion

Ref 4. Proceedings of the 2002 National Oilheat Research Alliance (NORA) Technical Symposium, BNL Report 52670, August 2002, Paper No. 02-10, Factors Affecting Oil Burner NOx Emissions, Victor Turk, R.W. Beckett Corporation, August 19-20, 2002.

Ref 5. Fouling of Heat Transfer Surfaces in Domestic Oil-Fired Heating Boilers, BNL 64833, T. Butcher, W.L. Litzke, Y. Celebi, Brookhaven National Laboratory and S. W. Lee CANMET Energy Technology Center-Ottawa, Natural resources Canada (Reprinted within BNL 52558 as part of the Proceedings of the 1999 Oil Heat Technology Conference and Workshop, April 1999).

Ref 6. Letter to ASTM Subcommittee EW Chairman, from Vic Turk of the RW Beckett Corporation, dated December 2, 1999, regarding proposed revisions to fuel oil specifications, and supporting engineering analyses of the impact on heating equipment cleaning intervals of lower sulfur oil.

Ref 7. State Energy Data Report, DOE/EIA-214(99), May 2001.

Ref 8. Oilheat Advantages Project - Engineering Analysis and Documentation Report by J.E. Batey and R. Hedden, Copyright 1995 by the Oilheat Manufacturers Association

Ref 9. Proceedings of the 2002 National Oilheat Research Alliance (NORA) Technology Symposium, BNL report 52670, August 2002, Paper No. 02-03, Maximizing Fuel Oil Quality and Heating System Performance, Wai Lin Litzke, Brookhaven National Laboratory and associated presentation viewgraphs provided at the NORA Technology Symposium at the Oilheat Visions Conference, August 19-20, 2002 
Ref 10. Litzke, W. L., Butcher, T. A., and Celebi, Y. Fuel sulfur and boiler fouling Proceedings of the 1995 Oil Heat Technology Conference and Workshop at BNL, March 1995. R. McDonald ed. BNL Report 52475 (April 1995).

Ref 11. Butcher, T., Lee, S.W., Celebi, Y., and Litzke, W. Fouling of heat-transfer surfaces in oilfired boilers for domestic heating, Journal of the Institute of Energy, v. 70, pp 151-159, December 1997.

Ref 12. US Department of Energy, Weekly Petroleum Status Report, Table 15, page 27, May 2004.

Ref 13. Batey, J.E., and McDonald, R.J., Low Sulfur Home Heating Oil Demonstration Project Summary Report, funded by the New York State Energy Research and Development Authority, BNL-74956-2005-IR, June 2005.

Ref 14. Roger J. McDonald, Evaluation of Gas, Oil and Wood Pellet Fueled Residential Heating System Emission Characteristics, Brookhaven National Laboratory, December 2009. 


\section{Appendix A. Description of Energy Tracking \& Control Method.}

Energy Tracking \& Control (ETC) is a software-based system that relates fuel use to outdoor air temperature by incorporating both outdoor air temperature and time into a newly developed fuel use factor. ETC is different from other calculations in that use simple heating degree days that are not normalized in time. The ETC method produces fuel use tracking accuracy of 99 percent - far superior to conventional heating degree day-based methods that are often used to evaluate fuel savings. The plots that follow compare the accuracy of the ETC and conventional Degree Day methods for tracking fuel use.

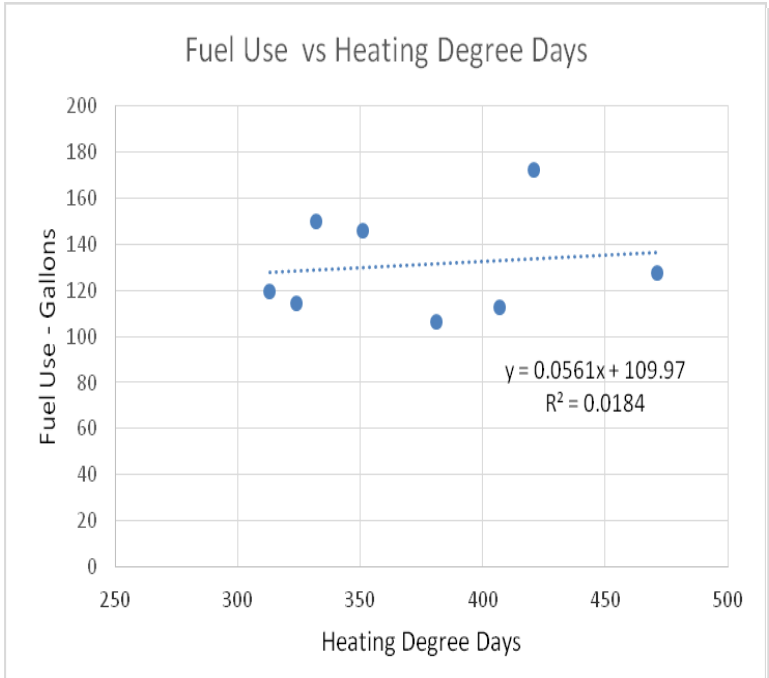

Figure 1a. Degree-Day Method

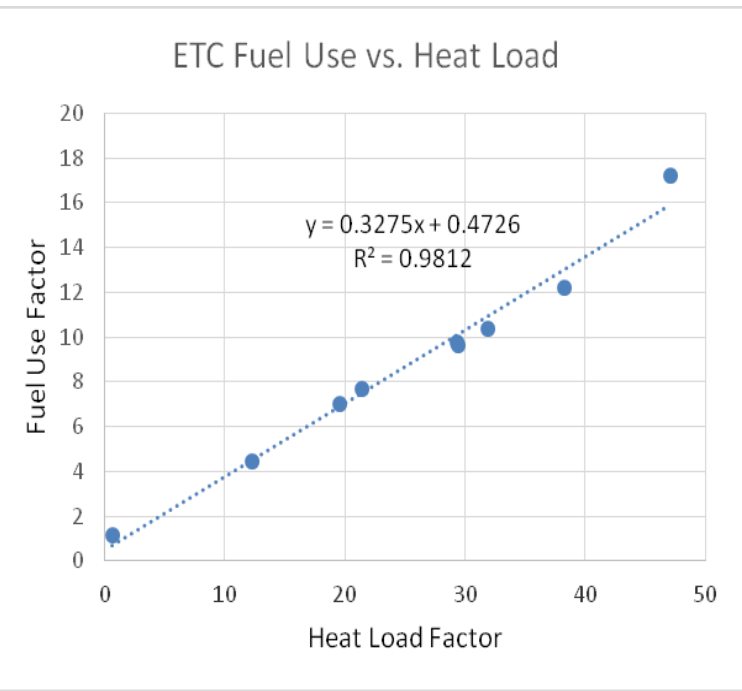

Figure 1b. ETC Method

Each point on the plots is a single fuel delivery.

For the Degree-Day method on the left, the x-axis shows the elapsed heating degree days since the last fuel delivery and the $y$-axis shows the gallons of fuel delivered. There is substantial scatter in the degree day plot on the left, indicating poor precision in predicting fuel use as a function of degree days. For example, at 410 heating degree days, the fuel use varies from 113 to 172 gallons for conventional methods. This is an error range of more than 50 percent.

The plot on the right demonstrates the superior accuracy with the ETC method. The Heat Load Factor in the ETC plot is a modified degree day (normalized in time), and the Fuel Use Factor is converted to gallons of oil. The ETC plot on the right has minimal 
scatter and predicts fuel use with an uncertainty of 1 percent. This is an typical uncertainty of only 5 to 10 gallons of oil per delivery. The relationship between heat load and fuel oil use is much more precise using the Energy Tracking and Control method which enable precise measurement of fuel savings after energy upgrades are installed in each house.

The line on the ETC plot on the right accurately predicts fuel use for each house and a characteristic equation is developed for that house. If the energy efficiency is improved by installing new heating equipment or building upgrades, a new equation and line is produced after the fuel use and outdoor air temperatures are re-evaluated using ETC.

An important application for ETC is accurate measurement of fuel savings after energy efficiency improvements are installed in homes and buildings. This includes new oil burners, new boilers or furnaces, improved controls, and building upgrades such as thermal insulation, and any other energy conservation option that impact fuel use. We will also test the benefits of using the ETC method for natural gas heating systems with energy upgrades.

\section{ETC Software Compared to Heating Degree Days - Side-by-Side}

ETC Software accurately measures energy savings by energy efficiency technology while Heating Degree Day analysis cannot. After a baseline ETC profile similar to the plot in Figure $1 \mathrm{~b}$ is calculated for a house, any energy-saving measure that is installed will change this fuel use profile. By comparing the new ETC profile with the old fuel use, actual fuel savings in that house is accurately measured. The uncertainty in this measurement is on the order of one percent. This is not possible with simple Heating Degree Day analysis because of the high scatter that is observed (see Figure 1a). The uncertainty in heating Degree Day profiles is on the order of 30 percent or higher. This is greater than the savings that is being evaluated. Therefore Heating degree day analysis cannot accurately determine fuel savings after energy-savings improvements are made.

The example case that follows show fuel oil savings measured by both the ETC and Heating Degree Day method for the same new boiler, new oil burner, and a new high efficiency condensation oil furnace. The accuracy of these measurements using ETC is within one percent and much higher than the uncertainty of the heating degree day method - which in many cases is higher than the fuel change being evaluate. 
Example Case. New Oil Boiler

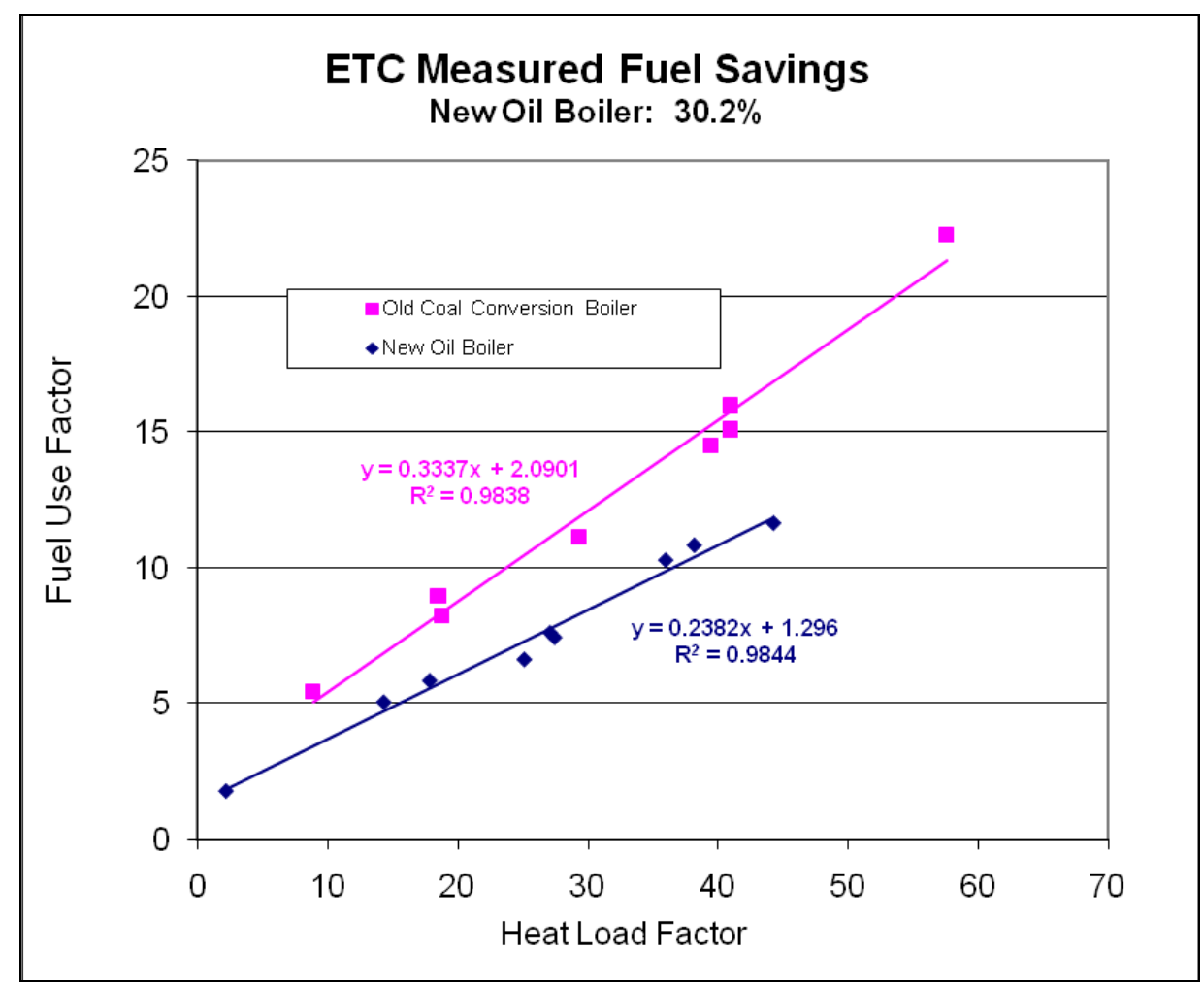

\section{ETC measurement of New Boiler savings}

In this case a new oil boiler was installed in a house to replace an outdated originally designed to burn coal. The ETC method was used and the upper line which is the fuel use profile for the older oil boiler before replacement and it has an R-Squared 0.9938 . This is an uncertainty of about one percent. The lower line is the fuel use profile after the new oil boiler was installed and again has a high $\mathrm{R}$-Square value of 0.9844 .

A fuel savings of 30.2 percent was measured with an uncertainty of less than one percent. ETC allows fuel savings for old outdated heating equipment to be measured with a high level of accuracy for the first time.

In contrast the plot that follows shows the same data that were analyzed using heating degree days. The upper line is the best fit for the delivery data before the new boiler was installed and the lower line was after the oil boiler. 


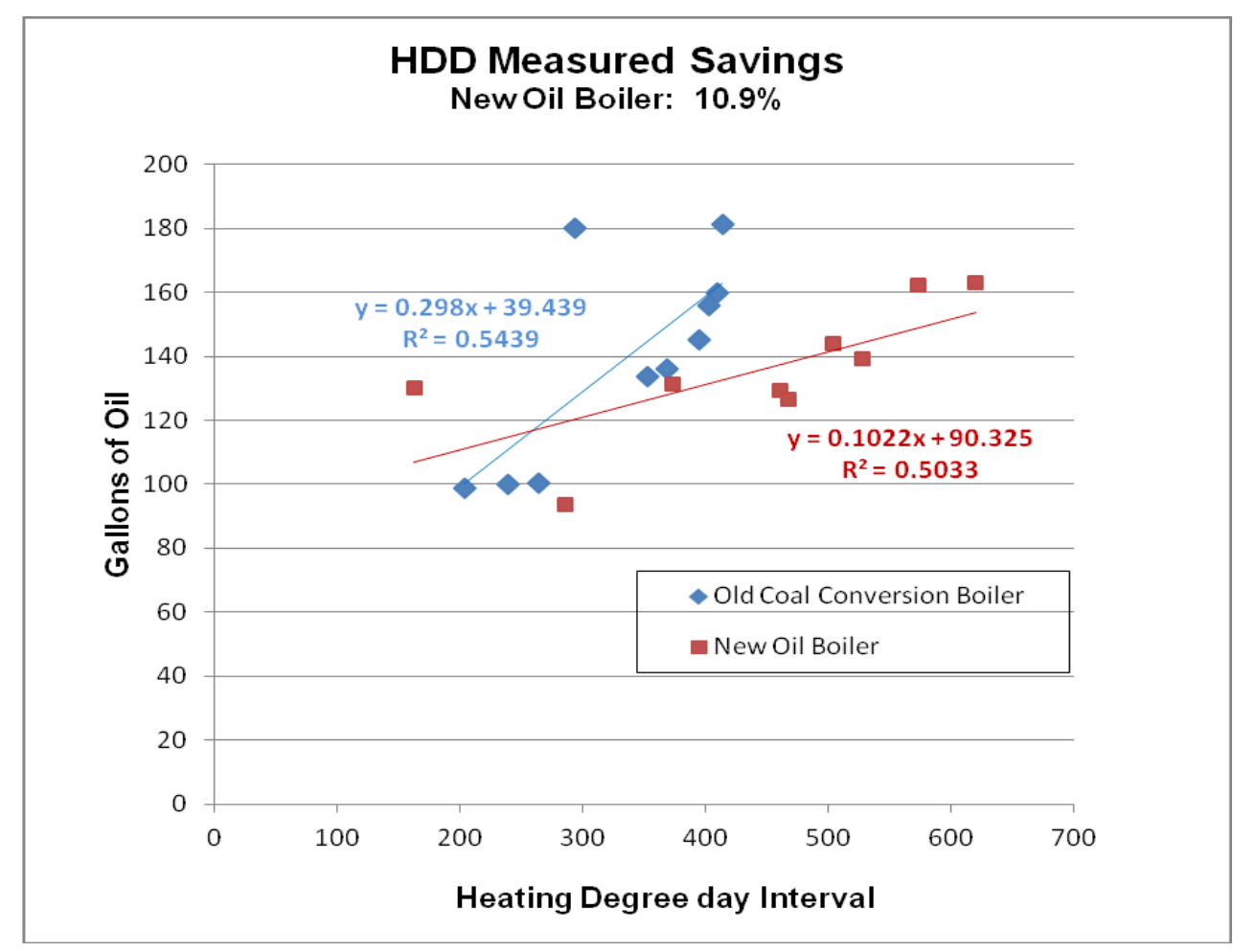

Degree day measurement of New Boiler savings

The R-Square values are 0.5439 and 0.5033 which indicate poor data fit and very high levels of uncertainty for these data sets. This is again evident from the wide scatter that is observed for these data points. The predicted savings using the heating degree day comparison is 10.9 percent, but for these very low R-Squared values. In contrast, the ETC-measured savings are 30.2 percent. Therefore, the heating degree day approach cannot be used to accurately or reliably measure the savings in this case.

Clearly, the Heating Degree Day analyses cannot be used effectively to measure savings after energy saving building and heating equipment options are installed. However, The Energy Tracking and Control method permits highly accurate measurement of energy savings in the field. The cost of the ETC method is substantially less than fully instrumenting houses and operating them for two years.

\section{Recent Results of ETC Field Measurements}

The ETC method has been used over the past several years to begin to measure energy savings in the field. A pilot study was successfully completed last year under a grant from the US Department of Energy to measure energy savings by the 
weatherization and heating equipment replacement programs. ETC was applied to analyze fuel oil use before and after each improvement and then the fuel savings were calculated. Measured savings included building insulation and weatherization cases, and the installation of new oil boilers and furnaces. A second study was completed for a major manufacturer of thermal insulation and included ETC measurement of fuel savings for wall and ceiling insulation. A third study is currently underway with Brookhaven National Laboratory through funding supplied under NYSERDA PON 1023 to measure fuel oil savings in the field for high efficiency boilers that were evaluated in the laboratory by Brookhaven National Laboratory.

These three case studies demonstrate the high precision and accuracy of the ETC method for accurately determining fuel savings in the field. They also show that actual savings are higher than expected based on AFUE evaluation, and can produce economically attractive payback periods especially as fuel prices continue to rise. A primary objective of the proposed work is to accurately measure fuel savings in the field for a range of energy-saving options, and then to perform payback analyses for each case.

The ETC field tests will also measure the range of savings produced by high efficiency boilers that includes the efficiency of the old boiler and other field-related variables. This compliments the laboratory testing at Brookhaven by showing actual savings for a range of field conditions. In this way ETC can help to characterize savings for high efficiency boilers for a full range of field conditions. Since the system is software-based many systems can be evaluated at a cost that is much lower than fully instrumenting test houses to measure savings. 
Appendix B. Laboratory Test Results for Normal S Heating Oil

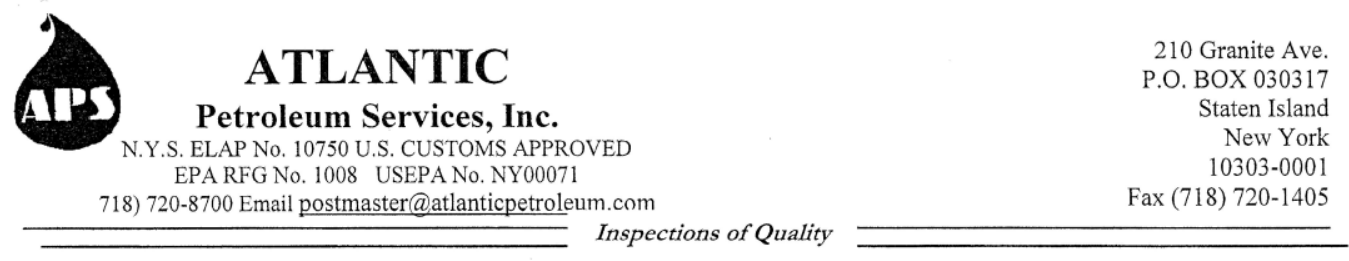

\section{Certificate of Analysis}

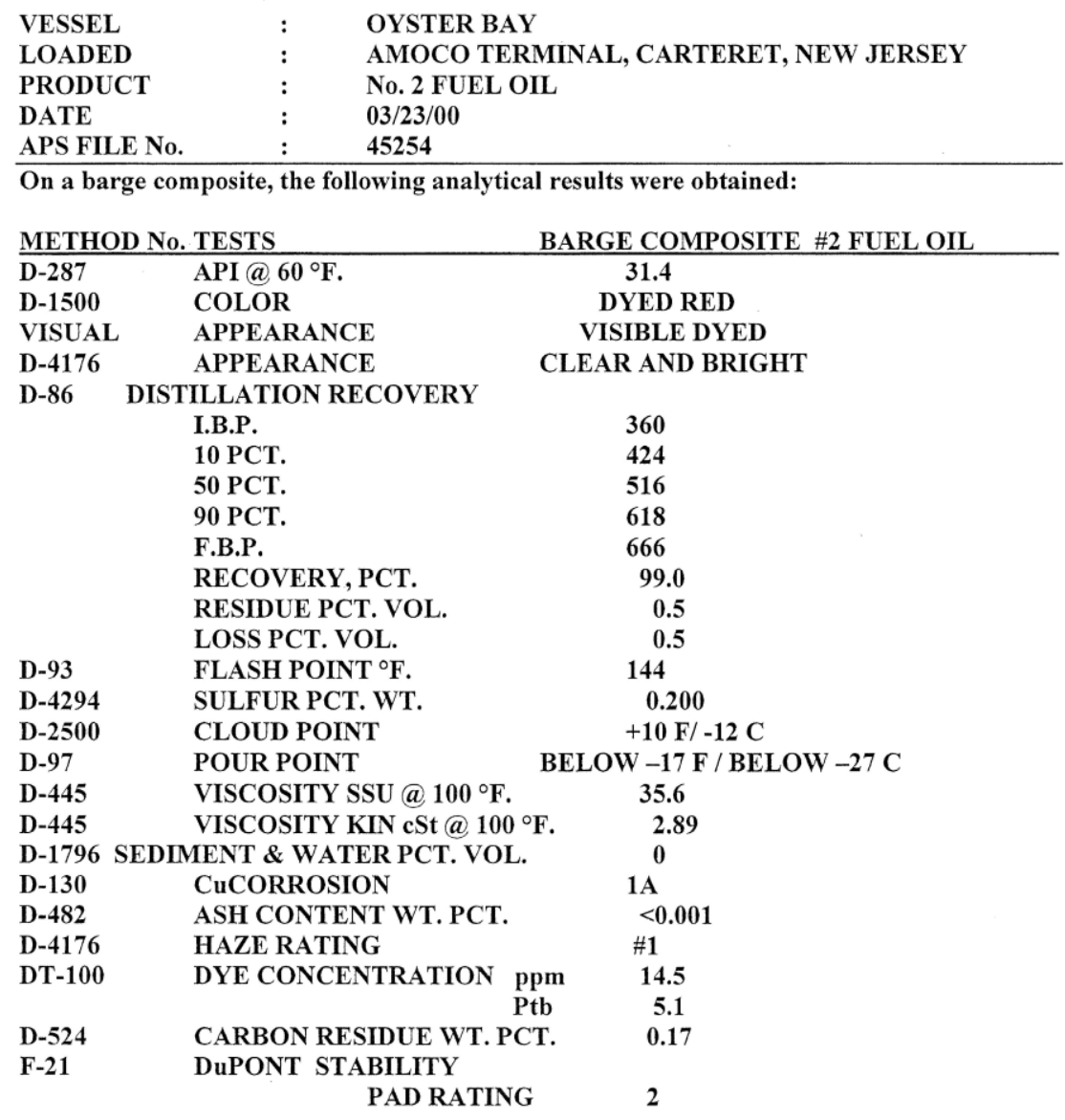

ATLANTIC PETROLEUM SERVICES, INC.

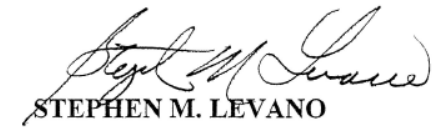


Appendix C. Boiler Fouling Comparison Scale by BNL

\section{BOILER FOULING COMPARISON SCALE}

Visual Determination from \#1 through \#5

Customer ID \#:

Date:

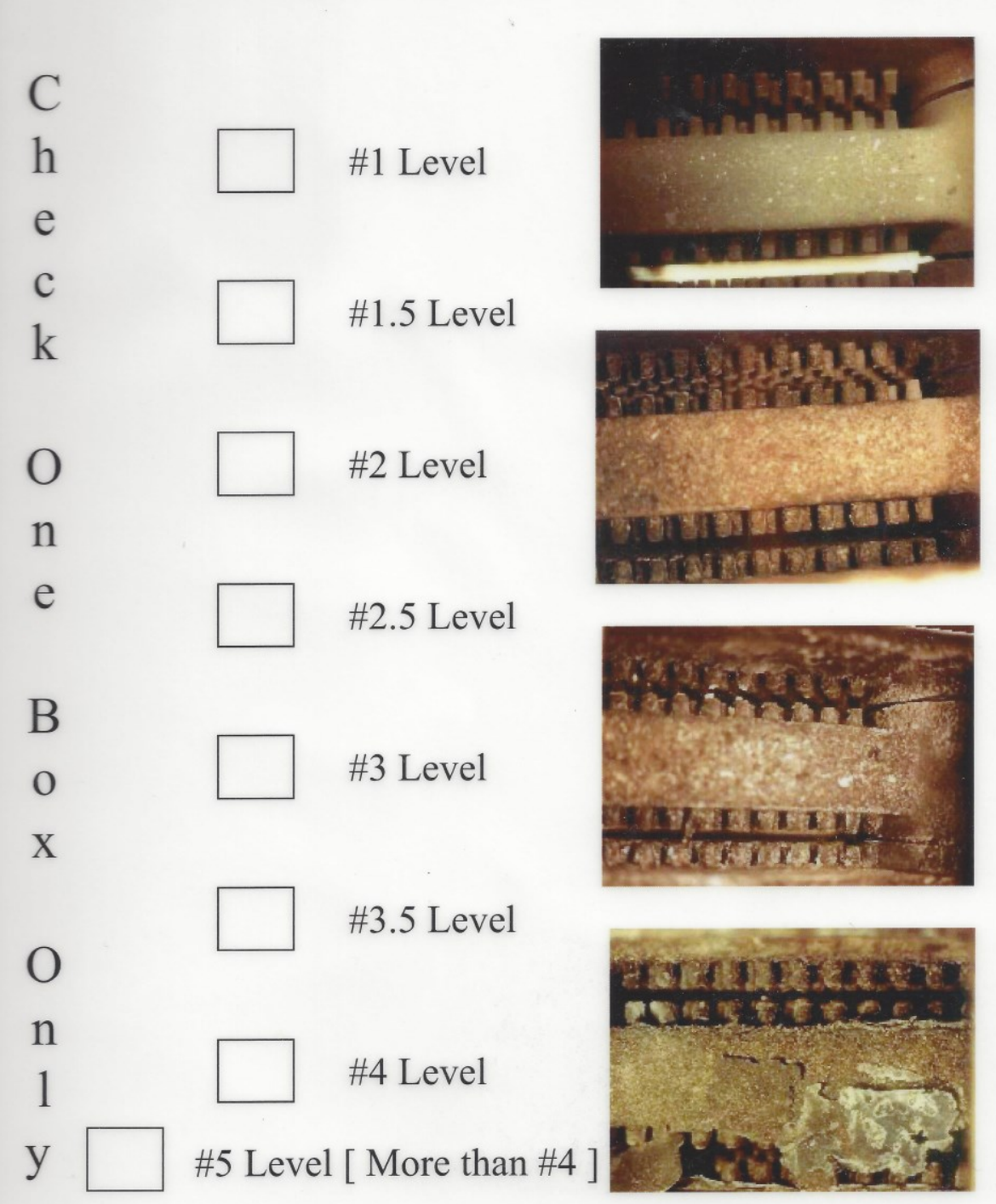




\title{
Appendix D. Summary of BNL Lab Tests of Fuel Pump Seals
}

\author{
Oil Pump Seal Testing Records
}

Finished: August 2011

Note* All pump tests have been terminated.

Pump \# 1 Viton lip seal (new pump, neat ULS fuel) - Test was terminated due to leakage (3,396 hours). Test started on December 14, 2007 (day 348) Cycle: 10 minutes on \& 10 minutes off

Pump \# 2 Viton lip seal (new pump, neat ULS fuel) - Test was terminated due to leakage $(3,720$ hours). Test started on December 14, 2007 (day 348) Cycle: 10 minutes on \& 10 minutes off

Pump \# 3 Carbon face seal (new pump, neat ULS fuel) - Test was completed successfully (7,512 hours). Test started on December 14, 2007 (day 348) Cycle: 10 minutes on \& 10 minutes off

Pump \# 4 Nitrile lip seal (new pump) - Test was terminated due to leakage $(6,600$ hours).

Test started on August 22, 2008 (day 235) Cycle: 10 minutes on \& 10 minutes off

Pump \# 5 Nitrile lip seal (new pump, neat ULS fuel)

Test started on October 17, 2008 (day 291) Cycle: 10 minutes on \& 10 minutes off

ULS Diesel fuel. Pump model A2VA-7116-2

Test completed successfully on 9/8/11 with total hours of 12672

Pump \# 6 Nitrile lip seal (used pump, approximately one year of field use, lab test with neat ULS fuel) Test started on November 14, 2008 (day 319) Cycle: 10 minutes on \& 10 minutes off ULS Diesel fuel. Pump model A2VA-7196-2

Test completed successfully on 9/8/11 with total hours of 12336

Pump \# 7 Nitrile lip seal (new pump with 5\% Biodiesel added to the ULS fuel)

Test started on December 23, 2008 (day 358) Cycle: 10 minutes on \& 10 minutes off Tests terminated due to complete seal failure at 4,008 hours.

Pump \# 8 Nitrile lip seal (new pump with $5 \%$ Soy Biodiesel added to the ULS fuel) Test started on October 5, 2009 (day 278) Cycle: 10 minutes on \& 10 minutes off Beckett Clean cut pump

Test completed successfully on 9/8/11 with total hours of 8436

Pump \# 9 Carbon face seal (used pump [pump \#1] 5\% Tallow Biodiesel with 95\% ULS) Test started on October 19, 2009 (day 292) Cycle: 10 minutes on \& 10 minutes off Danfoss BFPH 
Test completed successfully on 9/8/11 with total hours of 8288

Pump \# 10 Nitrile lip seal (new pump with $5 \%$ Soy Biodiesel added to the ULS fuel) Test started on November 4, 2009 (day 308) Cycle: 10 minutes on \& 10 minutes off Tests terminated due to complete seal failure at 2,287 hours.

Pump \# 11 Carbon face seal (new pump with 5\% Soy Biodiesel added to the ULS fuel)

Test started on January 11, 2010 (day 11) Cycle: 10 minutes on \& 10 minutes off

Tests terminated due to failure at (pump seized) between 2,040 and 2,400 hours.

Pump \#12 Nitrile lip seal (new pump with conventional No. 2 oil S 2000 ppm)

Test started on March 16, 2010 Cycle: 10 minutes on \& 2 minutes off

Pump model A2VA-7116-2

Test completed successfully on 9/8/11 with total hours of 10677

Pump Accumulated Running Time

\# 13396 hours - test terminated (to evaluate Nitrile seal) - slight leakage observed

\#2 3720 hours - test terminated with major leakage observed

\# 37512 hours - test was stopped based on successful completion of 7 years equivalent running time

\# 46600 hours - test terminated with significant leakage observed

\# 512672 hours - continues, very slight oil weep observed in past, now dry, 3/31/11 slight weep, 5/25/11 slight weep continues, pump seal wet. 9/8/11 Pump bottom surface wet with fuel, Test ended.

\# 612336 hours - very slight oil weep observed 6/24/2009, 3/31/11 dry, 5/25/11 dry, 09/08/11 Pump bottom surface wet with fuel, Test ended.

\# 74008 hours - complete seal failure on August 17, 2009, tests stopped

\# 88436 hours - continues, dry so far, 3/31/11 slight weep, 5/25/11 slight weep, 09/08/11 slight weep from seal, test ended

\# 98288 hours - continues, slight weep, 3/31/11 slight weep, 5/25/11 Dry, 09/08/11 Pump dry, test ended

\# 102287 complete seal failure on May 13, 2010, tests stopped

\# $112040+$ hours - pump seized between 2,040 and 2,400 hours, tests stopped.

\# 1210677 hours - continues, 5/25/11 Dry seal surface, 09/08/11 Pump dry, test ended 